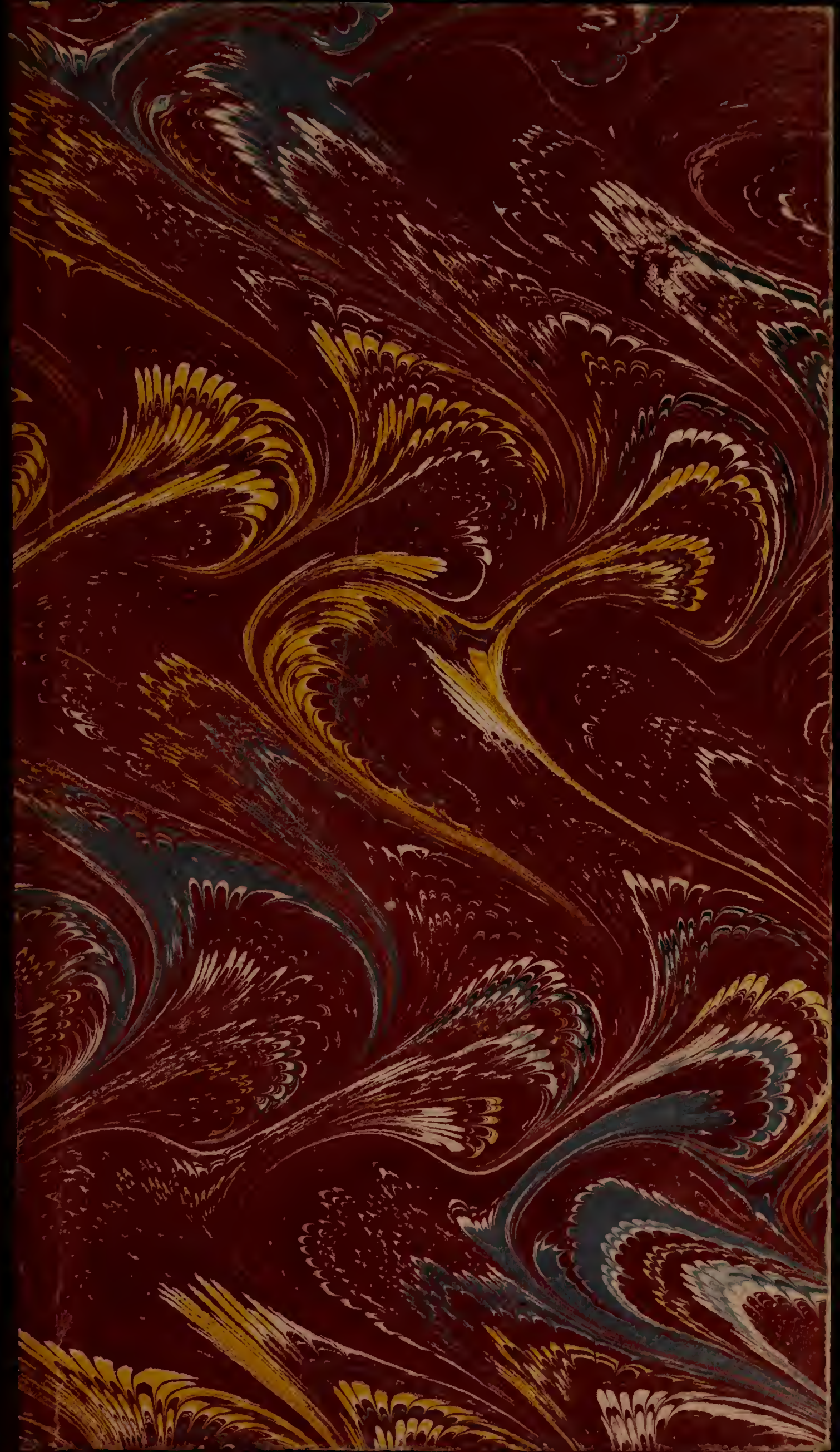




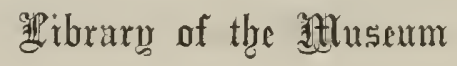

or

\section{COMPARA'TIVE ZOÖLOGY,}

at HaRTARD CULLEGE, CAMBRIDGE, IIASS.

founded by pribate subscription, in 1861.

Deposited by ALEX. AGASSIZ.

1 No.29.441

November 13,1891 .

ivelered. Mhas 



\section{Sonder - Abdruck}

aus

"Internationale Beiträge zur wissenschaftlichen Medicin"

Festschrift, Rudolf Virchow grewidmet zur Vollendung seines 70. Lebensjahres.

Band I.

\section{J)as Gibbon-Hirn \\ von}

W. Waldeyer.

Hierzu Tafel I und II. 



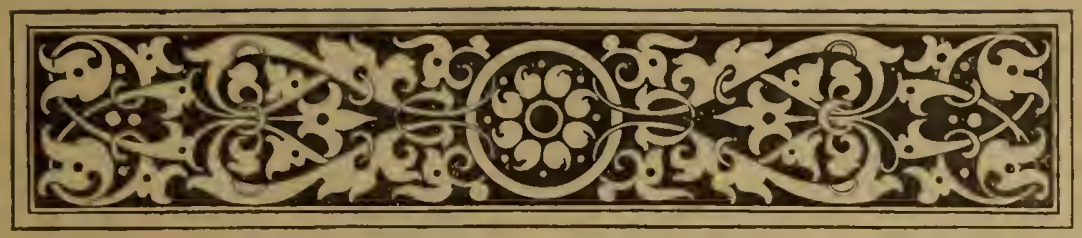

I.

$\mathrm{V}$ on den Gehirnen der Anthropoiden hat das des Genus Hylobates bis jetzt am wenigsten Berücksichtigung gefunden. Eine etwas eingehendere Schilderung liefern nur: Gratiolet, ${ }^{1}$ ) welcher auch mehrere Abbildungen giebt, Th. L. W. Bisch of ${ }^{2}$ ) mit fünf trefflichen Abbildungen vom Gehirn eines jungen Hylobates leuciscus, T. Chudziński, ${ }^{3}$ ) welcher ausser einer ausführlichen Beschreibung zwei Holzschnitte vom Gehirn eines Hylobates entelloides und vier Lithographien vom Gehirn des Hylobates leuciscus mittheilt, W. Flower ${ }^{4}$ ) und J. Deniker. ${ }^{5}$ ) Die Angaben Deniker's

1) Gratiolet, P., Mémoire sur les plis cérébraux de l'homme et des Primatc̀s 4., arec Atlas in Fol. Paris, Arthus Bertrand. (Ohne Angabe der Jahreszahl - 1 854 , nach einer Angabe in dem bekannten Werke von Leuret et Gratiolet, Anatomie du système nerveux considéré dans ses rapports avec l'intelligence, Paris, $1839-1857$ - in der Aufzählung der Werke Gratiolets im 2. Bande.

$\left.{ }^{2}\right)$ Bischoff, Th. L. W., Beiträge zur Anatomie des Hylobates leuciscus und zu einer vergleichenden Anatomie der Muskeln der Affen und des Menschen. Abhandlungen der mathem.-physikalischen Klasse der K. Bayerischen Akademie der Wissenschaften. München 1870.4 , Bd. X S. 198.

${ }^{3}$ ) Chudziński, Teofil, Anatomia porównawcza Zwojów mózgowych. In der Zeitschrift: Pamietnik towarzystwa nauk scislych w Paryzu. 4. T. X 1878 u. T. XII 1882. Jede der beiden Abhandlungen ist besonders paginirt; das den Gibbon Betreffende findet sich T. XII p. 5 I ff.

4) Flower, Wm. H., On the brain of the Siamang (Hylobates syndactylus, Raffles). The natural history review. London $186_{3}$ p. 279.

5) Deniker, J., Recherches anatomiques et entbryologiques sur les singes anthropoides. Foetus de Gorille et de Gibbon comparés aux foetus humains et aux anthropoides jeunes et adultes. Archives de Zoologie expérimentale et générale par H. de Lacaze-Duthiers, II Série T. III bis. Paris 1885. 
sincl um so werthvoller, als sie einen Fötus betreffen; vom Gehirn clesselben liegen drei Abbildungen vor (pl. XXIX, Fig. 3, 4 und 5). Keine dieser aufgeführten Abhandlungen geht indessen näher auf das Verhalten sämmtlicher Furchen und Windungen ein; auch vermissen wir fast ganz eine Besprechung der Reil'schen Insel, der Hirnbasis, des Kleinhirns und des inneren Aufbaues. Auch bei Chudzinski sind diese Punkte (abgesehen von den Furchen und Windungen) nicht eingehender besprochen worden.

So standen unsere Kenntnisse, als ich mich, im Besitze von drei wohlerhaltenen, verschiedenen Arten angehörenden Gibbon-Gehirnen, entschloss, eine erneute und möglichst umfassende Darstellung dieses, wie mir scheint, sehr wichtigen Anthropoiden-Gehirns zu geben. Nachdem ich meine Untersuchungen beendet hatte - die Abbildungen haben schon der anatomischen Section des X. internationalen medicinischen Congresses zu Berlin, August 1890 , vorgelegen - erschien noch eine mir durch die Freundlichkeit des Verfassers zugegangene ausführlichere Arbeit über das Gibbon-Hirn von Kohlbr ügge. ${ }^{6}$ Wenngleich Kohlbrügge in der beneidenswerthen Lage war I 2 Hylobatiden-Gehirne untersuchen zu können ( 8 ron Hylobates syndactylus, 2 von Hylobates leuciscus, je eines von $\mathrm{H}$. lar und $H$. agilis), so halte ich es dennoch nicht für überflüssig die Ergebnisse meiner Untersuchungen mitzutheilen, da auch Koh1brügge fast ausschliesslich die Grosshirnhemisphären behandelt und ich in einigen Punkten zu abweichender Meinung geführt worden bin. Um so mehr glaube ich mit meinen Beobachtungen nicht zurückhalten zu sollen, als durch die eingehenden und sehr werthvollen Untersuchungen Kohlbrügge's und G. Ruge's (über die Muskulatur und den Rumpf der Hylobatiden, mitgetheilt in demselben Werke Bd. II p. 2 I I und 366) die genaue Kenntniss der Gibbon-Sippe ein besonderes Interesse gewinnen muss. Es ergiebt sich nämlich, wie es Schlegel schon angedeutet hat, dass diese Sippe eine Sonderstellung in dem Affenkreise einnimmt. Die Hylobatiden stehen nach Ruge über den Katarrhinen, von denen sie sich frühzeitig abgespalten haben, aber nicht unter den Anthropoiden und nicht innerhalb der letzteren. Wie Kohlbrügge sich äussert 1. c. Bd. II, p. 205, sind "Anthropoiden und Hylobatiden keine einander folgenden Rangstufen, sondern Parallelbildungen." So darf ich denn hoffen, dass auch der geringe Beitrag, den ich zu geben vermag, freundliche Aufnahme finden werde.

$\left.{ }^{6}\right)$ Kohlbrügge, J. H. F., Versuch einer Anatomie des Genus Hylobates. In: "Zoologische Ergebnisse einer Reise in Niederländisch Ost-Indien", herausgegeben von Dr. Max Weber, Professor in Amsterdam. 8890 Bd. I p. 211 und $1891 \mathrm{Bd}$. II p. 139. Das Gehirn s. Bd. II p. I86- 197. 
Ich lasse zunächst noch die Ingabe derjenigen Literaturwerke folgen, welche sich nur mit einzelnen Theilen des Gibbon-Hirns beschäftigen, oder dasselbe nur kurz besprechen. Hierher zählen die Werke und Abhandlungen ron Sandifort, ${ }^{7}$ ) Vrolik, ${ }^{8}$ ) Huxley, Owe11, ${ }^{10}$ ) Broca, ${ }^{11}$ ) Pansch, ${ }^{12}$ ) Rüdinger, ${ }^{13}$ ) Gromier, ${ }^{14}$ ) Hervé, 15 )

7) Sandifort, (i., Ontleedkundige Beschouwing van een volwassen OrangOetan (Simia Satyrus Linn.) van het mannelijk geschlacht. In: Verhandelingen over de natuurlijke geschiedenis der Nederlandsche overzee'sche bezittingen door de Leden der natuurkundige Commissie in Indie en andere Schrijvers. Uitgegeven door C. J. Temminck. Afdeeling 7,oologie p. 29. Leiden $1839-1844$. Fol.

s) Vrolik, W., Recherches d'anatomie comparée sur le Chimpansé. Amsterdam 1841. Fol. Joh. Müller.

9) Huxley, Th., Lectures on the structure and classification of the mammalia delivered at the royal college of Surgeons. The medical Times and Gazette, 1864 iol. I. Lecture XIX p. $647(648)$.

$\left.{ }^{10}\right)$ Owen, R., On the anatomy of vertebrates. London i868. Vol. III p. I24.

II) Broca, P., Mémoires sur le cervean de l'homme et des Primates, publiés par S. Pozzi. Paris, Reinwald, 1888. Es sind hier sämmtliche einschlägigen Abhandlungen Broca's in dankenswerther Weise zusammengestellt. Die Bemerkungen über das Hylobates-Hirn finden sich in folgenden Arbeiten: a) Le grand lobe limbique et la scissure limbique dans la série des mammifères - Revue d'anthropologie i 878 , II Sér. T. I p. 385-498 (Mém. p. 259 - rergl. hier besonders S. 26 I Anm., S. 369, S. 378$)$. b) Sur le cerveau du Gorille - Bulletins de la Société d'anthropologie II Sér. T. XII 1877 p. $43^{2}-439$ (Mém. p. 583 ; vergl. hier S. 588). c) Étude sur le ccrveau du Gorills - Revue d'anthropologie 1878 II Sér. T. I p. I-46 (Mém. p. 601; vergl. besonders p. 625 und Anm. (laselbst, p. 639 , p. 643 Anm.). d) Nomenclature cérébrale, Revue d'anthropologie 1878 II Sér. T. III p. 193 (Mém. p. 652 ; s. besonders p. 680). e) Description élémentaire des circonvolutions cérébrales de l'homme d'après le cerveau schématique, Revue d'anthropologie II Sér. $\mathrm{I}_{3}$ T. VI P, I-34, 193-210, 385-40.5 et 1884 T. VII p. I-2I, (Mém. p. 707; s. besonders p. 734).

12) Pansch, A., a) Das Gchirn des Gorilla. In: Die menschenähnlichen Affen des Hamburger Museums. Abhandlungen aus dem Gebiet der Naturwissenschaften, herausgegeben von dem naturwissenschaftlichen Verein z.u Hamburg und Altona. Hamburg 1876,4 . S. 84 . - b) De sulcis et gyris in cerebris simiarum et hominum. Kiliae 1866 , Habilitationsschrift. - c) Ueber die typische Anordnung der Furchen und Windungen auf den Grosshirnhemisphären des Menschen und der Affen. Archiv für Anthropologie 1869 III.

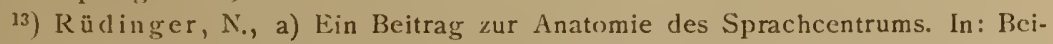
träge zur Biologie, Jubiläumsschr. f. Y. Bischoff, Stuttgart, Cotta r882, gr. 8 und 1) Ein Beitrag zur Anatomic der Affenspalte und der Interparietalfurche beim Menschen, nach Kasse, Cieschlecht und Individualität. In: Beiträge zur Anatomie und Embryolngic, Festgabe für J. Henle, Bonn 1882, 4., Max Cohen \& Sohn (Fr. Cohen). (In beiden Abhandlungen finden wir Abbildungen rom Hirn des Hylobates leuciscus.)

${ }^{14}$ ) Cromier, J., Étude sur les circonrolutions cérébrales chez. l'homme ct chez. les Singes, Thèse pour le Doctorat en médecine. Paris i874. 8. (Kurze Beschreibung der Grosshirnwindungen bei H. entelloides.)

1i) Hervé, G., La circonvolution de Broca. Étude de morphologie cérćbrale. Paris 1888 , ancienne maison Delah a ye et Lecrosnier, 8. (Abbildung der vorderen IHälfte eines Ciehirns rom "Gilbbon cendré" - H. leuciscus.) 
Cunningham, ${ }^{16}$ ) Eberstaller, ${ }^{17}$ ) Mingazzini, ${ }^{18}$ ) Parker ${ }^{19}$ ) und mir. ${ }^{20}$ )

In diesen zuletzt aufgezählten Arbeiten ist das Hylobates-Gehirn in Einzelnheiten entweder nur kurz und beiläufig erwähnt, so z. B. bei Broca, Pansch. Mingazzini, Vrolik, Cunningham und Eberstaller, oder aber die Beschrei. bung, wenn auch über das ganze Gehirn oder dessen grosse Hemisphären sich erstreckend, ist kurz und bietet gegenüber den früher aufgeführten eingehenderen Beschreibungen nichts Bemerkenswerthes ( $\mathrm{S}$ andifort, Huxley, Gromier und Owen, der, 1. c. P. 124, nur eine verkleinerte Abbildung der Seitenansicht eines Gibbonhirns - ohne Angabe der zugehörigen Species und ohne Text - giebt, oder endlich, die Schilderung, wenn auch genau und ausführlich, begreift doch nur einen kleinen Theil des Gibbon-Hirns, so bei Rüdinger die Umgebung der Insel und die dritte Stirnwindung, letztere auch bei Hervé, die Intraparietalfurche und die sogenannte Affenspalte, gleichfalls bei Rüdinger, die Sylvische Grube und die Insel bei mir. Wo erforderlich, wird bei der folgenden Beschreibung auf die bezüglichen früheren Angaben gebührende Rücksicht genommen werden.

Obwohl ich mir Mühe gegeben habe, die Literatur vollständig zu sammeln, ist es immerhin möglich, dass mir eine oder die andere Angabe entgangen ist. So habe ich mir z. B. A. Rauber's Abhandlung: "Das Gehirn der Anthropoiden" nicht verschaffen können, da ich sie nur in dieser ungenügenden Form citirt fand (bei Rauber: "Nervensystem und Sinnesorgane" II. B. II. Abth. des Lehrbuchs der Anatomie des Menschen, 3. Aufl, von C. E. E. Hoffmann und A. Rauber. Erlangen, Besold, r886, S. 446). Weder in den mir zugängigen Jahresberichten, noch in den sonst von mir eingesehenen Werken über die menschliche und vergleichende Anatomie des Gehirns fand ich diese Abhandlung erwähnt. Für den Nachweis von etwa Uebersehenem würde ich recht dankbar sein.

16) Cunningham, D. J., The intraparietal sulcus of the Brain. The Journal of anatomy and physiology cond. by Wm. Turner, Humphry and Mc. Kendrick, vol. XXIV, 1890 , p. 135. s. a. Transactions of the Royal Academy of Medicine of Ireland, vol. VIIl p. 495. Dublin $\mathrm{r} 890$.

17) Eberstaller, Zur Oberflächen-Anatomie der Grosshirnhemisphären. Wiener medicinische Blätter 1884, No. 16, 18, 19, 20 u. 21 .

18) Mingazzini, G., Ueber die Furchen und Windungen des Gehirns der Primaten und der menschlichen Frucht. In: Untersuchungen zur Naturlehre des Menschen und der Thiere, herausgeg. von Jac. Moleschott. Bd. XIV S. II9. 1889.

19) Parker, A. J., Cerebral convolutions of the Negro brain. Proceedings of the Academy of nat. Sciences, Philadelphia 1878. (P. I u. 339 wird nur ein paar mal das Hylobates-Hirn nach den Untersuchungen Anderer erwähnt.)

${ }^{20}$ ) Waldeyer, W., Sylvische Furche und Reil'sche Insel des Genus Hylobates. Sitzungsber. der K. Preuss. Akad. der Wissensch. zu Berlin, Stück XVI, 1801 vom 19. März. - (Abbildungen der Gehime von H. leuciscus, lar und syndactylus.) 
II.

Uebersichtliche Schilderung.

Von oben gesehen erscheint das Gibbon-Gehirn kurz-eiförmig, indem das vordere Ende gegen das hintere deutlich verjüngt ist. Auch bei der Betrachtung von unten her springt dies in die Augen - vgl. die um das Doppelte vergrösserte Fig. I (H. leuciscus). Besonders ausgeprägt finde ich dies bei dem mir vorliegenden Hirn von H. syndactylus. Immerhin ist die Verjüngung des sogen. „Stirnschnabels" (bec cle l'encéphale) nicht so bedeutend, wie bei vielen niederen Affen, auch ist das Gehirn höher, die Orbitalaushöhlung nicht so stark; die Stirnlappen sind grösser, die Orbitalkante ist mehr abgerundet und die Symmetrie der Windungen nicht so gross, wie bei den tiefer stehenden Primaten.

Das Kleinhirn ist vom Grosshirn völlig überdeckt. (Genaueres hierüber siehe später.)

Die grossen Spalten (Mantelspalte, grosse und kleine quere Hirnspalte) verhalten sich wie allgemein vom Menschen bekannt. Hervorgehoben mag auch gleich hier werden, dass wir sowohl ein foramen Magendii, als auch die von Axel Key und G. Retzius beschriebenen aperturae laterales ventriculi quarti deutlich ausgeprägt vorfinden.

Die grösste Breite des Hirns fällt zusammen mit dem Uebertritt der Balkenfurche (Sulcus calloso-marginalis) auf die convexe Oberfläche, ( $p$, Fig. 3,4 und 6 ) etwas hinter dem oberen (medialen) Ende der Centralfurche.

Von oben und von der Seite gesehen, ergiebt sich leicht die Begrenzung der vier bekannten Hauptlappen, indem sehr deutlich die Centralfurche (9) nebst den Sulci prae- und postcentrales, $(\eta, \imath u$. *), ferner die sogenannte Affenspalte $(\pi+\varphi+\sigma)$ und die fissura Sylvii $(\Sigma+\Sigma a+\Sigma p)$ hervortreten. Ein wenig Willkür waltet ja bei der Abgrenzung des Scheitellappens und Hinterlappens immer ob; beim Gibbon sind beide indessen möglichst gut umschrieben. Durch die (auch bei anderen Affen) sehr starke Entwickelung der I. Temporalfurche (i.) (sulcus parallelus, $t_{1}$ ), welche hoch hinaufreicht bis fast zur Intraparietalfurche (v), gestaltet sich dem Beschauer leicht und ungezwungen eine Dreitheilung wie folgt: r. Ein Stirnlappen, von vorn bis zur Centralfurche reichend; 2. ein Lobus temporo-parietalis, welcher die fissura Sylvii umkreist und keulenförmig gestaltet ist; der Stiel der Keule würde wesentlich aus dem gyrus tempor. I bestehen, der Keulenkopf rom lobus parietalis gebildet werden. Der gyrus parietalis II, namentlich das seit Gratiolet mit dem Namen des "pli courbe" belegte Stück desselben, welches um das obere Ende des sulcus tempor. I (v) her- 
umzicht, würde eine Uebergangswindung zum dritten Lappen, einem 3. Lobus temporo-occipitalis, herstellen. Letzterer würde wiederum eine annähernd keulenförmige Gestalt besitzen und den Rest des Schläfenlappens nebst dem Hinterlappen umfassen. Diese Dreitheilung ergiebt sich bei der Betrachtung von oben und von der Seite als eine viel natürlichere, als die hergebrachte in vier Lappen.

Die untere Fläche lässt ebenso wenig wie beim Menschen und bei den übrigen Anthropoiden eine Trennungsmarke zwischen Schläfenund Hinterlappen erkennen. Nach Wegnahme des Kleinhirns sieht man in der hinteren Hälfte, s. Fig. 5, einen gut abgesetzten Spindellappen (Lobulus fusiformis), F., während der Zungenlappen (Lob. lingualis), L., in die Hakenwindung ohne scharfe Grenze übergeht. Das fast kugelförnige, stark vorspringende untere Ende des Schläfenlappens ist durch eine tiefe Furche (5a) scharf eingeschnitten. Ihre Beziehungen zı den mehr rückwärts gelegenen Furchen der Unterfläche sind verschieden, wie später genauer darzulegen ist. In der hier vorgelegten Abbildung von Hyl. syndactylus (Fig. 5) geht sie in den sulcus temporalis III $(5+5$ b) ununterbrochen über, jedoch ist in der Höhe des Striches 8 ein Absatz zu merken.

Die unteren Endstücke der beiden Schläfenlappen nähern sich stark einander nach der Mittellinie hin, so dass die Gegend der von Henle so genannten Bodencommissur bedeutend vertieft und schmal erscheint.

Die orbitale Aushöhlung des Stirnlappens ist, wie bemerkt, nicht sonderlich tief; die tiefste Stelle wird von dem Sulcus orbitalis $\left(\mathrm{I}+\mathrm{I}^{\mathrm{b}}\right)$ eingenommen.

Die Reil'sche Insel erscheint an allen drei von mir untersuchten Gehirnen völlig verdeckt und kommt erst nach einer Eröffnung der Sylvischen Furche zu Tage; sie ist in Verhältniss zur Gesammtgrösse des Gehirns ansehnlich entwickelt. Mittelst eines deutlichen "Limen" (Schwalbe) setzt sie sich von der Substantia perforata antica, die gut ausgeprägt ist, ab.

Der Tractus olfactorius ist platt, im Uebrigen nicht anders ausgebilclet, wie bei den sonstigen Anthropoiden und wie beim Menschen. Wir erkennen weiter an der Basis nun den Balkenschnabel, der in die Lamina terminalis übergeht. Dahinter liegt das gedrungene Chiasma mit den davon abgehenden beiden recht starken Sehnerven. Die Tract us optici divergiren stark. Die Grosshirnschenkel sind gut ausgebildet, liegen aber tief, so dass sie in den Figuren I und 2 nicht zur Anschauung gebracht werden konnten. Der Querschnitt des linken Schenkels zeigt sich bei c. c. in Fig. 5. Zwischen beiden crura cerebri finden wir das verhältnissmässig kleine tuber cinereum, an diesem den breit aufsitzenden Stiel der 
Hypophysis (Pedunc. hypoph. Fig. 1) - die Hypophysis ist bei diesem Gehirn nicht erhalten.

Dicht dahinter zeigen sich die kleinen kugligen nahe beisammenstehenden corpora candicantia, die auch selır in die Ticfe grerückt liegen, so dass sie in den Figuren 1 und 2 nicht erscheinen. In der Spitze zwischen den beiden auseinander weichenden crura cerebri finden wir in geringer Ausbildung eine substantia perforata posterior.

Die Varolsbrücke springt deutlich vor, ihre Formenverhältnisse schliessen ganz an die des Menschen an. Scharf clurch den bekannten circulären sulcus von ihr abgegrenzt, liegt im Thale des Kleinhirns das stark entwickelte verlängerte Mark, dessen einzelne Stränge deutlich sich unterscheiden lassen; auch die Pyramidenkreuzung erkennt man leicht (s. Fig. I u. 2).

Die Nerven und Gefässe an der Hirnbasis zeigen im Grossen und Ganzen das rom Menschen bekannte Verhalten; doch will ich hier der Einzelbeschreibung nicht vorgreifen. Die Nerven sind stark entwickelt.

Der Gibbon hat ein ansehnliches Kleinhirn, welches in seiner Form dem menschlichen recht ähnlich sieht. Wir erkennen sehr gut von einander abgesetzt den Wurm und die Hemisphären, ferner die Abtheilungen des Ober- und Unterwurms mit der vallecula zur Aufnahme des verlängerten Markes und mit dem hinteren wie vorderen Einschnitte. Auch den sulcus horizontalis magnus Reilii, welcher die Hemisphären in einen Ober- und Unterlappen zerfällt, kann man leicht auffinden. Deutlicher als beim Menschen, indem sie mehr vorspringen, setzen sich die Mandel (T.), die Flocke (Fl.) und der sogen. Lobulus petrosus (Huschke) (Lob. petr. Fig. 2) ab.

Die Vierhügel kann man in der bekannten Weise leicht zur Anschauung bekommen. Die ganze Lamina quadrigemina ist stark entwickelt, die vorderen Hügel ansehnlich stärker als die hinteren.

Der Medianschnitt (Fig. 6, H. syndactylus) zeigt in characteristischer W'eise die den Anthropoiden und dem Menschen eigene vorwiegende Ausbildung des Grosshirnmantels über den Hirnstock. 1)as Bild wird ferner beherrscht vom Balken, an dem wir alle Theile: Rostrum (rostr.), genu, corpus und splenium (spl.) gewahren, letzteres in starker Ausbildung. Darunter erscheinen das grosse, sehr dünne Septum lucidum (spt.), die commissura ant. (c. a.), der Fornix, dessen crura ascendentia und corpus die Zeichnung wiedergiebt; hinter ihm der rundliche Thalamus opticus. Zwischen diesem und dem fornix erblickt man den starken plexus chorioideus medius (chor.) und das kleine spaltförmige foramen 
Monroi (for. M.). Die Zirbel (pi) mit ihrem Recessus pinealis ist ansehnlich und stark nach oben gerichtet. Die Vierhügel und das velum medullare anterius führen zum Kleinhirndurchschnitt, der hier mitten im Wurm, im Gebiete des sogen. arbor vitae, mehr kreisförmig erscheint als beim Menschen.

Die Hirnventrikel zeigen dasselbe Verhalten wie beim Menschen, nur sind sie sämmtlich sehr eng.

Als am meisten auf dem Medianschnittbilde hervortretende Furchen mögen genannt sein: der Sulcus calloso-marginalis $(p)$, der bei $p_{1}$ regelmässig auf die convexe Hemisphärenfläche umbiegt und als dessen Fortsetzung wohl die mit i4 bezeichnete Furche anzusehen ist. Deutlich ist immer ein sulcus subrostralis (15) (Eberstaller). Ferner die fissura parieto-occipitalis medialis $\left(\pi_{1}\right)$, mit der die fissura calcarina ( $(\omega)$ einen gut ausgebildeten $\mathrm{Z}$ wickel (cuneus) einschliesst. Auch der Vorzwickel (praecuneus) ist deutlich und fasst eine mehrfach verzweigte Furche in sich (0).

Zur allgemeinen Betrachtung des Gehirns gehören auch die Grössen- und Gewichtsverhältnisse desselben. Einiges wurde schon angedeutet. Ich fand folgende Hauptmaasse:

H. leuciscus: a) Grösste Länge der Grosshirnhemisphäre: $6,85 \mathrm{~cm}$.

b) Grösste Breite: $5,52 \mathrm{~cm}$.

c) Höhe von der Mitte der Brücke bis zum senkrecht darüber gelegenen Punkte der Mantelkante: $3,9 \mathrm{~cm}$.

d) Höhe des Kleinhirnwurmes: r,6 cm.

f) Grösste Länge desselben in der Medianebene: $1,9 \mathrm{~cm}$.

g) Grösste Breite des Kleinhirns: $4,78 \mathrm{~cm}$.

h) Länge der medulla oblongata vom distalen Beginne der Pyramidenkreuzung bis zur Brücke: $1,05 \mathrm{~cm}$.

i) Länge der Brücke: $1,15 \mathrm{~cm}$.

k) Grösste Breite der medulla obl.: 1,05 cm.

1) Grösste Breite der Brücke: $1,3 \mathrm{~cm}$.

Dieselben Maasse bei Hylobates syndactylus zeigten folgende Werthe:
a) $=6,3 \mathrm{~cm}$
e) $=1,8 \mathrm{~cm}$
i) $=1,05 \mathrm{~cm}$
b) $=5,5$,
f) $=1,8$
$\mathrm{k})=\mathrm{r}, \mathrm{O} 5 \mathrm{n}$
c) $=3,8$ "
g) $=4,6$,
l) $=1,3$ "
d) $=4,2$ "
h) $=1,0$,

Bei Hylobates lar ergaben sich:
a) $=6,7 \mathrm{~cm}$
e) $=1,9 \mathrm{~cm}$
i) $={ }_{1,15} \mathrm{~cm}$
b) $=5,4$ n
f) $=1,9$,
k) $=1,1$ "
c) $=4,0$,
g) $=4,7$ "
l) $=1,4$,
d) $=4,3$ "
h) $=1,1$,

Alle diese Maasse, die gut unter sich übereinstimmen, bezichen sich auf erhärtete und von ihren sämmtlichen Häuten befreite Gehirne.

Wir besitzen nicht viele Maassangaben über das Hylobates-Gehirn. Ich finde solche nur bei Flower 1. c. (Nat. hist. rev. 1863) und Deniker 1. c. (Archives de 
zool. deuxième sér. T. III bis, 1885). Flower mass den Schädelausguss eines erwachsenen Il. syndactylus; er fand:

Grösste Länge des Grosshirns 3 engl. Zoll $=7,52 \mathrm{~cm}$

$$
\begin{aligned}
& " \quad \text { Breite }=2,5 \text { Zoll }=6,4 \mathrm{~cm} \\
& " \quad \text { Höhe }=1,9 \text { Zoll }=4,8 \mathrm{~cm} \\
& " \quad \text { Breite des Kleinhirns }=2,2 \mathrm{Zoll}=5,6 \mathrm{~cm}^{2}{ }^{21} \text { ) }
\end{aligned}
$$

Deniker hatte einen $20 \mathrm{~cm}$ langen weiblichen Gilbbonfötus zur Verfügung, den er auf den 7.-8. Monat des Uterinlebens schätzt; wahrscheinlich gehörte er zu $H$. lar oder agilis. Ferner bestimmte er die grösste Gehirn-Länge bei einem $45 \mathrm{~cm}$ im Körper messenden jungen Hyl. leuciscus. Hier war sie $=6,2 \mathrm{~cm}$.

Die Maasse beim Fötus waren:

Grösste Länge des Grosshirns $=4,5 \mathrm{~cm}$

$$
\text { " Breite " } " \text { Höhe " } \quad=3,9 \text { " }
$$

Es ist die Hirnlänge hier $=22 \mathrm{pCt}$. der Rumpflänge, während sie bei dem $45 \mathrm{~cm}$ messenden jungen $\mathrm{H}$. leuciscus $12 \mathrm{pCt}$. der Rumpflänge erreicht. Deniker, in der Annahme, dass die Abbildungen Bischoff's (1. c. Abhdl. der K. Bayerischen Akad. Bd. X. math. phys. Klasse, 1870 , Taf. II) in natürlicher Grösse gehalten seien, was zutreffen mag, obwohl Bischoff nichts darüber sagt, maass die Länge des von Letzterem abgebildeten Hirns eines jungen weiblichen $H$. leuciscus von 7o $\mathrm{cm}$ Körperlänge und fand sie zu ebenfalls $6,2 \mathrm{~cm}$. Es stimmt dies nach meinen Nachmessungen für die Profilzeichnungen richtig; an den beiden Zeichnungen, welche das Gehirn ron oben und von der Basis wiedergeben, bekommt man ein wenig höhere Werthe $(6,35 \mathrm{~cm})$. Dieser geringe Unterschied kann jedoch das interessante Ergebniss, zu welchem Deniker für den Gibbon und auch für den Gorilla kommt, nicht abschwächen, dass nämlich das Wachsthum des Gehirns bei diesen beiden Anthropoiden - bei den übrigen dürfte es sich ähnlich verhalten - schnell sein Ende erreicht. Denn es beträgt bei dem Gibbon-Fötus die Hirnlänge $22 \mathrm{pCt}$. der Körperlänge, bei dem jungen Gibbon von $45 \mathrm{~cm}$ Körperlänge $12 \mathrm{pCt}$, bei Bischoff's Hylobates von $70 \mathrm{~cm}$ Körpermaass gar nur $9 \mathrm{pCt}$.

Was das Verhalten der einzelnen Grosshirnlappen zu einander betrifft, so erscheinen mir Stirn- und Scheitellappen ziemlich gleichmässig ausgebildet, vielleicht kommt auf den Scheitellappen ein kleines Uebergewicht. Der Schläfenlappen scheint etwas schmal, aber lang. Vom Hinterlappen behauptet Flower (1. c. nat. hist. uev. I 863), dass er ganz besonders kurz sei. Flower hat an einem andern Orte ein Vergleichsmaass für den Hinterlappen zu gewinnen versucht, indem er den am meisten nach hinten vorspringenden Punkt des Hippocampus major als Ausgangspunkt nahm 2:2) und von da nach vorn bis zum vordersten und nach hinten bis zum hintersten Grosshirnpole maass. Nahm er nun die vordere Entfernung, A., = Ioo an, so erhielt er einen procentischen Werth für die hintere Entfernung B., d. h. für die Entfernung des hintersten Punktes des Am-

$\left.{ }^{21}\right)$ Ich habe die duodecimale englische Linie $=2,1166 \mathrm{~mm}$, demnach den englischen Zoll $\mathrm{zu}$ rund $=25,44 \mathrm{~mm}=2,54 \mathrm{~cm}$ angenommen.

$\left.{ }^{22}\right)$ Flower, Wm. H., On the posterior lobes of the Cerebrum of the Quadrumana. Philosophical Transact, of the Royal Soc. of London. Vol. 152 (for the year 1862) p. 185. 
monshornes vom hinteren Ende der Grosshirnhemisphäre. So fand er diesen Werth B für das

$$
\begin{aligned}
\text { Genus Semnopithecus } & =47 . \\
& =53 . \\
\text { Homo Hapale } & =62 .
\end{aligned}
$$

Ein Hylobates-Hirn, dessen Art er nicht mehr bestimmen konnte, zeigte gar nur einen Werth von 4r. Darnach würde, so weit bekannt, Hylobates unter allen Primaten mit Einschluss des Menschen den kürzesten Hinterlappen haben. Denn dass die von Flower gewählte Marke eine passende ist, darüber kann wohl kein Zweifel herrschen. Die hinterste Ecke des cornu Ammonis liegt genau am Eingange zum Hinterhorn, was also hinter ihr liegt, muss als Hinterlappen bezeichnet werden. Eine äussere gute Marke haben wir auch an dem sulcus parieto-occipitalis, soweit er an der medialen Hemisphären-Fläche liegt.

Flower steht nach seinem Befunde des Werthes $B=4$ I auch nicht an, zumal er bei einem Hylobates lar (Maasse werden nicht mitgetheilt) ähnliche Charaktere fand, sich dahin zu äussern, dass die Kürze des Hinterlappens "one of the most marked characters of the brain of Hylobates" sei.

Meine eigene am Hirn von Hyl. syndactylus ausgeführte Messung zeigte ein etwas abweichendes Ergebniss. Ich verfuhr wie Flower, indem ich durch einen glatten Horizontalschnitt den Seitenventrikel bloss legte, so dass das cornu Ammonis zu übersehen war. Mit grosser Schärfe trat in diesem Falle der am meisten nach hinten am Eingange des Hinterhorns gelegene Umbiegungspunkt des Ammonshorns hervor. Die Entfernung (B.) von diesem Punkte bis zur Spitze des Hinterlappens in gerader Linie gemessen betrug genau $20 \mathrm{~mm}$, die Entfernung (A.) von demselben Punkte bis zur Spitze des Stirnlappens 4I mm. Diese zu roo gesetzt, giebt für B. den procentischen Werth:

$$
\begin{aligned}
4 \mathrm{I}: \mathrm{r} 00 & =20: \mathrm{x}- \\
\mathrm{x} & =48,7 .
\end{aligned}
$$

Darnach würde zwar Hylobates am hinteren Ende der von Flower ermittelten Reihe bleiben, immerhin aber noch vor das genus Semnopithecus $(\mathrm{B}=47)$ rücken, während die von Flower gefundene Ziffer 4 I für Hylobates auffallend niedrig erscheint.

Wie bemerkt, können wir meiner Ansicht nach auch durch den sulcus parieto-occipit. medialis (perpendicularis medialis), der beim Hylobates ziemlich senkrecht verläuft, zu einen brauchbaren Maassverhältnisse des Hinterlappens kommen, da er ja allgemein als Grenze des Hinterlappens gegen den Fronto-Parietallappen anerkannt ist. Da nun der Vorzwickel dem Scheitellappen entspricht und dieser 
cbenfalls beim Hylobates gut nach vorn gegen den Stirnlappen abgegrenzt ist, so können wir durch Messungen an der medialen Fläche cler Grosshirnhemisphäre auch zu guten V'ergleichsresultaten bezïglich dieser drei I appen gelangen, einmal unter den verschiedenen Hylobates-Arten selbst, clann aber auch unter den sämmtlichen Primaten, denn fast alle zeigen an der medialen Fläche die Grenzfurchen sehr deutlich.

Dass die von Flower angegebene Messungsmarke die wissenschaftlich richtigere ist, dessen bin ich mir wohl bewusst und möchte ich hier auf die ausgezeichneten Ausführungen W. Turner's über die Auffassung des Hinterlappens und die Bedeutung cler fissura parieto-occipitalis medialis und calcarina für denselben verweisen, welche er bei Gelegenheit des X. Internationalen medicinischen Congresses zu Berlin, August I890, in seinem Referate über die Hirnwindungen gegeben hat. ${ }^{23}$ )

Ausgehend von der Thatsache, dass bei einigen Primaten, wie Hapale Jacchus, und Halbaffen (Stenops und Lemur nigrifrons) ein Hirnlappen vorhanden ist, der eine Verlängerung des Seitenhorns birgt mit wohl entwickeltem calcar avis und der sich nach hinten weit über das Cerebellum erstreckt, ohne dass sich eine fissura parieto-occipitalis medialis zeigt, kommt Turner zu dem unabweislichen Schlusse, dass diese Furche nicht wesentlich für die Annahme cines Hinterlappens sei. Da nun aber bei den genannten Thieren eine fissura calcarina wohl entwickelt ist, so muss diese wichtige Furche als Merkmal für die Existenz eines Hinterlappens angesehen werclen.

Ich stimme dieser Darlegung vollkommen zu. Dennoch können wir aber die fissura parieto-occipitalis med. da, wo sie vorkommt, zur Erreichung praktisch brauchbarer Messungsergebnisse wohl verwerthen.

Ich fand an meinen Hylobates-Gehirnen folgende Werthe: ${ }^{24}$ )
I. Hylobates syndactylus.
$\left\{\begin{array}{l}\text { a) Länge des Hinterlappens } \\ \text { b) " } " \text { Vorzwickels }\end{array}\right.$
c) " " Frontallappens
$\left.\begin{array}{l}(\mathrm{H})=\begin{array}{ll}1,7 \\ (\mathrm{P})=\mathrm{cm} \\ \mathrm{F})=3,4\end{array}\end{array}\right\} 6,3$.

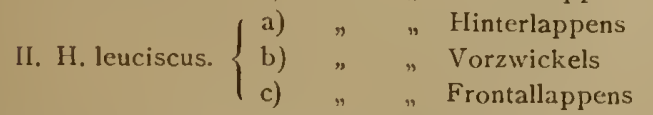
(F) $=3,4$ "
$(\mathrm{H})=1,6$

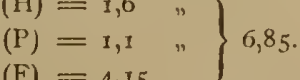

${ }^{23}$ ) Turner, Sir Wm., The convolutions of the Brain. A study in comparative anatomy. Verhandlungen d. X. internat. med. Congresses zu Berlin 1890 . Bd. II S. 8 , 1891. - s. a. The Journal of anatonıy and physiology, October 1890. Vol. 25 p. 105.

$\left.{ }^{24}\right)$ Gemessen wurde der gerade Abstand zwischen vier senkrechten Linien, von denen die erste durch die vordere Spitze des Grosshirns, die zweite durch den l'unkt, wo die fissura calloso-marginalis auf die Mantelkante tritt ( $\rho, F i g .6)$, die Iritte durch die Mitte der fissura parieto-occipitalis, die vierte durch das hinterste Ende der Grosshirnhemisphäre gezogen war. 


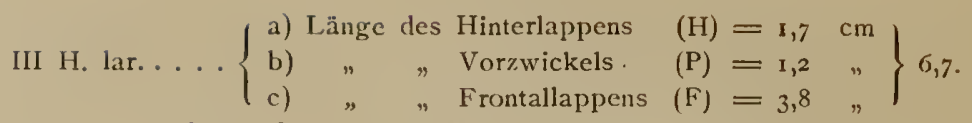

Demnach würden auf den Hinterlappen gegen den Frontoparictallappen entfallen bei :
I. H. synd. • . $1,7: 4,6$
II. H. leuc. . . $1,6: 5,2,5$
III. H. lar. . . . $1,7: 5,0$.

Setzen wir wieder die Frontoparietallänge $=100$, dann erhalten wir für den Hinterlappen bei:
I. H. synd. - . 37,0
II. H. leuc. - . 30,3
III. H. lar. . . . 34, o.

Es zeigt sich aus den mitgetheilten Grössen, dass die Maasse für den Hinterlappen und den Vorzwickel, so wie sie sich an der medialen Hemisphärenfläche ergeben, bei diesen drei HylobatesGehirnen weit weniger schwanken, als das Maass des Stirnlappens.

Ich bringe diese Messungen alle als einen ersten Beitrag; vielleicht ergeben sich doch bei weiterer Fortführung derselben nicht unwichtige Resultate.

Immerhin können wir schon Flower in dem Punkte zustimmen, dass das Genus Hylobates sich durch einen verhältnissmässig kurzen Hinterlappen auszeichnet.

Flower fand aber nun weiter, dass dieser Hinterlappen bei dem von ihm untersuchten Schädelausguss des Hyl. syndactylus einen beträchtlichen Theil des Kleinhirns unbedeckt liess und bei einem andern der Art nach nicht näher bestimmten Giblon das cerebellum nur eben (barely) bedeckte.

Diese Befunde konnten durch keinen der übrigen Untersucher bestätigt werden. Bisch off erklärt sich (1. c. Sitzungsber. d. B. Akad. d. W. Bd. X, S. 272) für diesen Punkt ausdrücklich gegen Flower. Bei dem von Deniker (1. c. Arch. de zool. par LacazeDuthiers, II Sér. T. III bis, 1885) beschriebenen Fötus war das cerebellum klein (I $5 \mathrm{~mm}$ lang, $22 \mathrm{~mm}$ breit) und völlig vom Grosshirn bedeckt. Dasselbe ergeben die Abbildungen von Chudziniski (1. c. Pamietnik towarzystwa nauk ścislich. Paris i 878 . T. XII. Holzschnitt F. S. $5^{2}$ u. Fig. 5 u. 6, Taf. I) und Kohlbrügge (Holzschnitt A. S. 189 , 1. c. Zool. Ergebnisse einer Reise in Niederl. OstIndien, B. II, Leiden 189r). Auch sagt Kohlbrügge ausdrücklich: "Das kleine Gehirn wird vollständig durch clas grosse bedeckt."

Die von mir untersuchten drei Gehirne zeigen ebenfalls eine vollständige Bedeckung des Kleinhirns durch das Grosshirn, wenn man das Gehirn in der norma verticalis betrachtet. (V'gl. die Abbildungen, Taf. I, Fig. I u. 2; Taf. II, Fig. 3, 4 u. 6.) Genauer dargestellt fand ich Folgendes: Da, wo das Kleinhirn zur Medulla 
oblongata hin seinen hinteren grossen Ausschnitt hat und in dessen Nachbarschaft ragen die Hinterlappen des Grosshirns über den hinteren Umfang des Kleinhirns hinaus (siehe Fig. I u. 2); mehr lateralwärts dagegen, wo der Umfang der Hinterlappen sich wieder einzuziehen beginnt, die beiden Kleinhirnhemisphären sich aber stärker ausladen, sieht man letztere ein wenig über die Grosshirnhinterlappen vorragen (Fig. I u. 2, Fig. 4 u. 6 - Fig. 3 steht nicht in cler norma verticalis, sonst würde das Gesagte auch hier merkbar sein). Dieser Vorsprung des Kleinhirns erscheint aber mehr seitlich, als gerade nach hinten gerichtet.

Ich bin vorläufig ausser Stande, den Widerspruch in den Befunden Flowers, der wenigstens bei dem untersuchten Schädelausguss von $H$. syndactylus ein sehr erheblicher ist, aufzuklären. Ich wäre versucht, die Abweichung clarauf zu schieben, dass Flower's Schädelausguss von einem älteren, völlig ausgewachsenen Thiere stammte, während die von Bischoff, Deniker, Kohlbrügge und mir untersuchten Gehirne von jüngeren Exemplaren herrührten. Es sprechen für diese Annahme auch die höheren Werthe, welche Flower für die Ausmaasse des Gross- und Kleinhirns fand, vergl. das vorhin Mitgetheilte. Auch Joh. Möller ${ }^{25}$ ) meint, class derartige Verschiedenheiten in verschiedenen Altersstufen ihren Grund haben möchten. Kohlbrügge giebt leider keine genaueren Nachrichten darüber. Es wäre sehr erwünscht, dass bei weiteren Untersuchungen auf cliesen Punkt besonders geachtet würde. Ich vermag zu meinem Bedauern über das Alter und die Grösse der Thiere, von clenen meine Hylobates-Gehirne stammen, nichts anzugeben.

Die Gewichtsverhältnisse anlangend, so haben wir genaue Angaben nur von Max Weber erhalten, welche Kohlbrügge (1. c. Zool. Ergebnisse einer Reise in Niederl. Ost-Indien B. II, Leiden I89I, p. 196) mittheilt. Demzufolge hatte ein männlicher $H$. syndactylus von $62,5 \mathrm{~cm}$ Körperlänge und $9500 \mathrm{~g}$ Körpergewicht ein Hirngewicht von $\mathrm{r} 30 \mathrm{~g}-$ ein $\mathrm{H}$. $q$ leuciscus von $50 \mathrm{Cm} \mathrm{K}$. L. und $6250 \mathrm{~g} \mathrm{Ge}-$ wicht ein Hirn von $94,5 \mathrm{~g}$ - ein männlicher $\mathrm{H}$. lar mit Milchgebiss (26 Zähne) bei 40,5 K. Länge und $3027 \mathrm{~g}$ Gewicht ein Hirn von $89 \mathrm{~g}$ - ein $\bigcirc \mathrm{H}$. synd. (Milchgebiss 24 Zähne), Körperlänge $35 \mathrm{~cm}$, Körpergewicht $2057 \mathrm{~g}$, ein Hirn von $116 \mathrm{~g}$ - ein $\sigma^{\prime} \mathrm{H}$. synd. (Milchgebiss 20 Zähne) mit 28,5 cm Körperlänge und I $25^{\circ} \mathrm{g}$ Körpergewicht, ein Hirn von $\mathrm{roo} \mathrm{g}$. Die hieraus zu ziehenden Schlüsse ergeben sich ohne Weiteres; nur möchte ich hervorheben, class clarnach H. syndactylus das weitaus grösste Hirngewicht hat, und dass, nach der Höhe der Gewichte zu urtheilen, die von mir untersuchten

25) Möller, Joh., Zur Anatomie des Chimpanse-Gehirns. Archiv für Anthropologie. Bd. $17, \mathbf{1} 888$. 
Gehirne sämmtlich jungen Thieren angehört haben müssen. Ich erhielt nämlich von den drei stark in Alkohol gehärteten Gehirnen folgende Gewichtszahlen:
I. Hyl. syndactylus $=63 \mathrm{~g}$,
II. H. lar $=73 \mathrm{~g}$,
III. H. leuciscus $=70 \mathrm{~g}$.

Die Hirnhäute waren entfernt, vom Rückenmark war das Gebiet des I. und II. Cervicalnerven als an der medulla oblongata befindlich, mitgewogen worden. Nehmen wir bei der starken Erhärtung der Gehirne in Alkohol einen Gewichtsverlust in maximo mit Broca von $30 \mathrm{pCt}$., so erhalten wir als wahrscheinliche Gewichte der frischen Gehirne bei

$$
\begin{aligned}
& \text { I. H. syndact. }=82 \mathrm{~g}, \\
& \text { II. H. lar }=95 \mathrm{~g}, \\
& \text { III. H. leucisc. }=9 \mathrm{I} \mathrm{g} .
\end{aligned}
$$

Die Erhebung weiterer Hirngewichte unter Berücksichtigung des Alters, der Körperlänge und des Körpergewichts wäre sicherlich von Interesse.

III.

Einzelbeschreibung.

Nachdem wir im Voraufgehenden ein Bild von den allgemeinen Form- und Grössenverhältnissen des Gibbon-Hirns zu geben versucht haben, gehen wir nun zur genaueren anatomischen Beschreibung der einzelnen Theile über. Ich handle diese $a b$ in der Reihenfolge: A. Furchen und Windungen der Grosshirnhemisphären (Pallium und Rhinencephalon), B. Hirnbasis mit den Gefässen und Nerven, nebst der medulla oblongata, C. Innerer Aufbau des Grosshirns, D. Kleinhirn, E. Hirnhäute. -

A. Die Furchen und Windungen des Grosshirns haben bislang fast ausschliesslich das Interesse der Forscher, welche sich mit dem Gibbon-Hirn beschäftigten, auf sich gezogen und so finden wir bezüglich derselben die meisten Angaben. Immerhin glaube ich im Folgenden noch einiges Neue geben zu können.

I) Fossa Sylvii und Insula Reilii. Billiger Weise wird unter den sämmtlichen Grosshirn-Furchen die Sylvi'sche Grube vorangestellt; mit ihrer Beschreibung verbinden wir zweckmässig die der Insel. Da ich bereits an einem anderen Orte (1. c. Sitzungsber. d. K. Preuss. Akademie der Wissenschaften I 89 I, Stück XVI, 19. März) beides, soweit das vorhandene Material reichte, genau beschrieben habe, so beschränke ich mich auf die Wiedergabe der Hauptsachen.

Wir können an der ganzen, mit dem Namen der Sylvi'schen Grube (Fossa Sylvi) belegten Spalte (ニ in den Figuren), unter 
Berücksichtigung der genauen Schilderungen von Broca26) und Schwalbe2i) unterscheiden: Die vallecula Sylvii 28 ) und die fissura ${ }^{29}$ ) Sylvii mit einem hinteren, vorderen horizontalen und vorderen aufsteigenden Aste. Beim Gibbon finden sich alle diese Stücke mit Ausnahme des vorderen horizontalen Astes, der nur in wenigenFällen spurweise vorhanden zu sein scheint. Die vallecula Sylvii ist klein, dreiseitig und entspricht der Substantia perforata antica, welche ihren Boden bildet; von vorn her ragt das Ursprungsfeld des Tractus olfactorius in die vallecula hinein. Die vallecula Sylvii biklet ein wesentliches Stück des einen der beiden vergleichend-anatomischen Haupttheile des Gehirns, des Rhinencephalon, und ist ihre besondere Unterscheidung deshalb wichtig. (Siehe hierüber Turner 1. c. The convolutions of the Brain, Verhdl, des X. Internat. med. Congresses in Berlin, Bd. II P. 9 (I5). - The Journal of anat. and physiol. vol. XXY. 1890 , p. 105 (113). Die fissura Sylvii gehört zu dem anderen Haupttheile, dem Hirnmantel (Pallium). - Die vallecula geht lateralwärts in die ansehnliche tiefe fissura Sylvii über, unter der man den Spaltraum zwischen dem Fronto-Parietal-Lappen einer- und dem Temporallappen andererseits zu verstehen hat. In diesem Spalte eingeschlossen und beim Gibbon gänzlich verdeckt, liegt die Insel (Insula Reihii). Indem die vallecula in die fissura übergeht, verschmälert sie sich zunächst und verliert bedeutend an Tiefe, indem sich zwischen ihr und der fissura eine schwellenartige Erhöhung, gerade wie beim Menschen, die "Inselschwelle“, "Limen Insulae“, (Schwalbe) einschiebt; die fissura Sylvii wird dann wieder tief. Gleich beim Beginne ( $\Sigma$ Fig. 4) gabelt sich die Fissur in ihre beiden Aeste, in den weit längeren nach hinten und aufwärts gerichteten hinteren ( $\Sigma$ p. Fig. 3 und 4 ) und einen kurzen, beim Gibbon indessen

${ }^{26}$ ) Broca, P., a) Anatomie comparée du cerveau. Le grand lobe limbique et la scissure limbique dans la série des mammifères, Revue d'anthropologie 1878 . II. Sér. T. I p. 385. - Mémoires publ. par Pozzi, p. 259. b) Sur la topographie cranio-cérébrale ou sur les rapports anatomiques du crane et du cerveau. Rev. d'anthrop. 1876 , II. Sér. T. V p. 193 u 278. - Mémoires p. 48r. c) Étude sur le cerveau du Gorille, Revue d'anthropologie 1878 , II. Sér. T. I p. I (besonders wichtig) Mémoires p. 60r. d) Nomenclature cérébrale, dénomination des divisions et subdivisions des hémisphères et des anfractuosités de leur surface. - Rev. d'anthropol. 1878, II. Sér. T. III S. 193. - Mém. p. 652. e) Description élémentaire des circonvolutions cérébrales de l'homme d'après le cerveau schématique. Revue d'anthropol. II. Sér. T. VI 1883 p. 1, 193, 385 et T. VIl, 1884 p. 1. Mém. p. 707.

$\left.{ }^{27}\right) \mathrm{Sch}$ walbe, G., Lehrbuch der Neurologie. Erlangen $188 \mathrm{r}$.

${ }^{28)}$ Stamm, Truncus der fossa Sylvii (Broca, Bischoff, Schwalbe.)

${ }^{29}$ ) Schwalle gel)raucht für das, was er $537 \mathrm{ff}$. consequent "fissura Sylvii" nennt, S. 534 auch den Ausdruck "fossa". Ich schlage vor den Ausdruck "fossa" nur collectiv zu verwenden, wenn man das ganze Gebilde ${ }_{\text {vallecula }}+$ fissura + Kani mit einem Gesammtnamen bezeichnen will.

Virchow-Festschrift. Bd, 1. 
stets scharf und deutlich ausgeprägten vorderen Ast (¿ a Fig. 4), welcher sich in den Stirnlappen hinein erstreckt. Ich deute ihn mit Cunningham ${ }^{30}$ ) als Homologon des vorderen aufsteigenden Astes. S. w. u. Er misst bei allen drei Gehirnen 6-7 mm; dieselbe Länge giebt Hervé an (1. c. La circonvolution de Broca, Paris, 1888). Der hintere Ast (mit dem Zirkel gemessen) betrug bei

\section{H. leuciscus $\begin{cases}\text { rechts } & 15 \mathrm{~mm} \\ \text { links } & 16 \mathrm{~mm}\end{cases}$ \\ II. H. lar $\left\{\begin{array}{l}\text { rechts } 18 \mathrm{~mm} \\ \text { links } 20 \mathrm{~mm}\end{array}\right.$ \\ III. H. syndact. $\begin{cases}\text { rechts } & 17 \mathrm{~mm} \\ \text { links } & 15 \mathrm{~mm}\end{cases}$}

Drei mal unter den sechs vorliegenden zeigte sich der hintere Ast am hinteren Ende gegabelt und zwar sehr deutlich beiderseits bei $H$. leuciscus (s. Fig. 3 und $4 \Sigma$ p.), dann linkerseits bei H. syndactylus; rechterseits besteht bei diesem nur eine leichte Andeutung einer Gabelung; bei H. lar läuft der in Rede stehende Ast einfach aus. Bei H. syndactylus zieht der untere Gabelast, ganz flach werdend, in die erste Temporalfurche (i) aus. Eine ähnliche, ganz flache Verbindung besteht rechterseits zwischen dem oberen (längeren) Gabelaste und dem sulcus postcentralis. Leider ist diese Verbindung in den Fig. 3 und 4 nicht zum Ausdruck gekommen.

Was dieses Verhalten bei den sonst vorliegenden Beschreibungen und Abbildungen anlangt, so finden wir die Gabelung des hinteren Astes nur bei Gratiolet (l. c.) in einem Falle, (H. leuciscus Fig. 4 u. 6) und Deniker (l. c. Arch. de zool. 1885 pl. XXIX. Fig. 3 u. 4) und zwar auf beiden Seiten. Alle Uebrigen - und zwar beziehen sich die Abbildungen auf $H$. syndactylus (Sandifort und Kohlbrügge) und leuciscus (Kohlbrügge, Bischoff und Rüdinger (in den Festschriften f. Henle u. Bischoff ll. cc.) - haben einen einfach endenden hinteren Sylvischen Ast.

Den vorderen Ast bilden Alle übereinstimmend ab. Nur bei Kohlbrügge (1. c.) liegen sehr merkwürdige besondere Verhältnisse vor. Letzterer bildet in seiner Fig. A. (Hyl. syndactylus) eine Vereinigung der Fossa Sylvii mit dem Sulcus orbitalis externus der Autoren $a b$, in der Weise, als ob der vordere Schenkel der Fossa Sylvii ( $($ a) nicht blind ende, sondern in den Sulcus orbit. externus s. fronto-orbitalis ()) einmünde. (An der Hand unserer Figg. 1 u. 2, 4 u. 5 kann man sich leicht ein Bild von diesen Verhalten machen, wenn man sich $\mathrm{a}$ a bis in $\zeta$ hinein verlängert denkt). Kohlbrügge giebt an, dass er dieses Verhalten bei 3 Gehimen von Hylob. syndactylus an beiden Seiten, bei 2 anderen Syndact.-Gehirnen an einer Seite, ebenso, einseitig, bei dem Gehirn eines H. leuciscus gefunden habe. Da Kohlbrügge 12 Gehirne untersuchte, so fand er diese Verbindung also fast in der Hälfte der Fälle. In Gratiolets Fig. 6 I. c. scheint dasselbe alggebildet zu sein; wenn wir aber Fig. 5 desselben Autors vergleichen, so zeigt sich klar, dass in Fig. 6 nur eine Ungenauig. keit vorliegt.

Bei keinem meiner drei Gehirne fand ich eine Spur dieser Verbin-

${ }^{30}$ ) Cunningham, D. J., The Sylvian fissure and the Island of Reil in the primate Brain. The Journal of anatomy and physiology, vol. XXV p. 286. 189r. 
dung; beide Sulci waren stets clurch einen ansehnlichen Zwischenraum, welcher, wie ich mit Bischoff annehme, dem ventralen Schenkel des gyrus frontalis tertius (richtiger, s. w. u. "quartus") angehört, getrennt. Da Kohlbrügge wichtige Schlüsse für die Deutung der Stirnwindungen auf dieses Verhalten gründet, so bin ich genöthigt bei Besprechung der Stirnfurchen und Stirnwindungen nochmals auf diesen Punkt zurückzukommen. Hier ist noch die Frage zu erörtern, wie wir den beim $\mathrm{Gibbon}$ meist einfach auftretenden kurzen vordern Ast der fissura Sylvii zu deuten haben. Hervé, 1. c. p. 54, hält ihn für den Ramus horizont. anterior. Eberstaller ${ }^{31}$ ) glaubt, dass er (bei den Anthropoiden) beiden vorderen Aesten des Menschen, dem Ramus anterior ascendens + Ram. ant. horizontalis zusammen entspreche, während ihn Cunningham, ${ }^{32}$ ) sofern er überhaupt einem der beiden vorderen Aeste des Menschen zu homologisiren sei, als Ram. anterior ascendens deutet. Dieser Meinung muss ich mich anschliessen, jedoch nicht aus den von $\mathrm{C} u n n i n g h a m$ vorgebrachten Gründen, sondern weil ich an einem der von mir untersuchten Gibhon-Hirne, bei Hylobates leuciscus, auch eine Andeutung eines zweiten vorderen Astes fincle, der seiner Lage und Richtung nach nichts anderes sein kann, als ein rudimentärer Ram. ant. horizontalis. Ich verweise hier auf meine oben citirte Abhandlung: „Ueber die Sylvi'sche Furche und die Reil'sche Insel des Genus Hylobates" (Sitzgsber. d. K. Pr. Akad. d. Wiss. I891. p. 265). Man sieht dort in Fig. I A. und B. das vordere Ende der Sylvi'schen Furche deutlich gegabelt; der längere Gabelast zieht mehr aufwärts und ist der beim Gibbon constant vorkommende, der andere, ganz kleine, ist, so viel ich sehe, als Ram. ant. horizontalis zu deuten. Für diese Deutung spricht auch der Umstand, dass in denjenigen Fällen, wo bei menschlichen Gehirnen nur ein vorderer Ast gefunden wird, dieser sich wie der vordere a ufsteigende verhält. (Giacomini, citirt von Mingazzini; wahrscheinlich findet sich diese Angabe Giacomini's in dessen Werke: Varietà delle circonvoluzioni cerebrali nell' uomo, Torino 1881 , welches mir augenblicklich nicht zur Hand war. In den beiden anderen einschlägigen Werken Giacomini's (Guida allo studio delle circonvoluzioni cerebrali, 2 ed., Torino i 884 und I cervelli dei microcefalici, Torino 1890 , Stamperia dell' unione tipograficoeditriche) habe ich vergebens darnach gesucht). Auch muss angeführt werden, dass der entwicklungsgeschichtlich beim Menschen zuerst

31) Eberstaller, Das Stirnhirn, ein Beitrag zur Anatomie der Oberlläche des Grosshirns. Wien und Leipzig 1890.

32) Cunningham, D. J., The sylvian fissure etc. 1. c. The Journ. of anat, and physiol. vol. XXV 1891 p. 286. 
auftretende Ast der senkrechte ist. Mingazzini. ${ }^{33}$ ) In einer zweiten entwicklungsgeschichtlichen Arbeit desselben Autors ${ }^{34}$ ) finde ich nur angegeben, dass der vertikale vordere Ast sich rascher entwickle, als der horizontale (1. c. p. 507). Cunningham glaubt, dass bei den Anthropoiden überhaupt derjenige Theil der Insel fehle, der dem frontalen Operculum entspreche, es fehle dann auch dieses und das orbitale operculum, so dass von einem Ramus ant. horizontalis, der das frontale vom orbitalen operculum trennt, keine Rede sein könne. Dieser Deduction Cunningham's kann ich nicht beipflichten; muss mir aber vorbehalten, die Gründe dafür später an einem andern Orte, bei Besprechung der übrigen Anthropoiden-Gehirne darzulegen.

Bezüglich der fossa Sylvii wäre noch zu erwähnen, dass der hintere Ast - wenn man sich das Hirn mit der Basis auf einer horizontalen Unterlage aufruhend denkt - anfangs leicht aufwärts, dann ziemlich horizontal und endlich mit leichter Biegung aufsteigend nach hinten zieht. An beiden Aesten finden sich leichte Einkerbungen an den Rändern, jedoch von unbeständigem Character.

Die Begrenzung der Sylvischen Grube wird gebildet am vorderen Aste von der diesen umkreisenden dritten Stirnwindung, wie ich mit Bischoff annehme. Am hinteren Aste folgen dann, s. Fig. 4, Taf. II, das untere Ende der Praecentral-Windung, dann die PostcentralWindung, welche ihrerseits in die untere Scheitelwindung übergeht, speciell in denjenigen Theil, den man als gyrus s. lobulus supramarginalis (Ecker) bezeichnet hat. Dieser, das distale Ende der Sylvischen Grube unkreisend, geht dann in die erste Schläfenwindung (gyrus tempor. I) über. Secundäre, sogenannte Tiefenwindungen an den der Sylvischen Grube zugekehrten Flächen der eben aufgezählten, die Grube einschliessenden grossen Windungszüge, (opercula), wie sie beim Menschen so deutlich sind, zeigen sich beim Gibbon nur in unbedeutenden Spuren. So berichtet auch Rüdinger 1. c. „Ein Beitrag zur Anatomie des Sprachcentrums" Festschrift für Bischoff, Stuttgart, Cotta, 1882, S. 25. Die Ränder der Grube liegen dicht aneinander und halten, wie bemerkt, selbst beim jungen Thier die Insel völlig verborgen.

In den bisherigen Mittheilungen ist die Insel des Hylobates-Gehirns als eine glatte, völlig windungsfreie Bildung beschrieben worden, s. z. B. bei Bischoff, (1. c. Abhdl. der Münchener Akademie Bd. X, ferner bei Rüdinger (l. c. Festschrift für Bischoff, Stuttgart r882,

33) Mingazzini, G., Ueber die Furchen und Windungen des Gehirns der Primaten. Untersuchungen zur Naturlehre des Menschen und der Thiere. Herausgeg. von Jac. Moleschott XIV. Bd. S. 177, Giessen 1889 S. 182.

34) Mingazzini, G., Ueber die Entwickelung der Furchen und Windungen des menschlichen Gehirns. Ebend. Bd. XIII 1888 S. 498. 
S. 159) und bei Broca (1. c. L.e grrand lobe limbique ctc. Mém. rec. par l'ozzi, p. 369). Weitere Angaben über die Gibbon-Insel lagen bis zur V'eröffentlichung meiner Mittheilung in den Sitzungsber. der K. Preuss. Akad. d. Wissenschatten (1. c.) nicht vor. Ich konnte daselbst zeigen, dass eine völlig glatte Oberfläche der Insel bei keinem der drei von mir untersuchten Gehirne vorhanden war. Bei Hylobates leuciscus erwies sich sogar ein deutlicher sulcus, der vom limen aus in die Insel hineindrang und dieselbe bis zu ihrem hinteren (Schläfen-) Ende durchsetzte, so dass die Insel hier vie eine um diesc Furche herumgelegte einfache Hirnwinclung erschien. Ich glaube die Ansicht vertreten zu können, dass die erwähnte Furche dem Sulcus centralis insulae, wie er von Hefftler, ${ }^{35}$ ) Guldberg ${ }^{36}$ ) und Eberstalle ${ }^{37}$ ) beschrieben worden ist, entspricht, um so mehr, als diese centrale Inselfurche beim Menschen sowohl wie beim Gibbon über die Inselschwelle hinwegzieht in die vallecula Sylvii hinein und auf der Schwelle selbst noch als Furche sichtbar bleibt. In meiner eben citirten Mittheilung (Sitzungsber. d. K. Preuss. Akad. d. Wissenschaften I891 S. 265) hatte ich dies Hinüberziehen der Furche über die Inselschwelle zur vallecula noch als eine Ausnahme hingestellt; die inzwvischen weiter geführten Untersuchungen haben es mir als Regel ergeben. Dieser Umstand veranlasste mich, der Meinung von Turner ${ }^{38}$ ) beizupflichten, der zu Folge die Reil'sche Insel der Primaten zu homologisiren wäre der in die Tiefe versenkten sogenannten Sylvischen Windung (Gyrus sylviacus) der Carnivoren, oder aber, dass diese Windung der Carnivoren ein Rudiment der Primaten-Insel in sich fasse.

Ziehen ${ }^{39}$ ) hat neuerdings der Turner'schen Ansicht mit guten Gründen widersprochen. Vor der Hand kann ich zur Sache keine für mich entscheidende Stellung einnehmen, da ich bezüglich der Carnivoren-Gehirne nicht über eingehendere eigene Untersuchungen verfüge.

35) Hefftler, F., Die Grosshirnwindungen des Menschen und deren Beziehungen zum Schädeldach St. Petersburg 1873 (russisch). Vgl. Eberstaller, Anat. Anzeiger 1888 S. 382 .

${ }^{36)}$ Guldberg, G. A., Zur Morphologie der Insula Reilii. Anat. Anzeig. 1887 S. 659 No. 21 . vom $x$. October 1887.

${ }^{37}$ ) Eberstaller, Zur Anatomie und Morphologie der Insula Reilii. Anatom. Anzeiger 1887 S. 739 No. 24 v. 15. Nov. 1887 .

${ }^{39}$ ) Turner, Sir Wm., Comparison of the Convolutions of the seals and walrus with those of the carnivora and of apes and man. The Journal of anatomy and physiology normal and pathological by G. M. Humphry, Sir Wm. Turner and J. G. Mc. Kendrick, vol. XXII, (new Ser. vol. II) I 888 p. 554 .

${ }^{39}$ ) Ziehen, Th., Zur vergleichenden Anatomic der Hirnwinclungen mit specieller Berücksichtigung der Gehirne von Ursus maritimus und Trichechus rosmarus. Anat. Anzeiger 1890. No. 24, 27. Dec. 1890. 
Indcm ich für dic weitere Beschreibung der Gibbon-Insel auf meine mehrfach erwähnte Darstellung mich beziehe, sei hier nur noch erwähnt, dass die beiclen Schenkel der Winclung, welche als ..Insel “ um die genannte centrale Furche herumgelegt sind, nach Guldberg als pars frontalis und pars parieto-temporalis insulae bezeichnet werden, und dass der der pars frontalis entsprechende Windungsschenkel in die dritte Stirnwindung, die pars parieto-temporalis dagegen in die erste Schläfenwindung umbiegt. An der pars frontalis zeigen sich auch beim Gibbon schon Spuren einer weiteren Gliederung, während dies bei der pars parieto-temporalis noch nicht der Fall ist. Ich erwähne dies um so mehr, als sich bei den übrigen Anthropoiden und beim Menschen der Frontal-Lappen der Insel inmer als der weiter ausgebilclete zeigt.

Die Grössen-V ${ }^{\top}$ erhältnisse der Insel waren bei allen drei untersuchten Gehirnen dieselben:

$\begin{array}{clr}\text { Grösste } & \text { Länge } & \text { I } 5 \mathrm{~mm} \\ " & \text { Breite } & 8 \mathrm{~mm} \\ " & \text { Höhe } & 4-5 \mathrm{~mm},\end{array}$

am Alkohol-Präparat mit dem Zirkel gemessen.

A. 2. Die Furchen und Windungen des Stirnlappens.

Wir finden beim Hylobates-Gehirn am Stirnlappen folgende Furchen:

a) Auf der convexen Oberfläche in einiger Entfernung von der Mantelkante zwei bis drei kurze, im Ganzen der Länge nach (sagittal) verlaufende Furchen, an welche sich quere Aeste anschliessen (Fig. 3 u. $\left.4, \alpha, \beta, \because, r_{1}\right)$. Bei Hylobates leuciscus, s. die genannten Abbildungen, sehen wir rechterseits einen mehr quer (aufsteigend) verlaufenden Ast $\left(r_{i}\right)$, an den sich $T$ förmig ein longitudinaler Ast $(\gamma)$ anschliesst, sich sowohl nach hinten wie nach rorn über $\gamma_{\text {i }}$ hinaus erstreckend; es folgt dann nach vorn ein isolirtes Furchenstück ( 3$)$ in schiefer, jedoch vorwiegend querer Richtung; zumeist nach rorn haben wir ein longitudinales $(\alpha)$, welches mit einer kleinen Gabel endet. Die Richtung des hinteren Schenkels von $\gamma$, desjenigen Schenkels, zu welchem der Bezeichnungsstrich hinführt, ist so, dass man ihn auch mit $\gamma$ zusammenstellen kann. Dann würde man einen queren nach vorn winklig vorspringenden Schenkel haben $\left(\gamma+r_{i}\right)$, von dessen Winkel ein kürzeres longitudinales Stück ausgeht. Wir sehen, dass an der linken Hemisphäre, wenn auch mit geringen Aenderungen, sich dieselben Furchen finden. Die Unterschiede liegen

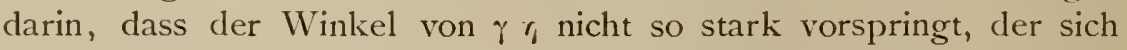
daran schliessende longitudinale Schenkel länger ist, dass das rechts isolirte Stück $\beta$ hier mit $\alpha$ und dem eben genannten longitudinalen Schenkel verbunden ist und sich nach abwärts über diesen Schenkel 
hinaus fortsetzt, also hier cloppelt so ausgedehnt ist, als auf der rechten Seite.

Ich betrachte $\gamma+\gamma_{1}$ als den Sulcus praecentralis superior, das übrige als den Sulcus frontalis superior $\left(f_{1}\right) ; \beta$ als eine Nebenfurche.

Bei Hylobates lar verhalten sich diese Furchen fast ebenso. Der longitudinale Antheil $\left(f_{t}\right)$, aus zwei Stücken bestehend, von denen das hintere mit dem Sulcus praec. sup. zusammenhängt, das vordere (hier an beiden Seiten isolirt) mehr medianwärts liegt; rechts sitzt hinten ein kurzes schiefes Furchenstück an dem vorderen longitudinalen $(x)$, in welchem wir vielleicht eine Spur von $\beta$ wieder erkennen dürfen. Fast genau so finde ich diesen Furchencomplex bei $H$. syndactylus.

In der Sandifort'schen Abbildung sehen wir rechterseits eine einzige continuirliche Furche $\left(f_{1}\right)$, daneben auch ein $\beta$ entsprechendes Stück, welches bis zur Mantelkante sich erstreckt. Bei Gratiolet (Fig. 4. u. 6) treffen wir dieselben Verhältnisse; die Seitenansicht (Fig. 6) zeigt, dass auch ein sulcus praecentralis superior angedeutet ist. Links findet sich auch $\beta$. Auch bei $\mathrm{Chudzińskil.} \mathrm{c.} \mathrm{und}$ in Bischoff's Figuren I u. III erkennt man unschwer denselben Typus wieder, ebenso hei $\mathrm{R}$ üdinger (Festschr. für Henle 1. c. Fig. 5 Taf. XXI), obwohl hier augenscheinlich der vordere Theil des Gehirns nicht völlig ausgeführt worden ist. Kohlbrügge's Fig. A (H. syndactylus) lässt eine ähnliche Disposition wahrnehmen, wie sie in meiner Fig. 3 rechterseits abgebildet ist, nur sind $z u f_{1}+\beta$ vier getrennte Stücke zu zählen. Die Figur B zeigt nur zwei in einer Fluclit liegrende longitudinale Stücke und ein kurzes Querstück, entsprechend einem S. praecentr. sup.

Gromier (1. c. S. 74) giebt keine Abbildungen; aus seiner sehr kurzen Beschreibung lässt sich nicht entnehmen, wie bei dem von $\mathrm{ihm}$ untersuchten Gibbon-Hirn die betreffenden Furchen sich verhielten.

Bei dem von Ueniker beschriebenen Fötus trifft man einen kurzen Querschenkel und einen cinfachen Längsschenkel rechts, links nur den Längsschenkel.

So sehen wir also bei diesem Furchensystem des Hylobates eine selbst in Einzelheiten grosse Uebereinstimmung, die gleichwohl allerlei Abänderungen zulässt, ohne allzugrosse Entfernung von einer typischen Grundform.

b) In ungefähr gleichem Abstande von den eben beschriebenen Längsfurchen ( $\because$. $\beta$. . ), wie diese von der Mantelkante, finclet sich ein zweites höchst charakteristisches Furchensystem, das des Sulcus praecentralis inferior (S. prc. inf.) Sulcus frontalis medius, (f. m. Eberstaller ${ }^{40}$ ), s. principalis (mihi). Dieses System be-

40) Wir befinden uns hier wieder einmal vor einer äusserst verwirrend('n Nomenclatur. Den sulcus frontalis medius (Eberstaller) des Menschen nannte Broca bei den niederen Affen, wo er Besonderheiten zeigt, Sillon rostral. Eloerstaller nennt ihn bei diesen Sulcus rectus und verwenclet den Namen sulcus rostralis für eine andere Furche, die auf der medialen Hemisphärenflăche des Stirulappens unterhalb des Balkenrostrum liegt. Nun wissen wir aber, dass auch der Sulcus olfactorius seit langer Zeit (Valentin) Sulcus rectus genannt wirc; also zwcimal clenselben 
steht aus einem queren aufsteigenden Schenkel, (£. Fig. 3 u. 4), an den sich, unter fast rechtem Winkel umbiegend, ein longitudinaler bis zum Stirnschnabel reichender (i, Fig. 3 u. 4) anschliesst. Beide Schenkel sind tief und kräftig ausgeprägt. Ueberhaupt gehört dieser Sulcus zu den bestentwickelten und am meisten typischen des Gibbon-Hirns.

Die longitudinale Furche (i), der Sulcus front. principalis, zeigt am wenigsten Abänderungen. Unter den 6 Sulci meiner drei Gehirne zeigte nur der rechtsseitige des $H$. syndactylus einen kleinen nach abwärts sich wendenden Seitenast, sonst fand sich die Furche immer einfach mit leicht bogenförmig geschwungenem, der Orbitalkante entsprechendem Verlauf. Der quere Schenkel erstreckt sich meist noch ein wenig über den longitudinalen hinauf, in einem Falle (bei meinem H. lar) fast bis zum Sulcus praecentralis superior, so dass nur eine schmale, selbst etwas in die Tiefe gesenkte Windung zwischen beiden lag, und man also einen fast ununterbrochenen sulcus praecentralis hatte. In anderen Fällen ist es so, wie meine $\mathrm{Ab}$ bildung zeigt, d. h. der quere Schenkel biegt einfach in den longitudinalen um ohne T-Ansatz. (S. Fig. 4).

Fast alle übrigen vorhandenen Abbildungen der citirten Autoren, denen ich hier noch Hervé, 1. c. und Rüdinger in der Festschrift für Bischoff (Anatomie des Sprachcentrums 1. c.) hinzufüge, zeigen dieses Furchensystem genau so, wie es hier beschrieben wurde.

Bemerkenswerthe Ausnahmen finde ich nur bei Owen, Sandifort, Gratiolet und Deniker.

Bei Owen's kleiner Abbildung sieht man nur einen Sulcus, der aus einem aufsteigenden und aus einem longitudinalen Schenkel besteht; der aufsteigende Schenkel ist zur Mantelkante hingewendet. Es ist mir zweifelhaft geblielsen, ob hier die erste oder zweite (jetzt in Rede stehende) Furchengruppe abgebildet ist. Bei Sandifort geht rechterseits der Sulcus front. principalis (der Längsschenkel) nach hinten (zur Centralfurche) hin, über den Querschenkel hinaus. Leider fehlt eine Seitenansicht, so dass man die Sache nicht völlig klar beurtheilen kann. Links sieht man gar keinen Querschenkel, wohl aber noch einen zweiten kleinen Lüngsschenkel unterhalb des Hauptschenkels.

Wichtig sind die Abbildungen von Gratiolet und Deniker, da sie Fötus betreffen. Bei Beiden zeigt sich übereinstimmend, dass nur der Sulcus principalis vorhanden ist, vom Sulcus praecentralis inferior noch jede Spur fehlt.

Beide bisher betrachteten Furchengruppen bilden das frontolaterale Furchensystem.

c) Das frontoorbitale Furchensystem. Dieses umfasst a) Die Olfactoriusfurche (Sulcus olfactorius), $\beta$ ) den Sulcus

Namen für ganz verschiedene Dinge desselben Lappens (!) Für den Gibbon konnte ich mir mit dem Namen "Sulc, front. medius" aushelfen, für die niederen Affen ist aus Gründen, deren Erörterung hier zu weit führen würle, eine andere Bezeichnung erwünscht. Ich schlage vor: Sulcus frontalis principalis, seiner Bedeutung für den Stirnlappen des Affengehirns entsprechend. 
orbitalis, i) den Sulcus fronto-orbitalis (orbitalis externus Bischoff.) Die Olfactoriusfurche habe $\mathrm{ich}$, dit sie sich ̈̈usserst einfach verhält, nicht abgebildet. Sie ist nur kurz, nur etwa dem hinteren I)rittel des Tractus olfactorius entsprechend, der sie cleckt und grösstentheils ausfüllt. Daher ist die Furche auch breit, dabei aber flacl,. Beide Furchen convergiren, wie die entsprechenclen tractus, zur Mantelkante hin (vgl. Fig. I, 2, 4 u. 5). Eine genauere Angabe in der Litteratur ïber diese Furche habe ich nicht gefunclen, falls nicht etwá Chudzinski sie berücksichtigt hätte. Seine Abbildung (H. leuciscus) Fig. 6, Taf. 1. c. T. XII, weicht ganz auffallend von meinen drei übereinstimmenden Befunden ab. Der Tractus olfact. rerläuft hier schnurgerade, wie mit dem Lineal gezogen, und an der rechten Seite, wo der Tractus entsprechend ist, sieht man eine lange in der Mitte durchbrochene Furche, deren hinteres Stück einen kleinen lateralen Nebenast besitzt. Kohlbrügge sagt nur, dass sich medianwärts vom Sulcus orbitalis noch der wenig ausgeprägte sulcus olfactorius fände. Die Abbildung Bischoff's von Hyl. leuciscus zeigt, wie mir scheint, die Olfactorius-Furche gar nicht. Die beiden schmalen Furchen, welche man in Fig. 2 auf Bisch offs Taf. II neben der Mantelfurche erblickt, glaube ich für die beiden später bei der Orbitalfurche zu beschreibenden medianen Nebenfurchen halten zu sollen (s. 9 in meiner Fig. 5). In Text wird nichts darüber gesagt. Wenn hier und da die Olfactoriusfurche noch als Fortsetzung des Sulcus frontalis primus angesprochen wird, so sind die Verhältnisse beim Gibbon wohl dazu angethan, dies zu widerlegen.

Der Sulcus orbitalis (triradiatus Turner, Incisure en H Broca), ist bekanntlich eines der wandelbarsten Gebilde des Gehirns, insbesondere beim Menschengehirn, man vergleiche die eingehende Beschreibung von $W^{T}$ eisbach. ${ }^{4}$ ) Bein Gibbon habe ich indessen eine weniger wandelbare Form gefunden. Ein Hauptzweig (I, Fig. 5, Hyl. syndact.), geht mit leicht lateralconvexem Bogen nach vorn, von ihm geht ein grösserer ( $\mathrm{I} b$ ) und mitunter noch ein kleinerer Nebenzweig nach lateralwärts ab. Würde an I b nach hinten noch ein Schenkel parallel zu I angefügt, so hätten wir die H-Furche. Neben dieser Hauptfurche zeigte sich bei $H$. syndactylus noch eine kleine medianwärts davon gelegene Nebenfurche (9). Bei H. leuciscus (s. Fig. I u. 2) war die Bildung im Principe ganz die gleiche, nur gingen die beiden Seitenschenkel (Fig. 2, r a u. I b) links ziemlich rechtwinklig und mehr nach rorn $a b$, während zugleich der Hauptschenkel (Fig. 2, I) weit nach hinten, fast bis zur fossa Sylvii reichte.

4) Weisbach, A., Die Supraorbitalwindungen des menschlichen Gehirns. Wiener med. Jahrbücher Bd. XIX 1870. 
Dic mediale Nebenfurche ( 9 in Fig. 5, 2 in Fig. 4) war kaum angedeutet, und zwar nur einseitig; sie ist in Fig. I u. 2 gar nicht wiedergegeben; (lagegen fand sich rechts eine kleine laterale Nebenfurche (Fig. I u. 2). Bei H. lar ähnelte die Form fast ganz der des H. syndactylus; hier war aber beiderseitig eine etwas verzweigte mediane Nebenfurche, jedoch lediglich rom Charakter einer Gefässfurche, entwickelt.

Sandiforts Abbildung zeigt fast das Gleiche, wenigstens linkerseits; man sieht auch hier eine longitudinale Hauptfurche mit 2 lateralen Aesten, daneben die longitudinale mediale Nebenfurche; rechts ist eine kleine Alweichung, insofern als die Hauptfurche drei Nebenäste zeigt, deren innerer auch nach $r$ ückwärts über die Hauptfurche hinaus verlängert ist.

Gratiolet zeichnet rechts denselben Befund, wie ich ihn gab, links geht von der Hauptfurche ein lateraler Seitenast aus, der zwci Nebenzweige nach vorn schickt. Die kleine mediale Nebenfurche ist links rorhanden.

Bischoffs Zeichnung ist nicht klar genug herausgekommen. Sehe jch recht, so haben wir beiderseits dasselbe: eine longitudinale Hauptfurche mit einem lateralen Seitenaste; ferner jederseits die gut entwickelte mediale Nebenfurche - s. meine Fig. 5 Nr. o.

Sowcit stimmen alle unsere Befunde gut überein, so dass man im Stande wäre, eine typische Form der Orbitalfurche beim Gibbon festzustellen, etwa einer Feder mit mehr oder weniger lateralen Fahnenästen vergleichbar, wozu in den meisten Fällen medianwärts noch die kleinere longitudinale Nebenfurche käme. Nur bei Chudzinski 1. c. finden wir von Hylobates leuciscus eine grössere $\mathrm{Ab}$ weichung, und zwar rechterseits. Hier zeigt sich eine longitudinale Furche, welche sowohl an ihrem hinteren wie vorderen Ende schwach lateralwärts umgeknickt erscheint, daneben ganz vorn ein kleines medianwärts gerichtetes isolirtes Furchenstück. Links kann man wieder einen longitudinalen Hauptast, der jedoch vorn erheblich schwächer wird, und einen starken Seitenast constatiren. Dass dieses Gehirn auch in der Olfactoriusfurche eine auffallende Abweichung von meinen Befunden darbot, wurde vorhin schon erwähnt.

Eines der unveränderlichsten Gebilde des Gibbon-Hirns und des Anthropoidenhirns überhaupt ist der Sulcus fronto-orbitalis ( $\%$ in meinen Figuren), oder orbito-frontalis [Broca und Hervé]. Die von Bischoff gebrauchte und ziemlich allgemein verbreitete Benennung: sulcus orbitalis externus kann ich nicht empfehlen, da sie die Vermuthung wach hält, als gehöre dieser Sulcus zum System des eben abgehandelten Sulcus orbitalis. Dass das durchaus nicht der Fall ist, lehrt jedes Gibbon-Hirn, welches uns in dieser Beziehung sehr deutliche Fingerzeige giebt. In jeder meiner Abbildungen, wie an den Präparaten sieht man die Furche völlig unabhängig von der Orbitalfurche. Dasselbe zeigen alle übrigen Abbildungen. Ebensowenig zeigt sich eine Verbindung 
dieser Furche mit der fossa Sylvii oder mit einem von deren Aesten. So wenigstens weisen es meine Präparate aus und die Angaben und Abbildungen aller übrigen Autoren mit Ausnahme Kohlbrügge's, welcher, wie schon vorhin erwähnt, in fast der Hälfte seiner Fälle eine Verbindung mit dem vorderen Schenkel der Sylvischen Grube feststellen konnte. S. dessen Abbildung 1. c. S. i 89 , Fig. A (H. syndactylus). $\mathrm{Ob}$ etwa Chudziríski (1. c.) in seinem Text etwas derartiges angiebt, vermochte ich, als der polnischen Sprache nicht genug mächtig, nicht zu sichern; seine Abbildungen zeigen nichts derartiges. Es ist befremdlich, dass Kohlbrügge unter seinen 12 Gehirnen nahezu die Hälfte mit dieser Verbindung ausgestattet fand, während dieselbe unter den etwa i6 Gehirnen, welche - die meinigen eingerechnet - sonst beschrieben sind, fehlte. Auf den Schluss, welchen Kohlbrügge aus seinen Befunden zieht, werde ich alsbald zurückkommen.

Hier sei noch erwähnt, dass der in Rede stehende Sulcus nur selten Verzweigungen zeigt. Bei meinem Hyl. leuciscus (Fig. I u. 2) hatte er eine solche rechterseits. Bei Syndactylus geht von ihm rechterseits eine ganz oberflächliche Gefässfurche zum vorderen Schenkel der Sylvi'schen Grube hin, ohne dieselbe jedoch völlig zu erreichen, wie ich ausdrücklich bemerken will. Eine Gabelung am vorderen oberen Ende zeigt Chudzinski's Fig. 6 Taf. I, Taf. XII 1.c. (Hyl. leuciscus) und Rüdinger's Fig. 4 Taf. II in der Festschrift für Bischoff. (1. c.) Sandifort bildet links eine grosse Gabelung am hinteren (unteren) Ende ab; rechts zeigt sich der mediale Gabelast abgetrennt. Am meisten entwickelt zeigt sich die Furche in der Abbildung Hervé's 1. c. Taf. I Fig. 2. Hier ist das obere Ende stark nach hinten umgekrümmt und entwickelt fünf kleine Seitenäste; dies ist ein einzig in seiner Art dastehender Fall. Auf die Deutung des fronto-orbitalen Furchensystems komme ich alsbald zurück.

d) Das fronto-mediale Furchensystem. Dieses ist das einfachste von allen Furchencomplexen des Stirnhirns und umfasst I. den sulcus calloso-marginalis, s. Fig. $6: p+p_{1}+14$, 2. die Schnabelfurche, sulcus rostralis (Eberstaller).

Der sulcus calloso-marginalis gehört zwar nicht ausschliesslich dem Stirnlappen an, jedenfalls aber in seinem bei weitem grössten Theile; so mag er denn an dieser Stelle beschrieben werden. Genaueres kann ich über ihn nur nach dem Gehirne von Hyl. syndactylus berichten, da ich nur dieses halbirte. Er zeigte sich hier aus drei Stücken bestehend, der pars anterior (14 Fig. 6), der pars media (, Fig. 6) und der pars posterior seu externa ( $p_{1}$ Fig. 3, 4 und 6). Die pars anterior war von den beiden übrigen getrennt 
und besteht aus einem dem Balkenknie parallel laufenden Schenkel, der einen radiären Seitenast nach vorn sendet. Die pars media erwies sich in diesem Falle als eine ganz einfache, dem Balkenkörper parallel verlaufende tiefe Furche, die, ungefähr dem Beginn des Splenium corp. call. entsprechend, sich unter stumpfem Winkel nach aufwärts wendet, um dann schnell in die senkrechte Richtung überzugehen, bis sie die Mantelkante erreicht; dort biegt sie wieder ziemlich scharf in clas auf der convexen Hemisphärenfläche zu Tage tretende Endstück ( $\left.\rho_{1}\right)$ um. Bei Hyl. leuciscus (Fig. 3) verlief dies Stück vollkommen symmetrisch auf beiclen Seiten eine beträchtliche Strecke weit auf der Aussenfläche der Hemisphären hinter dem oberen Ende des Sulcus centralis (i) und postcentralis (i, \%). Ebenso verhielt es sich bei Hyl. syndactylus, nur war es hier ohne jede Biegung, während es bei $\mathrm{H}$. leuciscus zwei leichte Biegungen zeigt. Bei H. lar bestand eine Asymmetrie, indem der rechtsseitige Endschenkel ähnlich wie bei H. syndactylus gerade gestreckt ein Centimeter weit auf der Aussenfläche des Hirns in querer Richtung verläuft, der linke aber kaum die Mantelkante überschreitet, sich kurz gabelt und mit dem längeren Gabelaste sich nach hinten wendet.

Abbildungen von Medianschnitten geben noch Bischoff, Chudziński und Deniker. Bei Bischoff fehlt der dem Balkenknie parallel laufende Theil des vorderen Stückes, der mittlere zeigt, ähnlich wie beim Menschen mehrere Seitenäste bis in den Praecuneus hinein. Auf der convexen Fläche laufen beide Endstūcke etwas nach rückwärts geneigt (H. leuciscus). Bei Chudziński's Abbildung, die sich ebenfalls auf $\mathrm{H}$. leuciscus bezieht, ist das bogenförmige vordere Stück ( $1+$ in meiner Fig.) so wie es mir erscheint, nur klein und mit dem mittleren verbunden, während ein kleines vorn gelegenes Furchenrudiment wahrscheinlich dem radiären Schenkel entspricht. Auch hier finden sich am mittleren Stücke mehrere Seitenzweige nach auf- und abwärts gerichtet; hinten geht ein langer Ast, die ursprüngliche Richtung der Hauptfurche fortsetzend, in den Praecuneus hinein. Das Stück $p_{1}$ findet sich in der dorsalen Ansicht des Gehirns von H. leuciscus, ähnlich wie hier beschrieben; bei dem Gehirn des H. entelloides, s. den Holzschnitt, l. c. T. XII. p. 52 , zieht $\rho_{3}$ linkerseits nach rückwärts. Bei Denikers Abbildung vom Footus zeigt sich die Furche als einfache Bogenlinie, aber aus 2 getrennten Stücken, einem vorderen kleinen und hinteren grösseren bestehend. Das Stück $\rho_{1}$ fehlt gänzlich hier, wie bei dem Gorillafötus Denikers.

Verbindungen mit der fissura parieto-occipitalis medialis, calcarina und collateralis, wie sie beim Menschen vorkommen und dann einen grossen Furchenzug entstehen lassen, der durch alle Lappen an der medialen Grosshirnfläche hindurchzieht und schliesslich in die fissura collateralis ausläuft, habe ich beim Gibbon weder gesehen noch aus der Litteratur entnehmen können. Beim Menschen habe ich für einen solchen Furchenzug den Namen Sulcus fornicatus vorgeschlagen. S. meinen Vortrag über Hirnwindungen, X. Internat. medic. Congress zu Berlin, i 890, cit. bei $\mathrm{Wm}$. Turner 
(The convolutions of the brain etc. 1. c. Journal of anatomy and physiology rol. XXV S. 105 ( 144 ).

Eberstaller zerlegt den Sulcus auch in drei Stücke; den vertikalen Theil hält er für ein selbstständiges Furchenelement. Bei dem geringen Materiale, welches mir zur Verfügung steht, vermag ich aus der Untersuchung des Gibbon-Hirns kein neues Licht hicrauf zu werfen. Doch erscheint mir in dieser Beziehung sehr werthvoll der vorhin schon erwähnte Befund Deniker's, auf den Letzterer auch ausdrücklich aufmerksam macht, 1. c. p. 184 , dass bei den beiden von ihm untersuchten Anthropoiden-Föten (Gorilla und Gibbon) der vertikale Enctheil der Furche $\left(p_{1}\right)$ noch völlig fehlte, während der bogenförmige Theil schon gut ausgebildet war. Es spricht dies sehr beredt zu Gunsten Eberstaller's. Das vordere Furchenstück (14 Fig. 6) dürfte wohl dem sulcus genualis der Carnivoren gleichwerthig sein.

Wenig nur ist über den Sulcus rostralis (15, Fig. 6), wie ich ihn nach Eberstaller's Vorschlag benenne, zu sagen. Er ist nach meinen Befunden beim Gibbon recht ansehnlich, verläuft unterhalb des rostrum corp. callosi, nahe der Mantelkante und, leicht gebogen, ihr parallel und findet, sich so bei allen drei Gehirnen. Ganz gleich beschaffen erscheint er auch in den Abbildungen von Chudziński und Bisch off, sowie bei dem Deniker'schen Fötus. Letzterer bezeichnete ihn nach Broca als "Sillon sus-orbitaire". Diesen einander völlig deckenden Befunden nach zu schliessen, hätten wir also in dem Sulcus rostralis der Hylobatiden eine sehr beständige, gut entwickelte und gleichartige Bildung.

So weit die Furchen des Stirnlappens; die Windungen besprechen wir für den ganzen Lappen in Zusammenhange. Wir müssen folgerichtig vier longitudinale Frontalwindungen unterscheiden: den Gyrus front. superior s. primus, medius A., medius B. (s. secundus A. und secundus B.) und den Gyrus frontalis inferior s. tertius (die bekannte Broca'sche Windung). Ich erlaube mir diese Namen vorzuschlagen und nicht etwa: Gyrus fr. primus, secundus, tertius und quartus, denn es müsste nach dieser Nomenclatur der unter dem Namen Gyrus frontalis tertius allbekannte Brocasche Gyrus sonst als quartus bezeichnet werden, was aus praktischen Gründen zu vermeiden rathsam erscheint. Von denselben Gründen haben sich Eberstaller und Hervé leiten lassen, welche den zuerst (bei Verbrecherhirnen) wohl von Benedik $\mathrm{t}^{42}$ ) hervorgehobenen Vierwindungstypus des Stirnlappens bei dem Menschen und den Anthropoiden als den gewöhnlichen und regelrechten festgestellt haben, ins-

$\left.{ }^{42}\right)$ Vergl. hier auch Benedikt's Abhandlung: Beiträge zur Anatomie der Gehirnoberfläche. Wiener med. Jahrbücher. 84. Jahrg. 1888 S. 39. 
besondere Eberst aller, dessen vortreffliche und gründliche Arbeit ich hier besonders hervorheben möchte. Der Gyrus frontalis primus umfasst das Gebiet zwischen dem sulcus calloso-marginalis und dem sulcus frontalis superior; in ihm befindet sich die Mantelkante. Lässt man die Mantelkante als ein windungstrennendes Element zu, so kann der auf der medialen Hemisphärenfläche gelegene Theil des gyrus frontalis primus auch als eine besondere Windung unter dem Namen ..gyrus marginalis" beschrieben werden, mit demselben Rechte, wie man einen Praecuneus und Cuneus von den übrigen Stücken des Scheitel- und Hinterhauptslappens abtrennt. Sehr logisch ist das Verfahren nicht, practisch jedoch brauchbar. Der Gibbon würde also einen sehr klar ausgeprägten $\mathrm{Gy}$ rus marginalis haben. Will man das Stück zwischen Sulcus rostralis und Sulcus olfactorius nicht als besonderen Gy rus olfactorius gelten lassen, wozu ich geneigt wäre, dann muss man auch dies zur ersten Hirnwindung hinzuzählen; die Rostralfurche wäre dann eine im ersten Hirngyrus gelegene Nebenfurche.

Der Gyrus frontalis secundus s. medius $A^{\$ 3}$ ) liegt zwischen dem sulcus front. superior und dem Sulcus frontalis principalis. Der Gyrus frontalis secundus B. ${ }^{44}$ ) zwischen diesem und dem sulcus fronto-orbitalis, der Gyrus frontalis tertius stellt eine kleine Windung dar, welche um den vorderen Ast der Sylvischen Furche herumgelegt ist und beim Gibbon noch als Theil des Gyrus front. secundus B. erscheint. Nach oben hat er aus diesen Grunde keine Grenze, basalwärts begrenzt ihn ebenfalls der Sulcus fronto-orbitalis und zwar dessen auf der Orbitalfläche sichtbarer Theil. Die Fig. 3, 4 u. 5 erweisen dies Alles leicht.

Auf der Orbitalfläche ist der Gyrus olfactorius, den man als Fortsetzung von $F_{1}$ (dem Gyrus front. primus) auffassen liann, wegen der kurzen schräg verlaufenden Olfactoriusfurche nur sehr klein; er begreift einen Theil der Mantelkante und wird am einfachsten bis zur Rostralfurche (15, Fig. 6) gerechnet, weiter nach oben bis zum sulcus genualis (14, Fig. 6), woselbst er dann in die erste Stirnfurche (im engeren Sinne) sich verliert. Unterhalb der Rostralfurche sowohl, wie zwischen dieser und der Kniefurche (sulcus genualis) haben wir dann je eine Uebergangswindung zum Gyrus fornicatus, s. Fig. 6. Einen desto beträchtlicheren Umfang erreicht der "gyrus orbitalis", so könnte man wohl am einfachsten den ganzen Complex ron Windungen, welcher zwischen dem Sulcus olfactorius und dem Sulcus fronto-orbitalis liegt, benennen. Dieser Gyrus orbitalis kann als Fort-

4.3) Mediale Etage der mittleren Stirnwindung Eberstaller. ( $F_{2}$ med.)

44) Laterale Etage der mittleren Stirnwindung Eberstaller ( $\mathrm{F}_{2}$ lat.) 
setzung des Cyrus frontalis sccundus $A . \nmid-$ B. aufgefasst werclen und wird auch gewöhnlich so genommen.

Beim Gibbon steht nichts im Wege noch weiter zu gehen und den Längsschenkel des Sulcus orbitalis ( 1 in Fig. 4 u. 5) als Fortsetzung des Sulcus principalis (is in Fig. 4) zu betrachten; clann würden wir die beiden Theilstücke des Gyrus frontalis secundus, den Theil A. und den Theil B., auch auf der orbitalen Fläiche wiederfinden. A. würde zwischen der Olfactoriusfurche und dem Längsschenkel der Orbitalfurche zu suchen sein, B. zwischen diesem und der Fronto-Orbitalfurche; in $\mathrm{B}$. würden sich dann die secundären lateralen Zweige der Orbitalfurche hineinerstrecken.

Nach hinten wurzeln sämmtliche vier longitudinalen Stirnwindungen in der fünften, der queren oder aufsteigenden Stirnwindung: Gyrus praecentralis (Wilcler). ${ }^{45}$ ) (Ich weiche hier in der Namengebung der. Kürze halber von Huschke, Ecker und Schwalbe ab, welche den allerdings sprachlich besseren, aber längeren Namen: Gyrus centralis anterior gewählt haben). Diese charakteristische Winclung ist beim Gibbon so gut ausgeprägt wie beim Menschen. Nach hinten begrenzt von der stets sehr klar entwickelten Centralfurche (i), Fig. 3 u. 4), hat sie nach vorn und unten den mit der Principalfurche verbundenen aufsteigenden Sichenkel ( $\approx$, Fig. 4$)$, über dessen Bedeutung alsbald noch das Nöthige gesagt werden soll, nach vorn und oben das mehr quer gelegene Stück der ersten Stirnfurche ( $i \mid$ \%, Fig. 3 u. 4). Aus ihr entwickelt sich, in ihr wurzelnd von oben nach unten zunächst die erste Stirnwindung (an der Mantelkante); hier geht auch, um das obere Ende der Centralfurche herum, der gyrus praecentralis in dem gyrus postcentralis über. Dann, zwischen erster Stirnfurche und der Principalfurche wurzelt breit in ihr die Abtheilung A. der zweiten oder mittleren Stirnwindung. Deren Abtheilung B., mit dem lateralen Schenkel der dritten Stirnwindung zusammenfliessend, geht, die Sylvische Grube von oben begrenzend, aus dem unteren Ende des Gyrus praecentralis hervor. Letzterer ist beim Gibbon meist etwas breiter als der Gyrus postcentralis.

Die letzte, zum Stirnlappen gehörige Windung ist cler vordere Theil des Gyrus fornicatus, den man allerdings auch, dem Vorgange von Broca ${ }^{46}$ ) und Schwalbe ${ }^{47}$ ) folgend, mit anderen Bildungen zusammen, als den sichelförmigen $Z u g$, Tractus falci-

45) Wilder, Burt, G., Human cerebral fissures, their relations and nanies and the methods of studying them. American naturalist, Octoloc $\$ 886$.

46) Broca, P., 1. c. Le grande lobe limbique etc., Mém. 259 et Recherches sur les centres olfactifs. Revue d'anthropologie 1879 II. Sér. T. II p. $3^{8} 5$ - Mérnoires publ. par Pozzi p. $3^{8} 3$.

47) Schwalbe, l. c. Neurologie p. 567 . 
formis $(\mathrm{m})^{48}$ ) beschreiben kann, obwohl die diesen Zug bildenden Theile (Gyrus fornicatus + Uncus + Gyrus dentatus + fasciola cinerea + fimbria + fornix + Lamina septi lucidi) theils dem Rhinencephalon, theils dem Pallium, also verschiedenen Haupttheilen des Hirns, angehören.

Der Gyrus fornicatus (Fr. Arnold) als Ganzes besteht aus einem vorderen, dem Bereiche des Stirnlappens und Scheitellappens angehörigen Stücke (gyrus callosus) und aus einem hinteren, dem Hinterund Schläfenlappen zuzutheilendem Abschnitte. In meinen Zeichnungen lässt sich das Ganze nicht gut übersehen. Durch Combination der Figuren 5 und 6 vermögen wir uns jedoch die Gewölbewindung vorzustellen, wie sie sich beim Gibbon verhält. Wir sehen sie, Fig. 6 bei y beginnen; dort werden durch eine ganz seichte Furche zwei Abtheilungen deutlich y und $z$, deren jede mit einer kleinen Anschwellung beginnt; eine ähnliche knötchenförmige Anschwellung (x) sehen wir auch am Beginn der ersten Stirnwindung oder des gyrus marginalis, dicht unterhalb des hinteren Endes der Rostralfurche. z ist der sogenannte Pedunculus corporis callosi. Nun wendet sich der Zug, den Balken umkreisend, zuerst zwischen dem rostrum und der Rostral-Furche, dann zwischen genu und der Genual-Furche, endlich zwischen der Calloso-marginal-Furche und dem Balken genauer gesagt, zwischen der Calloso-marginal- und der Balkenfurche (sulcus callosus), d. h. derjenigen Furche, welche die obere Balkenfläche von der Hemisphäre trennt - nach hinten. Dort tritt er in den Bereich des Scheitellappens und zwar des sogen. Vorzwickels. In der Abbildung (Fig. 6) sehen wir den letzteren zwischen den Furchen $\rho_{1}$ und $\pi_{1}$ (dem Sulcus parieto-occipitalis medialis) als nahezu viereckiges Feld; in diesem eine ähnlich dem Sulcus orbitalis vielfach verzweigte Furche $(\mathrm{o})=$ Sulcus subparietalis (Broca) (fissura arcuata praecunei Sernow). ${ }^{\prime \prime}$ ) Dieselbe besteht aus einem bogigen, um das Splenium des Balkens verlaufenden Schenkel, von dessen etwas winklig ausgezogener Mitte ein gerader Zweig zur Mantelkante aufwärts steigt, der sich oben dreifach gabelt. Der Gyrus callosus verläuft nun zwischen Splenium und bogigen Theil dieses Sulcus subparietalis verschmälert hin, tritt am Hinterlappen vorbei um das Splenium herum zum Schläfenlappen, wo wir ihn in den Gy rus hippocampi übergehen sehen. Dieser Uebergang ist in Fig. 5 wiedergegeben. Mit PC ist dort der Praecuneus (Vorzwickel) bezeich-

43) Ich ziehe die Beziehung "Tractus" vor, weil die Gestalt der hier zusammengezogenen Dinge mit nichts weniger eine Aehnlichkeit hat, als mit einem „Lappen".

${ }^{49}$ ) Sernow, D., Die individuellen Typen der Hirnwindungen des Menschen Moskau 1877. Referirt von Stieda, Archiv für Anthropologie Bd. XI 1879 p. 287. 
net, davor liegt das durchschnittene crus cerebri (c. c.) mit der Brücke. Im Praecuneus sehen wir eine Furche, welche ihn nicht völlig in zwei Theile trennt; diese Furche ist das hintere Stück des Bogentheils der Furche (o) Fig. 6. Der zunächst dem crus cerebri gelegene Theil des Praecuneus ist nun die Fortsetzung des gyrus callosus; derselbe verschmälert sich, wie man sieht und geht in die Tiefe, geht dann aber über in den breiten Gyrus zwischen den Furchen $w_{1}$ einerseits und 10,5 und 5 a andererseits, der hinten mit $\mathrm{L}$, bezeichnet ist, vorn mit $\mathrm{U}$. Dieser breite Gyrus, von seinem mittleren Theile an, ist der Gyrus hippocampi, der vorn in die sogenannte Hakenwindung (Uncus, U, Fig. 5) sich fortsetzt und nach hinten mit dem sogenannten Lobulus lingualis (L, Fig. 5 ) in Verbindung steht. Der Uncus ist auch in Fig. 6 als der am tiefsten herabreichende Vorsprung sichtbar. Eine kleine Furche, welche von dem Sulcus $w_{1}$ (der fissura calcarina) nach medianwärts ausläuft und in die Uebergangsstelle des Gyrus callosus zum Gyrus hippocampi quer einschneidet, ist leider in der Fig. 5 viel zu stark wiedergegeben worden. Darlurch wird (nach der Figur) der Anschein erweckt, als ginge der Gyrus callosus nicht ununterbrochen in den Gyrus hippocampi über. Das ist aber in der That der Fall; die kleine Furche geht nicht über die ganze Breite des Gyrus fornicatus weg, sondern schneidet ihn nur ein wenig ein.

So wie es hier beschrieben (H. syndactylus), also offener, wenn auch schmaler Uebergang des vorderen Theiles des Gyrus callosus in den Gyrus hippocampi und damit Herstellung eines den Balken ganz umsäumenden, der Umbiegung der Hemisphäre selbst folgenden, nahezu in sich selbst zurück laufenden Windungszuges, finde ich es auch bei dem von mir untersuchten Hirn des $\mathrm{H}$. leuciscus. Bei H. lar dagegen ist die kleine Furche, von $\omega_{1}$ ausgehend, die in Fig. $5 \mathrm{zu}$ stark ausgezeichnet ist, in der That vorhanden; sie verbindet $\omega_{1}$ (den Sulcus calcarinus) mit dem Sulcus hippocampi $(8$, Fig. 5 und Fig. 2), so dass äusserlich der Gyrus fornicatus dort völlig unterbrochen erscheint. In der Tiefe der kleinen Furche findet jedoch durch eine deutlich ausgesprochene Tiefenwindung eine Verbindung zwischen Gyrus callosus und Gyrus hippocampi statt, so dass wir auch hier einen echten Gyrus fornicatus haben. Beide Varianten sind bekanntlich auch beim Menschen vorhanden, und wir können überhaupt sagen, dass das ganze System des Gyrus fornicatus beim Gibbon dem des Menschen sehr ähnlich ist.

Da wir schon jetzt des Sulcus subparietalis erwähnten, so mag er auch hier alsogleich völlig abgehandelt werden. Wir kommen dann nachher beim Parietallappen nicht mehr darauf zurück. Er gehört zu den sehr wandelbaren Bildungen, beim Gibbon sowohl 
wic bein Menschen. Die andere Hälfte des Syndactylus-Hirns zeigt ihn ebenso, wie er in Fig. 6 wiedergegeben ist. Fast genau so erscheint er nicht selten beim Menschen, s. z. B. Fig. II p. $4^{\mathrm{I}}$ bei Giacomini, ${ }^{50}$ ) ich habe ihn auch öfter so gefunden. Bei H. lar und leuciscus war fast nur der Bogentheil ausgebildet, mit oder ohne Verbindung mit dem Sulcus calloso-marginalis.

Bei Chudziński, (1. c.), Taf. I. Fig. 8, sehen wir nur den Bogentheil, und zwar in Verbindung mit dem Sulcus calloso-margin. ausgebildet; darüber und darunter jedoch noch je eine flache mit dem Bogentheil parallel laufende Furche, die den Praecuneus in mehrere übereinander liegende Stūcke trennen, und von denen die unterste noch weit in den Gyrus callosus sich hineinerstreckt und die Continuität des Gyrus fornicatus zu unterbrechen scheint. So zeigt es ähnlich auch Bischoffs Figur IV, bei dem auch der Uebergang des Sulcus callosus in den Sulcus hippocampi sich in derselben Weise, wie hier geschildert, gestaltet.

Bei dem von Deniker beschriebenen Fötus ist dieser Furchencomplex noch nicht vorhanden.

Eine Andeutung eines Lobulus paracentralis (Betz) habe ich beim GibbonGehirn nicht gefunden.

Nach der Schilderung des Thatsächlichen beim Stirnlappen möge eine kurze Angabe der verschiedenen Ansichten über die Deutung seiner Theile eingeschaltet werden. Es handelt sich hier vornehmlich um die vier longitudinalen Stirnwindungen, sowie um die sie trennenden Furchen. Ich fasse mich recht kurz, nur um meine Ansicht zu begründen und den Leser zu orientiren, indem ich auf die eingehenden und gründlichen Erörterungen von Hervé (1.c.) und Eberstaller (1. c.) verweise.

Wir müssen von den pithecoiden Affen ausgehen, bei denen. sich auf der convexen Hirnoberfläche folgende Furchen befinden: I. Eine Furche $=\hat{o}$ (Fig. 4$)=$ dem Sulcus principalis; diese erreicht jedoch den aufsteigenden Schenkel $\varepsilon$ nicht, sondern hört in einiger Entfernung vor ihm auf. Dagegen geht $s$ weiter nach oben zur Mantelkante und sendet dort oberhalb is und nahezu parallel is einen kurzen Längsschenkel nach vorn. Die Furche $\partial$ bei den niederen Affen, unser Sulcus principalis, wird dort Sulcus rostralis (Broca) genannt (Sulcus rectus Eberstaller); der Sulcus $₹+$ seinem Längsschenkel heisst der Sulcus arcuatus. Bei manchen Affen nun zeigen sich auch schon Furchen entsprechend $\alpha, \beta, \gamma, \gamma$ in unserer Figur. Ein vorderer Schenkel der fissura Sylvii $(\Sigma a)$ ist eben so wenig vorhanden als ein Sulcus fronto-orbitalis ( $)$; wenigstens fehlen diese bei den meisten Affen, während bei einigen, z. B. bei Cynocephalus und Cercopithecus, Spuren davon vorhanden sind. Ich kann Rüding er ${ }^{51}$ ) hier beistimmen.

50) Giacomini, C., Guida allo studio delle circonvoluzioni cerebrali dell' uomo. II. ediz. Torino, 1884 . Loescher.

$\left.{ }^{51}\right)$ Rüdinger, 1. c., Festschr. f. B ischoff, Taf. II Fig. 1, 2, 3. 
Nun deuteten Leuret und Gratiolet, dem später Rud. Wagner, Broca und Gromier beistimmten, so, dass sie den Iängsschenkel des Sulcus arcuatus als erste Stirnfurche, Sulcus frontalis primus des Menschen, nahmen und die Furche (i), (Sulcus principalis) als homolog dem Sulcus front. secundus (des Menschen). Sie hatten dann die drei gyri frontales so, dass der Sulcus principalis die Grenze zwischen zweiter und dritter Stirnwindung bildete und somit die pithecoiden Affen eine recht ansehnliche dritte Stirnwindung erhielten. Der aufsteigende Schenkel des Sulcus arcuatus wäre der Sulcus praecentralis.

Pansch nahm den Sulcus arcuatus für das Homologon des Sulcus praecentralis inferior + des Sulcus front. secundus des Menschen; als Sulcus frontalis primus betrachtete er die Furchenstücke $\left(\alpha+\beta+\gamma+\gamma_{i}\right)$. Der Sulcus principalis (rostralis) des Affenhirns habe gar kein Homologon beim Menschen.

Bisch off und Rüclinger meinen, dass der vertikale Schenkel des Sulcus arcuatus $=$ der praecentralen Furche sei, der longitudinale $=f_{1}$ (der ersten Stirnfurche); eine dritte Stirnwindung gebe es nicht - oder doch nur rudimentär, mit der zweiten noch innig vereinigt (Rüdinger). Der Sulcus principalis bedinge nur eine Unterabtheilung in der zweiten Stirnwindung.

Schwalbe hat die Ansicht ausgesprochen, dass der Sulcus arcuatus + clem Sulcus rostralis (principalis m.) als eine Furche aufzufassen seien und zwar als $f_{1}$; so auch Mingazzini, der den Längsschenkel des Sulcus arcuatus + dem Sulcus principalis für $f_{1}$ nimmt.

Anders Eberstaller und Hervé. Ersterer hat bereits im Jahre I $88+$ beim menschlichen Gehirne einen nahezu constanten frontalen Sulcus, den er Sulcus frontalis medius nennt, nachgewiesen. ${ }^{52}$ ) Dieser Sulcus liegt inmitten der zweiten Stirnwindung und theilt dieselbe in einen oberen und unteren Zug. Der Sulcus frontalis secundus $\left(f_{2}\right)$ des Menschen liegt basalwärts von diesem Sulcus front. medius, den Eberstaller mit $f_{3}$ bezcichnet.

Hervé's ausführliche Arbeit (1. c.) erschien 1888. Er erwähnt Eberstaller's in derselben nicht; Eberstaller hat wiederum Hervés Arbeit nicht gekannt, als er seine ausführliche Darlegung gab, 1. c. 1890. Nun erwähnt aber Hervé, dass bereits Chudziı́ski, dessen Werk (l. c.) 1882 erschienen ist, zu clenselben Ergebnissen kommt, wie Hervé selbst. Wie gesagt, kann ich dies aus eigenem Studium nicht beurtheilen. Eberstaller und Hervé, zu denen also auch Chudziński zu stellen wäre, kommen nun im Wesentlichen zu denselben Schlüssen:

$\left.{ }^{52}\right)$ Eberstaller, Ueber Gehirnwindungen. Oesterreichische Aerztliche Vereinszeitung No. 8, 15. April 1884 . 
I. Als Sulcus frontalis primus $\left(f_{j}\right)$ der niederen Affen (wenn wir immer die Honologie mit dem Menschenhirn festhalten), ist der Furchencomplex zu erachten, der sich bei einigen parallel der Mantelkante vorfindet, zwischen dieser und dem Längsschenkel (sagittalen Schenkel) des Sulcus arcuatus. Findet sich hierzu ein verticaler (querer) Schenkel, so ist dieser dem Sulcus praecentralis superior hominis gleich zu stellen.

Demnach wären beim Gibbon die Furchenelemente $\alpha+\beta+$ einem Stück von $\gamma$ (s. Fig. 3 und 4 Taf. II) als erste Stirnfurche, und die Furchen $\gamma$ und das andere Stück von $\gamma$ als Sulcus praecentralis superior zu deuten.

2. Der grössten Zahl der niederen Affen fehlt der Sulcus frontalis secundus des Menschenhirns. Als solcher ist vielmehr der Sulcus orbitalis externus (Weisbach und Bischoff) anzusehen, oder wie ich ihn hier genannt habe, der Sulcus fronto-orbitalis (orbito-frontalis, Broca, Hervé). Daher kann erst bei den Anthropoiden von einem ordentlich entwickelten Sulcus frontalis inferior ( $=$ Sulc. fronto-orbitalis) die Rede sein. Dass jedoch bei einigen pithecoiden Affen Spuren dieses Sulcus bereits gefunden werden, ist vorhin bemerkt worden.

Die Feststellung dieser Homologie gebührt, so weit ich sehe, vor Allem Eberstaller. Hervé drückt sich nicht ganz so bestimmt darüber aus. Dass der Sulcus fronto-orbitalis die Fortsetzung von $f_{2}$ sei, giebt Hervé auch an; (1. c. p. 24). Demgemäss ist die Furche $\zeta$ des Gibbon (der Sulcus fronto-orbitalis der Anthropoiden) homolog der 2. Stirnfurche $\left(f_{2}\right)$ des Menschen.

3. Der Sulcus rostralis, s. rectus s. principalis der pithecoiden Affen ist homolog der mittleren Stirnfurche (sulf. fr. medius) des Menschen, Eberstaller. Auch die Frontomarginalfurche Wernicke's gehört diesem Sulcus an. Eberstaller ist auch hier, meiner Meinung nach, entschiedener in der Feststellung der Konstanz einer solchen mittleren Stirnfurche als Hervé, wenngleich der Letztere im Prinzip zu demselben Ergebnisse gelangt.

Es heisst bei ihm S. 70: „Mais sur un grand nombre de cerveaux, et non parmi les plus simples, la face convexe de $\mathrm{F}_{2}$ est parcourue en son milieu par une série d'incisures et des sillons isolés, quelque fois continus, qui manifestement la dédoublent sur une partie plus ou moins notable de son longueur en deux plis distincts. Il n'est pas très rare d'y retrouver en arrière, entre les deux racines, la branche infléchie du sillon courbe (i. e. der sulcus accuatus der pithecoiden Affen), et sur la partie antérieure de la circonvolution, où ses incisures isolées affectent ordinairement une direction plus au moins transversale, le sillon rostral. Broca a très bien vu chez l'homme ce dernier sillon, bien qu'il n'en ait pas saisi la signification." - Und nach Anführung der Worte Broca's fährt Hervé fort: "Cette incisure transversale, que l'on retrouve toujours avec un peu d'attention, repond à 
ce que Wernicke a nommé le sillon fronto-marginal. Elle représente pour nous ce qui reste du sillon rostral simien."

Beim Gibbon haben wir den Sulcus principalis stets rorgefunden, und zwar in der charakteristischen Weise mit dem Sulcus praecentralis inferior vereinigt. Er trägt hier noch ganz den pithecoiden Character. Wichtig ist seine ursprüngliche Unabhängigkeit von Sulcus praecentralis inferior, wie die Abbildungen der Gibbon-Fötus von Gratiolet u. Deniker beweisen. Das Verhältniss zum Sulcus praecentralis, so constant es auch erscheint, ist somit ein secundäres und stimmt also mit dem Verhalten der pithecoiden Affen, sowie auch mit den meisten Fällen beim Menschen, wo das Homologon des Sulcus principalis die praecentrale Furche nicht erreicht.

4. Eberstaller und Hervé geben an, dass der sagittale (Längs-) Schenkel des Sulcus arcuatus bei den Anthropoiden verkümmere oder zersprengt erscheine. Beim Menschen finde man seinen Rest in einem oberen Seitenaste der unteren Präcentralfurche, der sich durch seine bedeutende Tiefe auszeichne und in der rückwärtigen Partie der mittleren Stirnwindung einen Vierwindungstypus bedinge. In dem eben mitgetheilten Passus aus Hervés Werk ist offenbar auch die Rede von einem solchen Reste.

Was beim Gibbon aus diesem Aste, wenn er überhaupt sich entwickelt - s. sein Fehlen bei den Fötus - wird, ist uns nicht bekannt. Hervé meint, dass er mit dem Sulcus principalis verschmelze; dafür liegen aber gar keine Beweise vor. (Hervé p. 55: „Le sillon rostral se continue avec la branche infléchie du sillon courbe.)“

5. Die pars ascendens $(\varepsilon)$ des Sulcus principalis, oder besser gesagt, die aufsteigende, mit dem Sulcus principalis verbundene Furche des Gibbon ist unzweifelhaft homolog dem Sulcus praecentralis inferior des Menschen. Ich stimme, wie vorhin schon kurz angegeben wurde, diesen Deutungen Eberstallers, Chudzinski's und Hervés vollkommen bei. Später, an einem anderen Orte, bei Besprechung der übrigen Anthropoiden-Gehirne, werde ich Gelegenheit nehmen, die Gründe dafür ausführlicher zu entwickeln. Dann werden auch die Meinungen der übrigen Autoren auf diesem Gebiete: Meynert's, ${ }^{53}$ ) Benedikts, ${ }^{54}$ ) Valent i's, ${ }^{55}$ ) Giacominis ${ }^{56}$ ) und Anderer, insbesondere über die praktisch so wichtig gewordene Frage nach dem Vierwindungstypus des Stirnlappens, ihre Berück-

${ }^{53}$ ) Meynert, Th., Die Windungen der convexen Oberfläche des Vorderhirns beim Menschen. Archiv für Psychiatrie Bd. VII 1877 .

$\left.{ }^{54}\right)$ Benedikt, M., 1. c. und: Anatomische Studien an Verbrecher-Gehirnen. Wien 1879 p. 107.

5s) Valenti, G., Contributo allo studio delle scissure cerebrali, Pisa r 8 go. Atti Soc. Tosc. Sc. Nat. Vol. XI.

${ }^{56)}$ Gia comini, C., 1. c. 
sichtigung finden. Ich kann eben erst unter Heranziehung der pithecoiden Affen, der Anthropoiden und des Menschen, an der Hand reichlicher Abbildungen, in gebührender Weise vorgehen.

Von neueren Autoren sind Gromier, Deniker und Kohlbrügge bezüglich des Gibbon-Hirns anderer Meinung.

Gromier 1. c. spricht die Ansicht aus, dass der Sulcus principalis der pithekoiden Affen beim Gibbon nach abwärts verdrängt und im Sulcus fronto-orbitalis zu suchen sei; auch lässt er in Folge dessen die obere Stirnwindung ausserordentlich verbreitert sein. Dass diese Deutung irrig ist, liegt auf der Hand.

Deniker deutet einfach nach dem äusseren Verbalten seine obere Furche, welche höchst wahrscheinlich auch so aufzufassen ist, als sulcus frontalis primus, die $z$ weite als sulcus frontalis secundus, die folgende, entsprechend unserm $\Rightarrow$, als sulcus orbitalis externus und gelangt so zu drei Stirnwindungen ganz derselben Art wie die gewöhnliche Beschreibung beim Menschen; nur dass dann auch der Gibbon eine sehr grosse dritte Stirnwindung hätte.

Kohlbrügge stützt sich wesentlich auf den vorhin hervorgehobenen Befund, dass der vordere Ast der fossa Sylvii in den Sulcus fronto-orbitalis in beinahe der Hälfte der Fälle überging, und fasst dann auch, wie seiner Zeit Pansch, den Sulcus fronto-orbitalis als vorderen Ast der Sylvischen Furche auf. So wäre dieser beim Gibbon von einer ungewöhnlichen Länge. Den seit Bischoff allgemein so angenommenen echten vorderen Schenkel der Sylvischen Grube nennt er „vordere Grenze des Operculum". Ausserdem deutet er wie Deniker, nimmt also den Sulcus rostralis (principalis) als zweite Stirnfurche und gelangt somit wie Deniker und Pansch zu einer sehr grossen dritten Stirnwindung.

Ich muss bekennen, dass eine Vereinigung des Sulcus frontoorbitalis mit dem Bischoff'schen vorderen Schenkel der fossa Sylvii noch gar kein Recht giebt, den Sulcus fronto-orbitalis, der in den meisten Fällen bei sämmtlichen Anthropoiden isolirt liegt und ganz anders verläuft, als sich sonst, z. B. beim Menschen, ein vorderer Ast der Sylvischen Grube darstellt, als einen solchen zu deuten. Vor der Hand hat mich Kohlbrügge's Darstellung noch nicht überzeugt und ich hoffe bei der erwähnten späteren Gelegenheit die vollannehmbaren Beweise für die von Chudziński, Eberstaller, Hervé und mir vertretene Auffassung, die ja zum Theil auch die Bischoff's und Rüdingers ist, liefern zu können.

A. 3. Die Centralfurche und die Furchen und Windungen des Scheit ellappens.

Die Grenzen des Scheitellappens sowie deren Unsicherheiten wurden bereits vorhin berührt; ich werde später, nach Abhandlung des Hinterlappens und Schläfenlappens, auf dieselben zurückblicken müssen.

Von Furchen sind hier zu besprechen: a) der Sulcus centralis, der die Grenze gegen den Stirnlappen bildet, b) der Sulcus postcentralis, c) die Fissura parieto-occipitalis medialis, d) der Sulcus intraparietalis, e) die Fissura parieto-occipitalis externa, f) der Sulcus subparietalis (dieser wurde bereits im vori- 
gen Kapitel abgehandelt), g) u. h) zwei kleine Nebenfurchen ( $\mu$ und $\tau$ in den Figg. 3 u. 4), welche beim Gibbon ziemlich beständig auftreten. Ausserdem fällt noch in den Scheitellappen hinein das obere Endstück $\left(\rho_{1}\right)$ des Sulcus calloso-marginalis, dessen wir vorhin schon gedachten.

Die entsprechenden Windungen oder Unterlappen sind: a) der Gyrus postcentralis, b) der Praecuneus (Vorzwickel), c) die obere oder erste Scheitelwindung (Gy rus parietalis primus s. superior), sich an b anschliessend, d) die untere oder zweite Scheitelwindung (Gyrus parietalis secundus s. inferior) mit ihren Theilstücken: Gyrus supramarginalis und Gyrus angularis.

a) Der sulcus centralis - ich gebrauche diesen von Huschke eingeführten Namen wegen der centralen Lage dieser Furche, obwohl Huschke einen andern Sinn damit verband und eben deshalb Pansch gegen diese Bezeichnung Verwahrung einlegte - verläuft beim Gibbon nahezu gestreckt und ziemlich senkrecht (s. Fig. 4) fast über die ganze Convexität der Hemisphäre. Den Rand der Sylvischen Furche erreicht er, so weit jetzt bekannt, jedoch niemals, wohl aber öfter den Mantelrand (bei den von mir untersuchten Gehirnen erreicht er ihn genau bei $H$. lar u. H. syndactylus, bleibt dagegen von ihm entfernt, ungefähr ebensoweit wie unten von der Sylvi'schen Furche, bei H. leuciscus (s. Fig. 3 u. 4). Dass die Furche je in nennenswerther Weise über den Mantelrand hinaus auf die mediale Hemisphärenfläche vorgerückt wäre, scheint auch nie beobachtet zu sein; bei H. lar war es in geringem Grade der Fall. Man bemerkt in ihrem Verlaufe nur drei leichte Biegungen, diese aber, wie meine Gehirne und die sonst gegebenen Abbildungen lehren, fast beständig: gleich zu Anfang unten über der Sylvi'schen Grube eine leichte Convexität nach vorn, dann eine sanfte Biegung convex nach hinten, nun wieder eine letzte convexe Biegung nach vorn; das obere Ende ist stets nach rückwärts gerichtet. Mitunter sieht man eine kleine Gabelung, entweder am oberen oder unteren Ende.

Die von Eberstaller 1. c. und von Cunningham ${ }^{57}$ ), welche Beide die genauesten Beschreibungen geliefert haben, erwähnte kleine accessorische Furche am unteren Ende (Sulcus transversus inferior sulci centralis) scheint beim Gibbon nicht vorzukommen, ebenso wenig wie Verbindungen mit anderen Furchen.

Wichtig sind die ron Eberstaller und Cunningham beim Menschen constant gefundenen Tiefenwindungen der Centralfurche, da sie mit entwicklungsgeschichtlichen Vorgängen im Zusammenhange

3i) Cunningham, D. J., The fissure of Rolando. The Journal of anatomy and physiology by Sir Wm. Turner, Humphry and Mc. Kendrick, vol, XXV 18 y. 
stehen; ich habe solche beim Gibbon nicht getroffen. Die Verhältnisse liegen hier also im ganzen viel einfacher.

Cunningham betont die grosse Länge der Centralspalte bei den Anthropoiden. Wenn ich nach seinem Vorgange die Länge der Mantelkante gleich Ioo setzte, so mass die Centralfurche bei

$$
\begin{aligned}
& \text { H. leuciscus . }=48,9 . \\
& \text { H. syndactylus . }=48,7 . \\
& \text { H. lar . . . }=46,0 .
\end{aligned}
$$

Nach Cunningham's Messungen hat die Centralfurche des erwachsenen Menschen einen Index von 39,3, des Chimpanse $=5^{\mathrm{I}, \mathrm{I}}$, des Orang $=47,2$. Es stimmt also auch für den Gibbon, dass, worauf Cunningham hinwies, die relative Länge der Centralfurche (im Verhältniss zur Länge der Mantelkante) bei den Anthropoiden nicht unbeträchtlich grösser ist als beim Menschen. Auf den gewundenen Verlauf der Furche beim Hylobates kann hiervon nicht viel in Rechnung gesetzt werden; hier kommt wohl Alles auf den zweiten von Cunningham hervorgehobenen Factor: der reichlicheren Anhäufung von Hirnmasse zwischen Sylvi'scher Furche und Mantelkante bei den Anthropoiden.

Wie es Hesch158) und Eberstaller, 1. c. p. 32, für den Menschen hervorgehoben haben, schneidet auch beim Gibbon die Centralfurche schief ein, so dass die hintere Furchenlippe die vordere überdeckt.

b) Das System des Sulcus intraparietalis ist das für den Scheitellappen weitaus bedeutungsvollste. Beim Gibbon tritt klar hervor, was neuerdings Rüdinger ${ }^{59}$ ) und Eberstaller ${ }^{60}$ ) für den Menschen besonders betont haben (vgl. auch die früheren Angaben von Turner, ${ }^{61}$ ) Pansch, ${ }^{62}$ ) Ecker ${ }^{63}$ ) und Schwalbe ${ }^{64}$ )), dass zu diesem System die Sulci postcentralis, intraparietalis und parieto-occipitalis lateralis zusammengehören.

Die neueste Schilderung dieser Furchen, insbesondere der parieto-

58) Hesch1, R., Die Tiefenwindungen des menschlichen Gehirns und die Ueberbrückung der Centralfurche. Wiener med. Wochenschr. 1877 No. 4 I S. 985.

59) Rüdinger, 1. c. Festschrift für Henle, Bonn 1882. Max Cohen \& Sohn.

$\left.{ }^{60}\right)$ Eberstaller, Zur Oberflächen-Anatomie der Grosshirn-Hemisphären. Wiener medic. Blätter, herausgeg. von W. Schlesinger, No. 16, 18-21, Wien 1884 . Bergmann \& Co.

61) Turncr, Sir Wm., a) Notes more especially on the bridging convolutions in the Brain of the Chimpanzee. Proceedings of the Royal Soc. of Edinburgh, 19. Februar 1866 . b) The convolutions of the human cerebrum, Edinburgh 1866.

62) Pansch, A., De Sulcis et gyris in Cerebris Simiarum et hominum, Kiliae 1866. Habilit. Schrift.

$\left.{ }^{63}\right)$ Ecker, Al., 1. c., Hirnwindungen.

${ }^{64)}$ Schwalbe, G., Neurologie 1. c. 
occipitalis lateralis liefert Cunningham ${ }^{65}$ ), dem Eberstaller's und Rüdinger's Arbeiten nicht bekannt gewesen zu sein scheinen.

Was zunächst die ron mir angewendeten Bezeichnungen anlangt, so ziehe ich für die longitudinale Furche den längeren älteren Namen Turner's, Sulcus intraparietalis der kürzeren Bezeichnung von Pansch (S. parietalis) vor, weil letztere zu Verwechselungen leichter Anlass geben kann. Interparietalis (Ecker), statt intraparietalis zu sagen, liegt kein Grund vor, und da soll man den Namen dessen, der den Sulcus zuerst benannt und genauer beschrieben hat, lassen. - Ich wähle der Kürze halber für die vordere Querfurche die Ecker'sche Bezeichnung: Sulcus postcentralis, welche auch Schwalbe festhält, schlage aber für die dritte der zugehörigen Furchen einen bisher nicht üblichen vor: Sulcus parieto-occipitalis lateralis, weil ich mit Eberstaller der Meinung bin, dass dieser Sulcus, der mit Ecker's Sulcus occipitalis transversus sicher grösstentheils zusammenfällt, ebenso auf der lateralen Hemisphärenfläche den Scheitellappen vom Occipitallappen abgrenzt, wie es die seit langem so benannte Fissura parieto-occipitalis medialis auf der medialen Fläche thut. Ferner gehen mitunter die beiden Sulci parieto-occipitales an der Mantelkante, wenigstens beim Gibbon, s. w. u., in einander über. Andere Namen für den Sulcus par. occ. lat. sind: "Sulcus perpendicularis externus", oder "Affenspalte".

In meinen Figuren bezeichnen i und * (Fig. 3 u. 4) die beiden Hauptabtheilungen des Sulcus postcentralis, v den sulcus intraparietalis, 9 und o die beiden Schenkel des Sulc. par. occ. lat., der in diesem Falle (H. leuciscus) in der Verlängerung von $\sigma$ nach rückwärts und abwärts bis zur lateralen Occipitalkante verläuft, ungefähr dahin, wo wir den Jensen'schen Furchencomplex ${ }^{66}$ ) (die Incisura praeoccipitalis Schwalbe ${ }^{67}$ ) und den Sulcus praeoccipitalis Meynert ${ }^{68}$ ) zu suchen haben. Auch geht er nach medianwärts bei $\pi$ in den Sulcus parieto-occip. medialis über.

Diese drei Sulci bilden also zusammen, wie die Fig. 3 unmittelbar zeigt, ein grosses I, dessen mittlerer Verbindungsschenkel sagittal, die beiden anderen frontal (transversal) ziehen. So finde ich es in allen meinen drei Gibbonhirnen, und so zeigen es auch die

65) Cunningham, D. J., The intraparietal Sulcus of the brain. Transactions of the Royal Academy of medicine in Ireland. Vol. VIII 1890 S. 495. - Journal of anatomy and physiology by Humphry, Turner and Mc. Kendrick. Vol. XXIV 1890 p. 135 .

$\left.{ }^{66}\right)$ Jensen, J, Die Furchen und Windungen der menschlichen Grosshirnhemisphären. Laehr's Zeitschrift für Psychiatrie. Bd. XXVII Berlin 1871 .

${ }^{67)}$ 1. c. Neurologie p. 556 .

68) Meynert, Die Windungen der convexen Oberfläche des Vorderhirns bei Menschen, Affen und Raubthieren. Arch. f. Psychiatrie. Bd. VII 1877. 
übrigen mir bekannt gewordenen Figuren von Sandifort, Gratiolet, Chudzinski, Bischoff, (1.1. c. c.) Rüdinger (Festsch. für Henle 1. c.) und Kohlbrügge 1. c., welche diese Furchen wiedergeben. Nur die Abbildungen von Owen 1. c. und Deniker 1. c. weichen $\mathrm{ab}$, indem bei beiden die Verbindung zwischen der Intraparietalspalte und der Affenspalte noch nicht besteht. An der linken Seite fehlt bei Deniker's Fötus auch noch die Verbindung mit dem Sulcus postcentralis. Es ist dies Factum wichtig, da ja Deniker's Abbildung von einen Fötus entnommen ist; wahrscheinlich entspricht Ow en's Abbildung ebenfalls einem jungen Thier. Bei dem älteren von Gratiolet abgebildeten Fötus besteht diese Verbindung schon. Beim menschlichen Fötus haben wir anfangs auch keine Yerbindung zwischen dem Sulcus intraparietalis und par. occ. lat. (Cunningham 1. c. Ecker, ${ }^{69}$ ) Pansch, ${ }^{70}$ ) Bischoff, ${ }^{71}$ ) Reichert. ${ }^{72}$ )

Im Einzelnen finden sich vielerlei Verschiedenheiten, namentlich in dem Verhalten der Affenspalte.

Was zunächst den Sulcus postcentralis angeht, so unterscheidet Eberstaller, 1. c. "Wiener medic. Blätter", daran drei Elemente: I. den Sulcus postcentr. medialis; es ist dies das zunächst der Mantelkante gelegene Stück \% (Fig. 3, 4); dieses trennt das obere Scheitelläppchen $\left(\mathrm{P}_{1}\right)$ von dem Gyrus postcentralis $\left(\mathrm{C}_{2}\right) ; 2$. den Sulcus postcentralis lateralis, welcher unserem i (Fig. 3,4) entspricht und den Gyrus supramarginalis ( $\mathrm{zu}_{2}$, dem unteren Scheitelläppchen gehörig) von $\mathrm{C}_{2}$ trennt. Das dritte Element ist ein kleiner schräg gestellter Sulcus (Sulcus postcentralis transversus), welcher (beim Menschen) sich zum Sulcus postcentr. lat. gerade so verhalten soll, wie der sulcus centralis transversus, s. vorhin, zum sulcus centralis. Ein Zusammenfluss dieser drei Stücke soll selten sein.

Beim Gibbon fehlt durchweg das dritte Element, während die beiden anderen sehr schön entwickelt sind. Einen Zusammenfluss sieht man auf der linken Seite von H. leuciscus (Fig. 3); rechts ist i von * auch nur durch eine schmale Uebergangswindung getrennt. Bei H. syndactylus besteht der Zusammenfluss auf beiden Seiten und die postcentrale Furche ist fast geradlinig geworden, sehr ähnlich der Centralfurche. Bei H. lar haben wir rechterseits einen $\mathrm{Zu}$ sammenfluss; linkerseits fehlt der obere Schenkel $\%$, der untere ist

${ }^{69}$ ) Ecker, A., Zur Entwgesch. der Furchen und Windungen der GrosshirnHemisphären im Fötus des Menschen. Arch. f. Anthropol. III I 869.

$\left.{ }^{70}\right) \mathrm{Pansch}$, A., Ueber die typische Anordnung der Furchen und W'indungen auf den Grosshirnhemisphären des Menschen und der Affen. Archiv für Anthropol. III. 1869 .

${ }^{71)}$ Bischoff, Th. L. W., Die Grosshirnwindungen des Menschen. Abhdl, d. K. Bayrischen Akd. d. Wiss, Bd. X. Math. naturw. Klasse.

72) Reichert, B., Der Bau des menschlichen Gehirns. Leipzig I861. 
aber sehr lang. Die Intraparietalfurche geht immer ron dem unteren Furchenstücke ab, wie auch beim Menschen.

Die Abbildungen der übrigen Autoren zeigen fast ebenso häufig den Zusanmenfluss wie die Trennung, so dass also eine einheitliche Furchenbildung beim Gibbon für mindestens die Hälfte der Fälle angenommen werden darf. Cunningham (1. c., Intraparietal fissure) geht wohl zu weit, wenigstens bezüglich des Gibbon, wenn er sagt, p. 490: .This appears to be the usual condition in the Chinpanzee and the gibbon."

Der bogenförmige Verlauf der Intraparietalfurche ist nicht so ausgeprägt wie beim Menschen. Der von Eberstaller 1. c. an der höchsten Stelle des Bogens abgehende, zur Mantelkante hin gerichtete Ast wurde von mir viermal beobachtet; auch Kohlbrügge zeichnet ihn in seiner Fig. A und B. Vielleicht entspricht ihm auch die kleine Furche $=$ (Fig. 3 und 4), welche ich dreimal dann fand, wann der Ast nicht vorhanden war. ${ }^{73}$ ) Beides zeigen auch die übrigen Abbildungen. Niemals traf ich beim Gibbon die von Eberstaller genau angegebenen und auch von Cunningham berücksichtigten Unterbrechungen; es ist das hochinteressant, weil wir in dem Vorhandensein der zahlreichen Brückenwindungen die höhere Entwickelung des Menschenhirns sehen. Auch die übrigen Abbildungen vom Gibbon lassen solche nicht erkennen.

In einem meiner Fälle (H. syndactylus, rechte Seite) sieht man, wie auch bei Chudzinski (Fig. 5) eine kurze, nach abwärts in das untere Scheitelläppchen verlaufende Furche.

Der Uebergang in das hintere Querstück, die Affenspalte, macht sich stets genau so, wie es Eberstaller vom Menschen beschreibt, dass nämlich die Intraparietalfurche ungefähr auf die Mitte der Affenspalte trifft, und zwar beim Hylobates mehr rechtwinklig, so dass wir einen lateralen und medialen Schenkel des Sulcus parietooccip. lat. erhalten. ${ }^{74}$ )

Die letztere Furche, die Affenspalte selbst, fasse ich so auf wie Eberstaller, d. h. ich halte sie für die auf der lateralen Hemisphärengrenze auftretende Grenzfurche zwischen Hinterlappen und Scheitellappen.

73) Wenn die kleine Furche - (Fig. 3 u. 4) ganz abweichend zu liegen scheint, so muss in Betracht gezogen werden, dass hier auch der laterale Schenkel der fissura parieto-occip. medialis eine ganz ungewöhnliche Lage hat; er ist nämlich, siehe die genauere Besprechung weiter unten, gegabelt und der vordere lange Gabelast geht gerade nach vorn in sagittaler Richtung (von $\pi$ aus Fig 3 ).

is) Abgesehen von dem Falle Denikers und Owen's, welche beide wahrscheinlich Fötus angehören, haben wir einen Fall bei Chudziński (H. leuciscus, Fig. 5 u. 7 Taf. II), wo dieser Uebergang nicht besteht, sondern hinten eine schmale Uebergangswindung zwischen dem 1. u. 2. Scheitelläppchen vorhanden ist. 
Was die von den verschiedenen Autoren, s. besonders Ecker 1. c., Schwalbe 1. c. u. A. vorgebrachten Ansichten über die am Menschenhirn der Affenspalte zu homologisirende Furche anlangt, so ist zu einer eingehenden Discussion hierüber nicht der Ort und werde ich, wie auf so viele andere Fragen von allgemeinerer Bedeutung, hierauf auch erst bei den übrigen Anthropoiden-Gehirnen eingehen können. Eberstaller und Cunningham (1. c. The intraparietal fissure. Royal. Irish Acad. of Med. vol. VIII. I89o) haben sich hierüber eingehend ausgelassen und finde ich, so weit ich bis jetzt selbst nachgesehen habe, ihre Auffassung zutreffend, der zufolge Bedenken vorliegen, den Sulcus occipitalis externus Ecker's beim Menschen mit der Affenspalte in vollständige Homologie zu bringen; am genauesten ist Cunningham auf die Sache eingegangen. Man wolle hierzu den Passus p. $3^{6}$ (Anmerkung) in Ecker's Hirnwindungen, 2. Aufl., vergleichen, den Eberstall er 1. c., Wiener med. Blätter, nicht erwähnt; dieser enthält das Wesentliche der Ecker'schen Auffassung.

Die Form der Bildung dieser Furche und ihr Verhalten zur Fissura parieto-occip. medialis kann unter Umständen beim Gibbon ganz so werden, wie es Eberstaller vom Menschen schildert, s. z. B. Fig. A von Kohlbrügge und Eberstaller's Fig. 2 p. I3, 1. c. (Wiener med. Blätter.)

Bei den von mir untersuchten Gibbons ist ein gut entwickeltes Operculum occipitale vorhanden, wie schon Eberstaller und auch die übrigen Autoren angeben. Kohlbrügge fand es meist unvollständig entwickelt. Bei Hylobates lar habe ich dasselbe entfernt und stellte folgenden Befund fest: Bedeckt sind der grösste Theil des hinteren Schenkels des arcus parieto-occip., d. h. also des Windungsbogens, welcher den auf der äusseren Hemisphärenfläche sichtbar werdenden Theil des Sulcus parieto-occip. medialis umgiebt. Dieser Windungsbogen geht dann weiter in den Gyrus oder Lobul. pariet. I über. Es ist dies der „first annectant gyrus" der Engländer. b) Ein mit dem Ramus descendens des gyrus angularis zusammenfliessender Windungszug, ich will ihn die ,obere Wurzel des unteren Scheitelläppchens" nennen (second annectant gyrus der Engländer). c) Der untere Theil des Ramus descendens des Gyrus angularis selbst. Ueber den Ram. post. arcus parieto-occip. (first. annect. gyrus) geht ein ziemlich tiefer Gabelast hinweg bis in den Grund der Affenspalte hinein. Der sagittale Hauptast der Intraparietalfurche mündet in die Affenspalte aus, aber doch in anderer Weise, als es Cunningham 1. c. beim Chimpanse beschreibt und abbildet (Fig. 2 Cunningham's). Derselbe dringt zwischen I und II annectant gyrus, gerade wie es Cunningham zeichnet, in die Affenspalte ein; hier sendet er einen 
kurzen Schenkel aufwärts (Schenkel $k$ bei Cunningham); dieser begrenzt hinten den first annectant gyrus, schneidet jedoch nicht tief in denselben ein, so dass dieser Schenkel noch breit am Boden der Affenspalte in dem Hinterlappen wurzelt. Wie eben erwähnt, wird derselbe auch noch durch einen Gabelast des Sulcus par. occ. medialis eingeschnitten. Nun aber - und hier kommt die Hauptdifferenz mit Cunningham's Befund - geht auch ein langer Schenkel nach abwärts und bildet den tiefsten Boden der Affenspalte, soweit diese lateralwärts reicht. Bei $\mathrm{Cunningham} \mathrm{ist} \mathrm{dieser} \mathrm{ab-}$ wärts gehende Furchenschenkel von dem Boden der Affenspalte durch den second annectant gyrus getrennt, der hinter ihm liegt, während er bei meinem Hyl. lar vor dem Furchenschenkel gelegen ist.

Dass in diesem Falle auch der Sulcus temp. I in die Affenspalte mündete, wird weiter unten noch näher dargelegt werden.

Diese eben geschilderten Verhältnisse lassen ein noch genaueres Studium der Homologie zwischen Affenspalte und Sulcus occip. transversus des Menschen nothwendig erscheinen. Wie gesagt, ist das hier am Gibbon-Hirn allein nicht auszumachen; ich muss mir das für eine spätere umfassendere Veröffentlichung vorbehalten.

Die Fissura parieto-occipitalis medialis ragt beim Gibbon regelmässig auf die dorsale Hemisphärenfläche vor ( $\pi_{1}$ Fig. 3 und 4$)$, jedoch höchstens $0,5-\mathrm{I} \mathrm{cm}$, nach meinen eigenen Befunden. Was ihr Verhalten zur Affenspalte anlangt, so soll sie beim Mensehen mit dieser fast niemals communiciren, Eberstaller l. c. i.

Wenn ein starkes Operculum vorliegt und dasselbe namentlich nach der Mantelkante hin gut entwickelt ist, dann kann wenigstens äusserlich $\pi$, in $\pi$ continuirlich übergehen, wie es in Fig. 3 und 4 (s. besonders Fig. 3) von H. leuciscus gezeichnet ist. Der Fall ist sehr merkwürdig. Untersucht man genauer, so zeigt sich, dass hier $\pi_{1}$, d. i. die Fissura par. occip. medialis, sich ziemlich weit auf die convexe Hirnoberfläche erstreckt und sich dort weit gabelt mit einem hinteren und vorderen Aste, der vordere Ast zieht gerade vorwärts zur Furche $p_{1}$ hin und ist nicht bezeichnet, der hintere man gehe rom Buchstaben $\pi$ in Fig. 3 aus - geht in einem lateralconvexen Bogen nach rückwärts und äusserlich ohne Grenze in die Affenspalte $i$ über, wie eben bemerkt wurde. Hebt man aber den sich weit nach vorwärts erstreckenden Opercular-Wulst, über den die Linie "wegzieht, etwas ab, so sieht man eine operculirte Tiefenwindung, welche $\pi_{1}$ und $\pi$ von $\varphi$ trennt. Es besteht also auch hier eine Trennung beider Occipito-parietalfurchen. In der Litteratur habe ich keine Angabe einer Verbindung gefunden, und bei dem H. syndactylus lag die Sache, wie sie beim Menschen bekannt und 
speciell von Eberstaller genau dargestellt ist: Der laterale Schenkel von $\pi_{1}$ (der medialen Parieto-occipitalfurche) liegt imner nach vorn von der Affenspalte und ist durch einen schmalen, ihn umkreisenden Windungszug (arcus parieto-occipitalis), speciell durch dessen hinteren Bogenschenkel, von der Affenspalte getrennt. Wie wir sahen, kann aber dieser Bogen beim Gibbon stark gedeckt werden.

So ist es auch bei dem von mir untersuchten H. lar der Fall; aber wir finden hier wieder eine beachtenswerthe Eigenthümlichkeit bezüglich des Verhaltens dieser Furche zur Affenspalte. Der äussere Schenkel der Fissura parieto-occip. med. ist gegabelt wie im vorigen Fall, der hintere Gabelast ist vom Operculum gedeckt, geht aber, wie vorhin schon erwähnt, bis in den tiefsten Grund der Affenspalte über. S. auch weiter unten bei Besprechung des Gyrus parietalis inferior. - So hätten wir also hier eine Verbindung beider Furchen auch in der Tiefe.

Unbedeckt blieb der Arcus parieto-occip. in dem von Gromier 1. c. beschriebenen Falle.

Bei zwei der von mir untersuchten Gibbons (lar und syndactylus) hörte die Affenspalte, wie es ja auch vom Menschen bekannt ist, ungefähr an der Grenze des Schläfenlappens, sich ein wenig nach hinten umbiegend, frei auf. Bei $H$. leuciscus dagegen geht sie, s. Fig. 4, an dieser Stelle über den ganzen Schläfenlappen hinweg, diesen glatt vom Hinterlappen trennend, bis über die Mantelkante hin, dort noch eine kleine Seitenfurche abgebend. Diese Stelle, die auch etwas vertieft ist, entspricht vielleicht der Incisura praeoccipitalis, wie ich vorhin schon andeutete. Die Furche erreicht auf der unteren Hemisphärenfläche beinahe den Sulcus temporalis III.

Kohlbrügge, 1. c. p. 192, erwähnt bei H. agilis den interessanten, beiderseitig vorkommenden Fall einer Verschmelzung des Sulcus postcentralis superior mit dem oberen Ende der Fissura calloso-marginalis $\left(p_{1}\right)$.

Die kleine Furche $\mu$, welche ich bei zwei Gehirnen angedeutet fand, entspricht wohl einem der Sulci intermedii Jensen's beim Menschen, in der Auffassung, wie sie von Eberstaller, 1. c. i., vertreten worden ist.

c) Die Fissura parieto-occipitalis medialis wurde schon mehrfach erwähnt als Grenzfurche zwischen Scheitel- und Hinterlappen und in ihrem Verhalten zur Affenspalte. Sie ist für das Gibbon-Hirn ebenso charakteristisch, wie für das Menschenhirn und verläuft auch ganz ähnlich, nur mehr senkrecht und öfters mit einer kleinen Winkelbiegung nach vorn. S. Fig. $6 . \pi_{1}$; sie ist sehr tief und wird es immer mehr, je mehr sie sich der Fissura calcarina nähert, mit der sie meist zusammentrifft. Ueber dies V'erhalten weiter unten bei der Fissura calcarina mehr. Ueber ihr Verhalten 
auf der Mantelkante wurde bereits gehandelt. Kohlbrügge (l. c. p. 192) geht genauer auf diese Furche ein und beschreibt auch einen Fall, wo sie in die Fissura par. occ. lat. überging.

d) Der Gyrus postcentralis, wie ich ihn der Kürze wegen nach Wilcler 1. c. nenne, ist beim Gibbon, s. das vorhin bei den Furchen Gesagte, und Fig. 3 u. 4, stets sehr gut begrenzt und gut ausgebildet, weit besser als der Gyrus praecentralis. Er ist schmaler als dieser. Unten geht er mehr oder weniger breit an der Sylvischen Furche entlang in die untere Scheitelwindung (das untere Scheitelläppchen), speciell in dessen Gyrus supramarginalis über; an der Mantelkante (s. Fig. 3) biegt er einerseits nach vorn, um die Centralfurche herum in den Gyrus praecentralis ein und hängt hier auch - an der dem Lobulus paracentralis des Menschen entsprechenden Stelle - mit dem Gyrus marginalis (oder $F_{1}$ medialer Theil) zusammen. Dort ist er nach hinten von dem Endstück der Fissura calloso-marginalis begrenzt; um dessen laterales Ende er schliesslich in $\mathrm{P}_{1}$, das obere Scheitelläppchen, umbiegt.

e) Das obere Scheitelläppchen, oder der Gyrus parietalis superior oder primus geht über die Mantelkante hinweg in den Praecuneus über; seine Grenzen sincl aus der Beschreibung der Furchen (s. Figg. 3 u. 4) hinlänglich ersichtlich. In dem hier gezeichneten Falle erstreckte er sich sehr weit nach hinten (H. leuciscus), was bei den beiden anderen Species nicht der Fall war. Aússer den beschriebenen Furchen ( $:$ und dem vorderen Schenkel von $\pi_{1}$ ) waren mehr nach hinten noch 2 ganz seichte Furchen in ihm bemerkbar, welche von der Intraparietalfurche ausgingen.

Der Gyrus pariet. inferior s. secundus (unteres Scheitelläppchen $\mathrm{P}_{2}$ ) zerfällt beim Gibbon in bekannter Weise in die beiden Bogenwindungen, den um die Sylvi'sche Furche herumgelegten $\mathrm{C}_{\mathrm{r}} \mathrm{y}$ rus supramarginalis und den um das obere Ende der ersten Temporalfurche kreisenden Gyrus angularis. Da letztere Furche beim Gibbon steil und hoch hinaufragt, so entspricht dieser ein steiler Bogen. Eberstaller macht mit Recht auf die auch relativ viel grössere Entwicklung des untern Scheitellappens beim Menschen aufmerksam, in welcher, ebenso wie in der grösseren Entwicklung der Broca'schen Windung, einer der wesentlichsten Unterschiede des Menschen- vom Anthropoidenhirn begründet liegt. Wenn die Sylvische Furche sich gabelt und, wie es auch beim Gibbon mitunter der Fall ist, von der ersten Temporalfurche ein Gabelast nach hinten geht, aber die Furche umgeknickt ist, dann wird durch beide hintere Gabeläste (bezw. durch die nach hinten gewendete Umknickung von $\mathrm{t}_{1}$ ) eine gute Abgrenzung ron $\mathrm{P}_{2}$ gegen den Temporallappen ermöglicht, Eberstaller. Es ist dies auch beim Gibbon zuweilen in dieser 
Weise der Fall. Immer ist beim Gibbon der absteigende, in die zweite Temporalwindung umbiegende Schenkel des Gyrus angularis (pli-courbe Gratiolet 1. c.) sehr schmal. Bei H. lar und in geringerem Grade auch bei $H$. syndactylus überdeckte ihn von hinten her der am meisten laterale Theil des operculum der Affenspalte, so, dass er zu einer Tiefenwindung wird und dann der obere Theil des Sulcus temporalis primus sich äusserlich in die Affenspalte fortsetzt. Das erinnert an niedere Zustände. In Fig. 4 sieht man auch von den Winkel der Affenspalte, den sie beim Uebergange von $i$ zu $\sigma$ macht, einen kleinen Sulcus über diesen hinteren Schenkel des pli courbe zur Fissura temp. prima hinziehen, ohne dass er sie jedoch erreicht. Dieser Schenkel wird in den extremen Fällen zu dem erwähnten hinteren Gabelaste, der dann in die Affenspalte übergeht. So haben wir dies bei unsern Hyl. lar; hier ist der hintere Gabelast der ersten Temporalfurche sehr tief und stark entwickelt und geht, den pli courbe fast ganz durchschneidend, in die Affenspalte über. Wenn wir uns nun erinnern (siehe vorhin, Sulc. intraparietalis), dass auch die Fissura parieto-occip. medialis durch einen Gabelast mit der Affenspalte in Verbindung stand, so haben wir hier also eine continuirliche Furche, welche vom Temporalpol äusserlich beginnt, durch den Sulc. temp. I, zum Stamm der Fissura calcarina und zur Fissura hippocampi bis wieder fast zum Temporalpole zieht! Bei demselben Hylobates lar wendet sich der vordere Gabelast (Hauptast) der Fissura temporalis I stark nach vorn, bei Hylobates syndact., wo die Bedeckung durch das operculum minder stark ist, bleibt er in seiner aufsteigenden Richtung; an der linken Hemisphäre gabelte sich dieser Ast noch an seinem oberen Ende.

Ein sogenannter dritter oder hinterer Scheitelbogen (Bischoff, Eberstaller) ist, wie beide Autoren schon anführen, beim Gibbon nicht vorhanden.

7. Der Vorzwickel (Praecuneus) wurde zum Theil schon vorhin beschrieben. Er gehört, wenn man die Mantelkante nicht als Trennungsmarke nehmen will, zu $\mathrm{P}_{1}$. Bei seiner ausserordentlich charakteristischen, beim Gibbon fast quadratischen Form wird er aber am besten als besonderer Lappen beibehalten. Auf der Unterfläche wird er durch den gemeinsamen Stamm der Fissura parietooccip. med. und calcarina, die hier in die Fissura hippocampi übergehen, genau so wie beim Menschen begrenzt (s. Fig. $5 \omega_{1}$ ). Dass man von ihm unterhalb der Fissura subparietalis (o) einen Theil als zum Gyrus fornicatus zählend, abtrennt, wurde erwähnt. Vom Vorzwickel zum Zwickel leitet über jener schon oft erwähnte, das laterale Ende des Sulcus parieto-occip. medialis umkreisende Windungszug "arcus parieto-occipitalis" Eberstaller (Gratiolet's Premier 
pli (lu passage externe, Bischoff's obere innere Scheitelbogenwindung.) lis mag hier nochmals darauf aufmerksam gemacht werden, dass das Gibbonhirn ein grosses Interesse dadurch zeigt, dass diese Windung bald durch das operculum mehr oder minder bedeckt, bald ganz frei ist. Wir haben also beim Gibbon einen Uebergangszustand von den pithecoiden zu den anthropoiden Affen und dem Menschen. (Vgl. die vorhin erwähnten Angaben von Kohlbrügge und mir; hier sei nachgetragen, dass Bischoff die Windung auch frei fand.)

A. 4. Die Furchen und Windungen des Hinterlappens. Wir haben hier zu besprechen a) den Sulcus occipitalis primus, b) den Sulcus occipitalis secundus, c) die Fissura calcarina, d) einige Nebenfurchen, dazu die Windungen: e) die erste Hinterhauptswindung oder Operculumwindung (Gyrus occipit. primus s. operculi), f) die zweite Hinterhauptswindung, Gyrus occip. secundus, g) die dritte Hinterhauptswindung (Gyrus occipitalis tertius) und h) den Zwickel, Cuneus.

a) Die erste Hinterhauptsfurche zeigt ein sehr beständiges und charakteristisches Verhalten, s. Fig. 3, 4, 5 u. $6 \% \% 1, \%$. Sie verläuft horizontal, parallel der hinteren Umrandung des Lobus occipitalis, indem sie das operculum occipitale von hinten umgrenzt. Lateral auf der äusseren Hemisphärenfläche beginnt sie mit einem einfachen Stamme (\%), der sich zur Mantelkante hin gabelt $\%_{1}$ und $\%_{2}$; einer oder der andere dieser Gabeläste kann bis auf die mediale Hemisphärenfläche hinüberreichen ( $\%$ in Fig. 6). Von den sechs Furchen, die ich untersuchen konnte, zeigten fünf genau dieses Verhalten, nur an der linken Seite des Hirns von H. leuciscus, s. Fig. 3, ist der obere Gabelast selbstständig geworden. Die hier beschriebene gegabelte Hinterhauptsfurche ist fast auf allen mir bekannt gewordenen Abbildungen genau șo gezeichnet, und da sie auch bei pithecoiden Affen und den anderen Anthropoiden in derselben Weise vorkommt - vgl. die Abbildungen von Rüdinger ${ }^{75}$ ) und die Angaben von Joh. Mölle ${ }^{76}$ ) - so haben wir in ihr eine für das Affenhirn sehr bezeichnende Furche vor uns. Ich stehe nicht an, sie mit der von Eberstaller ${ }^{7 i}$ ) erwähnten triradiaten Furche des Menschenhirns zu homologisiren.

Sie ist mit voller Deutlichkeit auch an dem Deniker'schen Fötushirn zu sehen, nur ist die Gabelung noch nicht so ausgesprochen.

${ }^{75)}$ Rüdinger, l. c. Festschrift f. Henle. Bonn i882. Taf. XXI.

26) Möller, J., Zur Anatomie des Chimpanse-Gehirns. Archiv f. Anthropologie 1888 Bd. 17.

i7) Eberstaller, 1. c. "Oesterr. ărztl. Vereinszeitung" 1884 und "Wiener medic. Blätter" No. 16 etc. 1884 . 
Deniker vergleicht sie der zweiten Occipitalfurche des Menschen. Am erwachsenen Gibbonhirn zählt er drei Hinterhauptsfurchen. Wie wir sehen werden, ist dies angängig; nur sind die zweite und die dritte Furche wechselvoll und unbeständig.

Was b) die zweite Occipitalfurche anlangt, so finde ich sie bei dem hier abgebildeten Gehirn des H. leuciscus, s. Fig. 3 u. 4, $\psi$, sehr gut und klar entwickelt; sie ist dort auf beiden Seiten vorhanden und vollkommen selbstständig (in keiner Verbindung mit einer anderen Furche). Bei H. lar steht sie auf beiden Seiten in Verbindung mit der zweiten Schläfenfurche, erscheint geradezu als eine Fortsetzung dieser Furche in den Hinterlappen hinein; sie geht aber hier nicht so weit zur medialen Mantelkante vor, wie bei $\mathrm{H}$. leuciscus, wo sie bis in diese und rechts noch ein wenig darüber hinaus in die mediale Fläche sich erstreckt. Links gabelt sie sich an ihrem medialen Ende rechtwinklig, oder geht, wie man das auch beschreiben könnte, T-förmig in eine kleine Furche über, welche sagittal bis zum unteren Rande des Hinterlappens verläuft.

Bei H. syndactylus fand ich sie gar nicht entwickelt; es ist nicht ohne Interesse, dass hier auch nur eine unbedeutende zweite Schläfenfurche vorhanden war.

c) Die dritte Occipitalfurche fand ich deutlich ausgebildet nur bei $\mathrm{H}$. leuciscus. Sie läuft hier in etwa $2 \mathrm{~cm}$ Länge quer über die Unterfläche des Hinterlappens nahe der Mantelkante, also parallel der vorigen Furche. Der Mantelrand des Hinterlappens liegt zwischen diesen beiden Furchen. Die dritte Furche hängt an der einen Seite mit den sagittalen Furchen der Unterfläche ( $\mathrm{t} 3$ und collateralis) zusammen, an der anderen entsendet sie zwei ziemlich lange sagittale Aeste nach vorn in die Lobuli lingualis und fusiformis hinein.

d) Die Fissura calcarina ( $\omega$ in den Figuren $3,5,6)$ ist stets sehr gut ausgebildet, ganz nach dem menschlichen Typus. Sie ist beim Hylobates von sehr erheblicher Tiefe und bedingt im Hinterhorn die Ausbildung des calcar avis wie beim Menschen. Das laterale Ende der Furche reicht mehr oder weniger weit auf die dorsale Oberfläche der Hemisphäre hinauf und ragt dort stets in die Gabelung der I. Occipitalfurche hinein. Auch dies Verhalten ist für die Hylobatiden und die Anthropoiden überhaupt sehr charakteristisch. Ist die F. calcarina selbst gegabelt, so ragt wenigstens der hintere Ast in die Occipitalgabel hinein. Von interessanteren Besonderheiten sind zu erwähnen: Die Gabelung und das Verhalten zur Fissura parieto-occipitalis medialis. Die Gabelung beobachtete ich an den vier Spornfurchen der H. H. lar und leuciscus. Bei lar geht beiderseits die Furche als einfache auf die Aussenfläche der Hemisphären, um sich hier ziemlich rechtwinklig zu gabeln; der vordere Ast 
schneidet in das operculum ein. Indem bei diesem Gehirn etwa in der Mitte der Sulcus calloso-marginalis, clann nach hinten davon der Sulcus parieto-occipitalis medialis, endlich in ziemlich gleichem Abstand die Fissura calcarina, alle drei rechtwinklig die Mantelkante überschreiten, erhalten wir ein ganz eigenartiges Bild.

Ganz anders ist die Gabelung bei H. leuciscus; hier liegt sie im Bereiche der medialen Hemisphärenfläche, und die Gabeläste sind sehr lang. Da sie in derselben Flucht nach vorn und nach hinten laufen, so erscheinen beide zusammen wie eine lange sagittale $T$ Furche zum Stamm der Calcarina, s. w und o Fig. 3. Das Verhalten zur medialen parieto-occipital-Furche und damit die Gestaltung des Zwickels (Cuneus), ist in beachtenswerther Weise verschieden. Am meisten ähnlich dem Menschen zeigt sich in dieser Beziehung $\mathrm{H}$. syndactylus, s. Fig. $6, \pi$ und (1). Die calcarina liegt ziemlich horizontal, während die vordere Furche $\pi_{1}$ nahezu senkrecht steht; so kommt dann ein ansehnlicher dreieckiger Zwickel heraus. Auch vereinigen sich hier beide Furchen, s. Fig. 5, und der gemeinsame Stamm geht über eine Tiefenwindung (den zugespitzten Praecuneus, pli de passage parieto-limbique Broca) hinweg in die Fissura hippocampi über, wie das ja auch beim Menschen die Regel ist. Bei $\mathrm{H}$. lar und leuciscus findet keine Vereinigung der Sporn- und medialen Parieto-Occipitalfurche statt, sondern die Fissura calcarina geht allein in der angegebenen Weise in die Ammonsfurche über. Auch liegt sie, namentlich bei $\mathrm{H}$. leuciscus, nahe an der Fissura parieto-occip. medialis, so dass der Zwickel sehr schmal wird und keine klare Keilgestalt hat, sondern mehr einem Gyrus gleicht.

Von Nebenfurchen wurden schon einige erwähnt (Aeste der dritten Occipitalfurche, Querast der zweiten Furche); hier sind noch zu nennen der Sulcus cunei ( 2 in Fig. 6). In der genannten Figur liegt er, durch die Fissura parieto-occip. med. getrennt, in der Flucht der Subparietalfurche (o), zu der er auch wohl gehört. Bei H. lar tritt er rechts mit 2 Gabelästen in die Fissura parieto-occip. med. ein, links zeigt sich ein sagittal liegendes $T$, dessen unterer Schenkel mit der eben genannten Furche in Verbindung steht; oberhalb des T senkt die Fissura parieto-occip. med. noch einen kleinen Ast in den Cuneus hinein. Bei H. leuciscus, dessen $Z$ wickel, wie bemerkt, einem schmalen Gyrus gleicht, fehlt jede Furche in demselben. Gromier 1. c. erwähnt kurz einiger Nebenfurchen in Cuneus, sonst finde ich dieselben nicht beschrieben.

Zuweilen kann (s. Fig. 6 bei hineinragen, wenn nämlich, wie in diesem Falle, der sog. arcus parieto-occipitalis ganz frei zu Tage tritt.

e) Ueber die Windungen des Occipitallappens, von denen 
das Wichtigste schon bei den Furchen angegeben wurde, ist nicht viel mehr nachzutragen. Sie laufen, wie die Furchen, quer, und ist diese Querwindung, auf die auch Eberstaller ${ }^{78}$ ) für den Menschen aufmerksam macht, beim Gibbon hervorragend ausgeprägt. Bei H. leuciscus, s. Fig. 4, sind die Occipitalwindungen durch den Umstand, dass der Sulcus parieto-occip. lateralis (die Affenspalte) bei $\sigma$ quer über der Wurzel des Temporallappens hinzieht, völlig von den Schläfenwindungen auf der Aussenfläche des Hirns geschieden; aber auch bei H. lar und synd. wird die Grenze durch das nach hinten umgebogene laterale Ende der Affenspalte genügend markirt. Das in der Gabel der ersten Occipitalfurche steckende Windungsstück gehört dem Cuneus an. Auf der Unterfläche sind, wie sattsam bekannt, keine Grenzmarken gegen den Temporallappen vorhanden. Ich komme auf diesen Punkt zurück.

Von den Angaben der übrigen wiederholt genannten Autoren sei noch folgendes hervorgehoben: Bei Bischoffs Hylobates-Hirn fliessen Spornfurche und mediale Parieto-Occipitalf. nicht zusammen, auch Kohlbrügge l. c. und Deniker l, c. bei dem Fötus sahen es nicht. Dagegen finde ich dies Zusammenfliessen sehr klar in Chudzińskis (1. c.) Fig. 8, und Flower ${ }^{79}$ ) gibt es ausdrücklich an. Auch sehe ich in einer Anmerkung bei Deniker erwähnt, dass der Zusammenfluss bei Hylobates die Regel sei; bei 9 Hylobates-Hirnen, die er kenne, sei er stets da. Wichtig ist dies, weil es bei den pithecoiden Affen kaum vorkommt und an den Menschen erinnert. Die von Bischoff (1. c.) aufgeführte und gezeichnete horizontale Furche am $Z$ wickel, welche von der hinteren auf die mediale Fläche hinüberzieht, möchte ich nicht deuten. Kohlbrügge (1. c.) und ich fanden eine derartige Furche nicht.

A. 5. Die Furchen und Windungen des Schläfenlappens. Ich unterscheicle deren beim Gibbon folgende: a) den Sulcus temporalis I, b) den Sulcus temporalis II, c) den Sulcus temporalis III, d) die Fissura collateralis, e) die Fissura rhinalis, f) Nebenfurchen, g) den Gyrus temporalis I, h) den Gyrus temporalis II, i) den Gyrus temporalis III, k) den Gyrus seu Lobulus fusiformis, 1) den Gyrus s. Lobulus lingualis, m) den Gyrus uncinatus, s. Lobulus Hippocampi.

a) Der Sulcus temporalis I ist die längste Furche des Gibbonhirns; meist läuft er fast vollkommen parallel der Sylvi'schen Furche mit kaum hervortretenden Biegungen, so dass er, ähnlich wie die Centralfurche, einen gestreckten Eindruck macht. Er ragt mit seinem oberen Ende, dessen Gabelung und gelegentlicher Uebergang des hinteren Gabelastes in die Affenspalte schon beschrieben wurde, ansehnlich über die Fossa Sylvii hinauf. Unten erreicht er fast den Temporalpol (s. $\lambda$ in Fig. 4 u. 5).

An Ziveigen fand ich constant den mit 7 bezeichneten (Fig. 4);

i8) E berstaller, l. c. Wiener medic, Blätter 1884 .

${ }^{79}$ ) Flower, Wm., 1. c. Nat. hist, review 1863 p. 283. 
da wo dieser abgeht, benerke ich stets eine kleine Winkelbiegung der Hauptfurche. Die in derselben Figur hervortretenden Zweige 3 u. 4 sind Gefässfurchen, finden sich jedoch immer da, oder doch in der Gegend.

Kohlbrügge erwăhut die Verbindung mit der Affenspalte ebenfalls, die auch Gratiolet und Chudziński S. 54 1. c. abbilden, Bischoff bildet die von mir angegelenen Zweigfurchen getreu so ab, wie ich sie fand. Chudziński hat an einem seiner Gehirne (H. leuciscus, Taf. I) gar keine Zweigfurchen, ebensowenig Kohlbrügge an seiner Fig. A, während in Fig. B ein kleiner Seitenast an der von mir hervorgehobenen Stelle zu sehen ist. Bei Denikers Fötus ist der Sulcus temp. I deutlich entwickelt, reicht aber noch nicht hoch hinauf. Bei Sandifort biegt sich die rechtsseitige Furche stark nach vorn um.

b) Sehr viel Schwierigkeiten macht die zweite Temporalfurche; sie ist, man möchte sagen, meist nur bruchstückweise entwickelt, wie auch oft beim Menschen. So sehen wir in Fig. $4(\mathrm{H}$. leuciscus) ein solches Stück bei 6 , in welches die Zweigfurche 7 oberflächlich eintaucht. Dies Stück 6 geht um die untere Temporalkante herum auf die Stelle zu, wo man in der Figur die kleine Einbiegung und die von der Affenspalte herkommende Furche $\sigma$ sieht, kreuzt diese und findet sich noch eine Strecke weit auf der Unterfläche. An der andern Seite desselben Gehirns ist die Furche etwas besser entwickelt, geht weiter am Temporallappen hinab und mehr dem Sulcus $t_{1}$ parallel. Auch fehlt dort der Arm $\sigma$, so dass die Sache einfacher liegt. Die Furche ist aber vielfach stark geknickt, sehr wenig tief. Kurz, schwach und aus mehreren Stücken bestehend ist sie auch bei H. syndactylus, s. Fig. 5, wo man 4, 6 und auch den Gabelast von 5 b, der in einer Flucht mit 4 u. 6 liegt, als die Repräsentanten dieser Furche betrachten kann.

Besser ausgebildet ist die Furche bei Hyl. lar, wo sie, wie ich schon angab, sich direct in die zweite Occipitalfurche fortsetzt. Auch hat sie hier beiderseits Nebenzweige, die in die zweite Temporalwindung, also frontalwärts, dringen.

Von meinen Vorgängern beschreibt sie Kohlbrügge (1. c.) genau und giebt auch an, dass sie weit occipitalwärts vordringe; ich habe dies occipitale Ende, wie gesagt, als zweite Occipitalfurche gedeutet. Die von Kohlbrūgge constant basalwärts rom untern Ende der Affenspalte gefundene Furche entspricht offenbar dem, was ich in 6 und 7 gezeichnet habe, gehört also der zweiten und (in andern Fällen) der ersten Temporalfurche an. Bischoffs Abbildung (1. c. Fig. III) giebt den oft eigenthümlich gezackten Verlauf der Furche sehr gut wieder. Durch einen Querast mit dem Sulcus temporalis I verbunden, zeichnet sie Chudziński (Fig. $F_{5}, H$. entelloides); auch in seiner Fig. 7 Taf. I ist sie deutlich und mit einem frontalwärts gerichteten Aste versehen. In Gratiolets und Sandiforts Figuren ist nichts davon zu erkennen. Denikers Fötus stimmt insofern mit dem Befunde am erwachsenen Thier, als sich die Furche in kleinen getrennten Stücken anzulegen scheint.

c) Den Sulcus temporalis III handle ich zusammen mit der Fissura collateralis $a b$, da sie vielfach in einander überlaufen. Am 
klarsten ist ilhre Verbindung und ihr Verhalten in Fig. 5 (H. syndactylus) zu sehen. Wir haben hier ein deutliches Zungen- und Spindelläppchen (L. u. F.); die sie trennende Furche (ı) ist die Collateralfurche; darüber kann kein Zweifel bestehen; dann ist 5 b aber die III. Temporalfurche; 5 a kann ebensowohl als Fortsetzung der III. Temporalfurche als auch der Fissura collat. aufgefasst werden. Ich ziche vor, sie noch als III. Temporalfurche zu deuten, die dann lang am Schläfenlappen hinzieht und hier in die den Temporalpol tief einschneidende Fissura rhinalis (5a) mündet. Die Collateralfurche ist dann nur kurz. Für diese Deutung spricht das Verhalten des Gehirnes von H. leuciscus. Hier läuft eine lange Furche in fast gerader Richtung nach vorn zum Temporalpol, links ist sie mit der Rhinalfissur (5a) durch einen kleinen Querast verbunden, rechts nicht. Hinten liegt sie zwischen Lob. fusiformis und der dritten Schläfenwindung. Zwischen Lob. fusiformis und lingualis finden wir nun eine andere, nicht gar tiefe Furche etwa von $21 / 2 \mathrm{~cm}$ Länge, die aber ganz selbständig bleibt und nicht mit der eben beschriebenen in Verbindung steht; das ist nun zweifellos die Collateralfurche, denn sie trennt ganz deutlich einen Lobulus fusiformis und lingualis. Eine dritte Variante liefert das Gehirn des H. lar. Hier ist der Ast $5^{\mathrm{b}}$ an einer Seite nur ganz schwach, an der andern gar nicht entwickelt; es zieht eine einzige lange Furche zwischen den Lob. lingualis und fusiformis hindurch bis zur Rhinalfissur, mit der sie rechterseits verschmilzt. Lob. fusiformis und dritter Schläfengyrus sind nicht getrennt. Hier sind Fissura collateralis und dritte Schläfenfurche verschmolzen, richtiger wohl wäre es zu sagen, dass das hintere Stück derselben $=5 \mathrm{~b}$ in Fig. 5 nicht zur Entwicklung gekommen sei.

Die Verschmelzung mit der Rhinalfissur geschieht meist durch einen ganz kurzen, quer verlaufenden Ast; ein kleiner Absatz ist auch in Fig. 5 zu merken.

Da bei Sandifort das Kleinhirn nicht entfernt ist, so kann man aus seinen Abbildungen nicht viel über die vorstehend besprochenen Furchen entnehmen. Gratiolet bildet dieselben gar nicht ab, und auch Denikers Beschreibung und Zeichnungen geben darüber nichts Genaueres. Bischoff zeichnet die ron ihm als Collateralfurche ( 8 in seiner Fig. II) bezeichnete Rinne auch $k u r z$, so wie ich sie in 2 meiner Fälle fand. Ich bin aber nicht sicher, ob Bischoff richtig deutet. In seiner genannten Zeichnung kommt nach seiner Auffassung nur ein sehr kleiner Lobus lingualis gegen einen sehr grossen Spindellappen heraus. Ich bin der Meinung, dass die zweite Furche (bei l) der Fissura collat. entspricht, die dann allerdings auf c'er andern Seite sehr unregelmässig ausgebildet und unterbrochen wäre. Mich bewegt hierzu der Umstand, dass ich in 2 meiner Fälle mitten im Lobus lingualis (bei unzweifelhaft als solcher erkennbaren Collateralfurehe) einen ansehnlichen sagittalen Sulcus fand, wie B ischoff ihn in seiner Fig. II bei 8 zeichnet, der aber nur eine der beim Gibbon nicht selten vorkommenden Nebenfurchen darstellt.

Was $\mathrm{B}$ ischoff für die Fissura temporalis II ansieht, kann man aus seiner $\mathrm{Ab}$ - 
handlung nicht entnehmen. In Text sagt er kaum etwas mehr über sie als den Namen; sie soll in den Figuren mit 12 bezeichnet sein, diese Ziffer ist aber nicht aufzufinden, weder in Fig. II, noch in Fig. III, wo man doch die Furche erkennen müsste. Die lange Furche in Fig. III, welche gerade wie in meiner Fig. 5 nach vorn zieht, um durch einen kleinen rechtwinkligen Ast, gerade so, wic auch ich es meist finde, mit der Rhinalfurche sich zu vereinigen, trägt keine Bezeichnung. Nach meinen Befunde muss dies $t_{3}$, die dritte Schläfenfurche sein, von der aber Bisch off nichts angit bt.

Kohlbrügge (1. c.) geht auf die hier in Rede stehenden Dinge nur sehr kurz ein; er fand eine zweite der collateralis parallele Furche nicht. - Joh. Möller ${ }^{80}$ ) lässt die dritte Schläfenwindung beim Chimpanse fehlen. Mir scheinen deshalb die von mir beim Gibbon eruirten Befunde wichtig.

Von Nebenfurchen habe ich zu erwähnen: I. Die im Lobus lingualis sagittal verlaufende, soeben beschriebene Furche von $1 / 2$ bis $2 \mathrm{~cm}$ Länge; ich traf sie viermal (an den beiden Gehirnen von H. lar und leuciscus; sie hing einmal mit der dritten Occipitalfurche, s. vorhin, zusammen,) bei Syndactylus, s. Fig. 5, ist kaum eine Spur davon zu sehen. 2) Zweimal eine mit Strahlung versehene Furche im Spindelläppchen, s. I I Fig. 5. Die Rhinalfurche wird alsbald beim Rhinencephalon beschrieben werden.

Von den Windungen brauche ich nach der genauen Beschreibung der Furchen hier kaum noch etwas zu sagen; auch sind ihre Uebergänge schon beim Scheitel- und Schläfenlappen zur Sprache gekommen; nur wäre zu erwähnen, dass der zwischen 8 und 5 gelegene Windungszug, der sich nach hinten in das Zungenläppchen fortsetzt und nach vorn im Haken (U) endet, der Gyrus hippocampi ist, und dass an beiden den Sulcus temporalis I begrenzenden Windungszügen (Gyrus temporalis I und II) 2-3 ansehnliche, schräg gestellte Tiefenwindungen vorkommen, während sie doch in der Sylvi'schen Furche kaum gefunden wurde.

A. 6. Das System der Fissura und des Gyrus hippocampi, des sogen. Tractus falciformis (m.) Ich folge einer Aufstellung von Schwalbe, s. Neurologie 1. c. p. 567, wenn ich hier diejenigen Bildungen, die sich um die Fissura chorioidea, die Adergeflechtsspalte des Seitenventrikels, unterhalb des Balkens und um die Fissura hippocampi oberhalb des Balkens (und auch unterhalb desselben) entwickeln, hier zusammen stelle, denn es sind alles durch die Verwachsung der beiden Hemisphären mehr oder weniger abgeänderte und meist verkümmerte Hirnwindungen. Jeder Spalte entspricht natürlich ein doppelter Windungszug, der sie ja umkreist, und von denen der eine Zug sie auf der einen, der andere auf der anderen Seite begrenzt. Die Fissura chorioidea beginnt, wie beim Menschen, vorn mit dem Foramen Monroi. Das durch sie ein-

so) Möller, Joh., 1, c. p. 179. 
gestülpte Adergeflecht oder vielnuehr dessen Epithelüberzug, ist eine nach innen in den Seitenventrikel eingestülpte rudimentäre Hirnwindung, ähnlich einem Cornu ammonis. Die Spalte, die Fissura chorioidea (Theil der grande fente de Bichat), entsteht erst, wenn wir den Plexus chorioideus herausziehen, weil dann dessen Epithel, welches die Hirnwand repräsentirt, mit herausgezogen und von der übrigen Hirnwand abgerissen wird. So bekommt dann die Spalte zwei Ränder, welche Hirnwindungen oder vielmehr Rudimente von solchen darstellen: am oberen Spaltenrande das Septum lucidum, bezw. dessen beide laminae (Spt.) in Fig. 6, plus dem fornix (siehe Fig. 6) mit dessen Fimbria. Die Spalte setzt sich fort, wie beim Menschen, längs des ganzen Unterhorns bis zu dessen Spitze; so weit läuft dann auch ihr oberer Randgyrus aus den eben genannten Theilen bestehend. Septum lucidum und Fornix sind beide beim Gibbon ansehnlich entwickelt, auch ist die Fimbria deutlich; das durch die Spalte eingestülpte Ventrikelepithel, welches das Adergeflecht überzieht, verhält sich mit dem letzteren zusammen als plexus chorioides lateralis, gerade wie beim Menschen.

Der untere Randgyrus der Fissura chorioidea wird nun meines Erachtens von der sogenannten Stria cornea gebildet, die beim Gibbon ebenfalls vorhanden ist; sie läuft bekanntlich beim Menschen (so auch beim Gibbon) mit der cauda corporis striati bis zum Ende des Unterhorns und hängt dort ebenso mit der Fimbria zusammen, wie am Foramen Monroi mit dem Anfangstheile des Fornix. So umschliessen also diese beiden Randgyri die Fissura chorioidea. Schwalbe, 1. c. p. 502, giebt bei Besprechung der Stria terminalis (oder des Hornstreifens) die Beziehungen des letzteren zum Fornix und zur Fimbria völlig genau an: sie bezeichne die dorsale Grenzlinie des Adergeflechts-Epithels, während die Fimbria der ventralen Grenzlinie entspreche. Bei Besprechung seines Lobus falcifornis (unseres tractus falciformis) nimmt er aber den Hornstreifen nicht wieder auf, der doch hinzugehört. So weicht denn meine Beschreibung etwas ron Schwalbe's Darstellung ab.

Die zweite, ursprünglich der supracallosalen Region angehörige, in ihrem Bogenlaufe aber natürlich auch unter den Balken gelangende Furche unseres Tractus ist die Fissura hippocampi, die Ammonsfurche. Diese stülpt, ähnlich wie die Fissura chorioidea das Ventrikelepithel, eine dickere Schicht der medialen Hemisphärenwand ein, welche Einstülpung als Hippocampus oder Cornu a mmonis bekannt ist. Beim Gibbon ist der Hippocampus sehr gut ausgebildet; er wird im Seitenventrikel sichtbar am hinteren Thalamusrande, zeigt sich dann sofort als eine in der Mitte gekielte Hervorragung, an die sich vorn die breite Fimbria anlehnt, während 
hinten ein flacherer Theil in der Vertiefung zwischen Cornu ammonis und Calcar avis sichtbar wird. Am Eingange in das Hinterhorn springt clieser flachere Theil in einem kleinen $W$ inkel gegen dieses Horn vor. Der Kiel verliert sich, das ganze Ammonshorn wird im weiteren Verlaufe breiter und flacher, die Fimbria schmaler. Der pes hippocampi zeigt keine Digitationen.

Weil im innigen Zusammenlange, obwohl sonst nicht hierher gehörig, mögen auch der Calcar avis und die Eminentia collateralis hier ihre Besprechung finden. Beide sind bekanntlich gleichfalls in ne re Windungen. Der Calcar avis ist deutlich ausgeprägt, er misst etwa $9 \mathrm{~mm}$ in der Länge; die Eminentia collateralis zeigt sich bei dem darauf untersuchten Gehirne ( $H$. syndactylus) nur ganz schwach entwickelt, jedoch sicher zu erkennen.

Die Randwindungen der fissura Hip pocampi sind auf dem Balken eine obere und eine untere, die unterhalb des Balkens (am Unterhorn) mehr als eine mediale und laterale erscheinen. Die obere (später laterale) Windung ist der wohl ausgebildete Gyrus fornicatus (Fr. Arnold.) Derselbe ist in seinen einzelnen Theilen schon beschrieben worden. Er beginnt vorn unter dem Balkenschnabel mit dem Wulste y, s. Fig. 6, zieht dann als Gyrus genualis um das Balkenknie, dann als Gyrus callosus über den Balken weg in den Vorzwickel hinein unterhalb des Sulcus subparietalis (o) Fig. 6, und geht dann, vom Stamme der Fissura calcarina überbrückt, in den Gyrus Hippocampi über; dieser krümmt sich bei U (Fig. 5), dem sogenannten Uncus, hakenförmig unı, zum Uebergange in die untere (oder mediale) Windung, den Gyrus dentatus (Huxley). Verfolgen wir diesen den umgekehrten Weg, so sehen wir das umgekrümmte Stück des Uncus (bei 8 in Fig. 5, deutlich in drei kleine Querwülste zerfallen. Hebt man den Uncus etwas $a b$, so sieht man seine ganze obere Fläche mit mehreren secundären flachen Wülsten besetzt. An diesem umgekrümmten Hakenstücke liegt eine kleine graue Leiste, welche Giacomini ${ }^{81}$ ) zuerst beschrieben hat; sie ist bei unseren in Spiritus längere Zeit erhärteten Gibbon-Gehirnen nicht mehr deutlich zu erkennen. Diese Leiste (Benderella, Giacomini) geht über in die sehr gut entwickelte fascia dentata, die die Fissura hippocampi von der medialen Seite her begrenzt. Die fascia dentata entwickelt sich nun unterhalb des Balkenspleniums derart, dass ihr gerader Rand als eine Leiste erscheint (fasciola cinerea), während die kleinen grauen Zähnchen zu drei bis vier etwas grösse-

81) Giacomini, C., Benderella dell' Uncus dell' Hippocampo nel cervello dell' uomo e di alcuni animali. Torino, 1882. - s. a. Bandelette de l'Uncus de l'Hippocampe dans le cerveau de l'homme et de quelques animaux. Arch ital. de Biologie T. II 1882 S. $20 \%$. 
ren windungsähnlichen Zügen auswachsen, die unter dem lateralen Theile des Splenium einen deutlichen kleinen Wulst bilden. Der Wulst, den ich z. B. beim Pferde stark entwickelt finde, spitzt sich nach oben scharf zu und geht auf dem oberen Balkenrande in die schwach entwickelten sogenannten "Nervi Laucisii" über, die bis zu den Pedunculi corporis callosi beim Menschen zu verfolgen sind. Dies letztere bei den Gibbon-Gehirnen deutlich zu erkennen war mir nicht möglich. Eberstaller ${ }^{82}$ ) giebt an, dass die fascia dentata auch mit den sogen. Striae laterales, s. Ligg. tecta in Verbindung stehe, da diese letzteren mit den Nervi Lancisii, s. Taeniae liberae, im Zusammenhange wären und aus einer und derselben Bildung, dem embryonalen inneren Randbogen hervorgingen. Bei Thieren, Tapir, Fledermaus, sei an Stelle dieser beim Menschen und Affen unbedeutenden Streifen eine deutliche Windung (Rest des Randbogens, F. Schmidt, Kölliker) vorhanden, welche in die mediale Riechwurzel übergehe. Der Pedunculus corporis callosi umgreife die hintere Peripherie der Substantia perfor. anterior und setze beide Riechwurzeln mit einander in Verbindung. Dass der Pedunculus corporis callosi quer nach aussen zieht, hinter dem zur Substantia perf. ant. gehörigen tuberculum olfactorium (m.) - siehe w. u. - habe ich beim Gibbon auch gesehen, konnte aber eine Verbindung beider Riechwurzeln nicht sicher feststellen. Eberstaller nennt die Chordae Laucisii + Ligg. tecta = Gyrus supracallosus; diesen + fasc. dent. $=\mathrm{G}$. fornicatus internus. Alles zusammengefasst liegt hier im Ganzen der Tractus falciformis wie beim Menschen vor. Vgl. die genaue Beschreibung von Giacomini. ${ }^{83}$ )

A. 7. Das Rhinencephalon. Die bisher beschriebenen Theile gehören sämmtlich dem sogen. Hirnmantel (Pallium) an. Die vergleichende Anatomie und Entwickelungsgeschichte lehren nun, dass wir einen zweiten Theil am Gehirn sondern müssen, der mit dem Tractus olfactorius in näherer Beziehung steht und deshalb das Rhinencephalon genannt wird. ${ }^{84}$ ) Hierher sind zu rechnen: a) der Bulbus, Tractus und die Radices olfactorii; b) die Substantia perforata anterior; c) der Riechlappen, welcher mit dem Uncus

$\left.{ }^{82}\right)$ Eberstaller, Oesterreichische Aerztliche Vereinszeitung, Juli 1855. Ueber die historische Seite dieser Dinge, an deren Feststellung Tarin, Vicq d'Azyr, A. Retzius, Zuckerkandl und Giacomini insbesondere betheiligt sind, vergl. den Aufsatz von G. Retzius: Notiz über die Windungen an der unteren Fläche des Splenium corp. callosi beim Menschen und bei Thieren. Archiv f. Anat. und Entwickelungsgeschichte 1877 S. 474.

83) 1. c. Benderella etc. Torino 1882 und Circonvoluzioni cerebrali II edizione, Torino 1884 et Arch. ital. de Biol. I882.

84) Vergl. hierüber insbes. Turner l. c. The convolutions of the brain. Journ. of anat, 1890. 
Hippocampi zusammenfällt; d) die Riechfurche, Fissura rhinalis, welche den Riechlappen von dem Pallium abtrennt und durch die Fossa Sylvii in eine Fissura rhinalis anterior und posterior zerfällt (Krueg) ${ }^{85}$ ) Die frühzeitige Sonderung dieser Theile tritt bei Embryonen, und ihre dauernde Sonderstellung namentlich bei den niederen Thieren hervor. $\mathrm{Zu}$ dem Rhinencephalon tritt dann noch, wie Broca $\left.{ }^{86}\right)$ in sciner meisterhaften Arbeit gezeigt hat, der Gyrus fornicatus in nähere Beziehung.

Ueber den Bulbus olfactorius des Gibbon kann ich nichts aussagen, da derselbe an allen drei Gehirnen entfernt war, als ich sie erhielt. Der Tractus ist sehr dünn und platt, beide Tractus convergiren nach vorn; ein deutlicher kielförmiger unterer Vorsprung ist an ihnen nicht vorhanden. Was aber sehr interessant erscheint, ist die Thatsache, dass die beiden Wurzeln des Tractus (I a und I b) (Fig. 5) auch noch, so lang der Tractus an den Gehirnen erhalten war, gesondert waren (s. I, Fig. 5). Sie sind zwar äusserlich zusammen verbunden, trennen sich aber ziemlich leicht von einander. In Fig. 1 u. 2 ist das nicht wiedergegeben, leicht aber am OriginalPräparate zu erkennen. Zwischen den beiden divergirenden Wurzeln liegt graue Substanz, und mehr nach hinten sieht man ein deutliches graues Knötchen t b, Fig. 6), Tuberculum olfactorium) was ich auch bei den anderen Anthropoiden erkenne, und welches mitunter gleich einer Fascia dentata leicht gezähnelt oder gefurcht ist; dasselbe zieht quer und verliert sich in dem sogen. espace quadrilatère Broca's, in der Substantia perforata anterior. Ueber diese ist weiter nichts besonderes zu melden.

Als Lobus Hip pocampi oder rhinicus muss der sogenannte Uncus bezeichnet werden, s. U. in Fig. 5. Die Furche 5 a, welche ihn tief einschneidet, und von dem übrigen Theile des Schläfenlappens trennt, halte ich für die Fissura rhinalis posterior. Ueber ihre Verbindung mit der dritten Schläfenfurche und der Fissura collateralis wurde schon vorhin das Nöthige gesagt. - Dass die Tractus olfactorii schon beim Fötus lang und schmal seien, giebt Deniker an. Im übrigen ist das Rhinencephalon von Hylobates noch nicht beschrieben worden.

Ich schalte nun ein paar Worte ein über die Abgrenzung des Hinterlappens, namentlich mit Bezug auf Eberstaller's ${ }^{87}$ ) Vorschlag am Menschenhirn, die Abgrenzung vom Temporallappen so vorzunehmen, dass der letztere an der ganzen Unterfläche bis zum Occi-

$\left.{ }^{85}\right)$ Krueg,

86) Broca, P., 1. c. Le grand lobe limbique etc. Mém. publ. par Pozzi, pag. 259 und Recherches sur les centres olfactifs Ibid. p. 383 .

8i) Eberstaller, 1. c. Wiener medic. Blätter 1884 . 
pitalpole reichte, dieser also gar nicht mehr dem Hinterlappen, sondern dem Schläfenlappen angehören sollte. Ich kann mich aus praktischen Gründen dem nicht anschliessen. Man wird doch immer einen Lappen, in welchem das Hinterhorn liegt, und dieses erstreckt sich z. B. beim Chimpanse (nach J. Möller) ${ }^{\text {ss }}$ ) bis in das letzte Ende des Lappens, Hinterlappen nennen, und das zumeist nach hinten daran gelegene Stück davon abtrennen zu wollen, wird die topographische Anatonie nicht anerkennen. Die aus einem praktischen Bedürfniss hervorgegangene Eintheilung in die vier bekannten Lappen hat sich nicht nach natürlichen Grenzen gerichtet; man bemüht sich nun nachträglich solche noch aufzufinden und ist das gewriss sehr anèrkennenswerth; man möge nur darin nicht zu weit gehen, denn auch bei Eberstaller's Abgrenzung bleiben immer noch genug Uebergangsstellen. Ich würde beim Gibbon innen mit der Fissura parieto-occip. medialis, aussen mit der Affenspalte den Hinterlappen abgrenzen und ihn in dieser etwas schräg gestellten Ebene vom Temporallappen abschneiden. Das entspricht dem Begriffe eines Hinterlappens am besten und genügt völlig. Welche Furche am Gibbonhirn dem von Eberstaller als Grenzfurche hingestellten Sulcus occip. later. entsprechen würde, vermag ich nicht zu sagen, vielleicht i, s. Fig. 4 .

Indem wir uns zunächst an die äussere Oberfläche des Gehirns halten, wäre nun unserem Plane gemäss

B. die Hirnbasis nebst deren Gefässen und Nerven zu schildern. Ich habe diese Theile, die vom Gibbon noch nie genau abgebildet und beschrieben wurden, besonders sorgfältig zeichnen lassen, s. Fig. I und 2, in Fig. I bei doppelter Vergrösserung. Es überhebt mich das einer langen Beschreibung; ausserdem wurde schon bei der allgemeinen Uebersicht manches erwähnt.

Ich trage noch Folgendes nach: Bei H. lar zerfallen die Oliven durch zwei kleine Furchen in drei Querwülste; es kommt dies auch beim Chimpanse und beim Menschen vor (J. Möller und Schwalbe 1. 1. c. c.). Wir sehen hinten den $N$. cervic. II mit zwei feinen vorderen und einer dicken hinteren Wurzel entspringen (wie beim Menschen), während ungekehrt die vorderen drei Wrurzeln des N. cervicalis I stärker sind, als die zwei feinen hinteren (bein Menschen ebenfalls). Der starke N. accessorius zieht zwischen den vorderen und hinteren Wurzeln dieser Nerven durch. Fäden oberhalb des I. Cervicalnerven habe ich ihn nicht mehr erhalten sehen. Eine Trennung desselben in zwei Züge, wie sie Möller (1.c.) vom Chimpanse abbildet, ist nicht zu bemerken. Der Vagus

88) Möller, J., l. c. Chimpanse-Hirn S. 182. 
hat jederseits neun Ursprungsfïden, die sich - s. linke Seite der Fig. 1 - wieder in drei Bündel zusammenlegen. Den Glossopharyngeus sah ich mit zwei, den Hypoglossus mit I - I 2 Fäden hervorkommen; bein Gibbon ist der erstere gar nicht so zart, wie es J. NÏller (1. c.) rom Chimpanse angiebt. Wegen der übrigen Nerven, deren Verhalten wie beim Menschen ist, nur dass sie in Verhältniss stärker sind, genügt es auf die Figuren zu verweisen. Eine gresonderte, feine, laterale IVurzel des $\mathrm{N}$. oculomotorius (J. Möller, Schwalbe 1. l. c. c.) fand ich nicht. Der N. trochlearis war zu kurz abgeschnitten worden, um auf der Unterfläche zu erscheinen; seine Ursprungsverhältnisse sind dieselben wie beim Menschen.

Die Arterien der Hirnbasis, s. Fig. $\mathrm{I}$ und 2, sind in allem Wesentlichen clenen des Menschen gleich, wie unmittelbar aus den Abbildungen und deren Bezeichnung ersichtlich ist.

C. Auch bezüglich des inneren Aufbaues des Grosshirns ist schon mehreres bei der allgemeinen übersichtlichen Schilderung, sowie bei Besprechung des Tractus falciformis und des Rhinencephalon erledigt worden. Anderes musste, da wegen der Wichtigkeit der Windungsverhältnisse die Gehirne nicht zu weit zerlegt werden durften, für diesmal unerledigt bleiben. Nachzutragen wäre noch folgendes: Das Corpus striatum hat die Gestalt des menschlichen, nur erscheint es mir mit einem (verhältnissmässig) etwas schmäleren, längeren Kopfe; dies stimmt auch für den Chimpanse, J. Möller l. c. Der Schwanz geht wie beim Menschen mit der Stria cornea zusammen in das Unterhorn über. Der Thalamus opticus ist, wie bemerkt, gross und von rundlicher Form. Wir finden ein grosses, deutliches tuberculum anterius Thalami und ein mässig entwickeltes tuberculum posterius (Pulvinar). Die Commissura media ist, ebenfalls in Uebereinstimmung mit dem Chimpanse (J. Möller l. c.), sehr stark entwickelt und bildet, siehe Fig. 6, den rundlichen, weiss gehaltenen Querschnitt, der mit Th. bezeichnet ist.

Die Vierhügel wurden schon beschrieben. Vom vorderen geht ein starker Zug zum Tractus opticus. Das Corpus geniculatum laterale springt scharf vor, das mediale ist durch eine schwache Furche deutlich in zwei Stücke zerlegt. Ein deutliches frenulum (zum velum medullare anticum hin) liess sich nicht erkennen. Auch beim Chimpanse ist es, nach J. Möller l. c., schwach entwickelt. So weit der Medianschnitt es sehen liess, zeigte sich am pons und der Medulla oblongata nichts besonderes. Die $\mathrm{Zirbel}$ und die Hypophysis, sowie die Hirnventrikel wurden schon erwähnt. In einer späteren Arbeit gedenke ich auf diese Theile noch eingehender 
zurück zu kommen, die zum ersten Male genauer von J. Möller (1. c.) beim Chimpanse beschrieben worden sind.

D. Das Kleinhirn hat bis jetzt auch noch keine eingehendere Beschreibung erfahren. In der äusseren Form hat es ziemlich die des Menschen erreicht und erscheint im Verhältniss recht ansehnlich; namentlich sind die Hemisphären stark entwickelt. Unterschiede vom Menschen treten darin hervor, dass die Form des Wurmes auf dem Durchschnitte mehr rundlich erscheint, und dass die Tonsillen (T) Fig. I u. 2, sehr stark auf der Unterfläche hervortreten. Neben den Tonsillen nach lateralwärts erscheint die Flocke (Fl.), welche auch etwas mehr vorspringt. Nimmt man die Tonsillen vorsichtig hinweg, so sieht man genau, wie beim Menschen, die Flocke sich in einen Flockenstiel fortsetzen, bis zu einem zwar kleinen, aber deutlich entwickelten Nodulus (nod.), Fig. 6, und an den Stil sich ein velum medullare posterius (valvula Tarini) befestigen.

Lateralwärts von der Flocke zeigt sich ein stärker vorspringendes Läppchen, welches ich nach Huschke, ${ }^{89}$ ) da es im Hiatus subarcuatus des Felsenbeins liegt, lobulus petrosus nenne. Auch alle übrigen Lappen des Kleinhirns, wie wir sie beim Menschen treffen, kann man wiederfinden. Ich habe sie sowohl auf dem Medianschnitte, wie auch an Flächenansichten sorgfältig präparirt und zu isoliren versucht. Auf dem Medianschnitte (Fig. 6) deute ich die kleine Menge grauer Substanz auf den velum medullare anterius (valv. Vieussenii) als Lingula. Das Velum selbst ist zart - im Gegensatze zu dem des Chimpansen nach J. Möller (l. c.) - und zeigt auf dem Durchschnitte eine kleine knötchenförmige Anschwellung unmittelbar hinter den Vierhügeln $\left(\mathrm{q}_{1}\right)$. Ueber der Lingula folgt der Lobus centralis (1. c.), der ziemlich ansehnlich ist. Dann kommen der stattliche Mons superior (m. s. $)$ ) und der Mons inferior (Declive, m. $s_{{ }_{2}}$ ). Ein ganz kleines dreieckiges Stück, zu dessen Basis der Strich (fol.) hinführt, ist das folium cacuminis; es ging in die ansehnlichen lobi semilunares superiores beiderseits über. Mit ihm verbunden ist das starke Tuber valvulae (t. v.), worauf wir die Pyramis und die Uvula mit dem Nodulus folgen sehen. Immerhin erscheint es mir von Interesse, dass man die menschlichen Kleinhirnlappen auch am Hylobates-Kleinhirn ohne Zwang in wesentlich denselben Verhältnissen wiederfinden kann. In der Figur 6 sind die Hauptfurchen, wie ich sie wenigstens zu finden vermeine, etwas stärker gehalten.

Ich beschliesse meine Schilderung mit der Angabe, dass die Dura mater keine Besonderheiten aufwies, dass die von Axel Key und Retzius beschriebenen arachnoidalen Recessus sämmtlich vor-

89) Huschke, Schädel, Hirn und Seele des Menschen und der Thiere nach Alter, Geschlecht und Rasse. Jena 1854. (Text, S. 91 u. Erklärung der Tafeln S. 192.) 
handen waren, und dass die Pia mater an allen drei Gehirnen sehr zart war und sich nur schwer entfernen liess.

Ziche ich noch ein kurzes Ergebniss meiner Untersuchungen, so sprechen die Verhältnisse am Gehirn, wie ich sie fand, durchaus zu Gunsten der von G. Ruge und Kohlbrügge geäusserten Ansicht, dass die Hylobatiden neben den übrigen Anthropoiden stehen, nicht unter ihnen. Es überrascht in der That, an den kleinen Gehirnen der Gibbon's alle die Grundzüge wiederzufinden, welche den übrigen Anthropoiden-Gehirnen und auch dem menschlichen ihren Charakter verleihen. Es wurde im Text wiederholt darauf hingewiesen. Ich werde später bei Besprechung der sonstigen Anthropoiden-Hirne auf die Unterschiede näher eingehen, welche zwischen diesen und dem Gibbon-Hirn bestehen. Für diesmal möchte ich nur noch einige der hauptsächlichsten pithekoiden und anthropoiden Charaktere des letzteren hervorheben.

Pithekoid erscheint am Gibbon-Hirn die noch immer ausgeprägte deutliche Zuspitzung (der Schnabel), die, wenn auch verminderte Wölbung der Orbitalfläche, der Sulcus principalis, die noch kaum gefurchte Insel, die Affenspalte mit ihrem Operculum, die Ausbildung des Sulcus temporalis I und dessen gelegentliche Einmündung in die Affenspalte u. a. Anthropoid ist der grosse Stirnlappen, das Auftreten einer Broca'schen Windung, die geringere Symmetrie der Furchung überhaupt, die Ueberdeckung des Kleinhirns und die ganze Ausbildung des letzteren, der häufige Zusammenfluss der Fissura calcarina und parieto-occip. medialis, die reichliche transversale Furchung des Hinterlappens.

In manchen Dingen zeigt sich noch ein Schwanken, indem bei dem einen Gehirn bald mehr der anthropoide, bald mehr der pithekoide Charakter hervorgekehrt ist. So ist der Arcus parieto-occipitalis bald bedeckt, bald frei, der Zwickel bald gut ausgebildet, bald sehr schmal, und es gehört hierher auch die sehr verschiedene Furchenzeichnung an der untern Fläche des Temporo-occipital-Lappens.
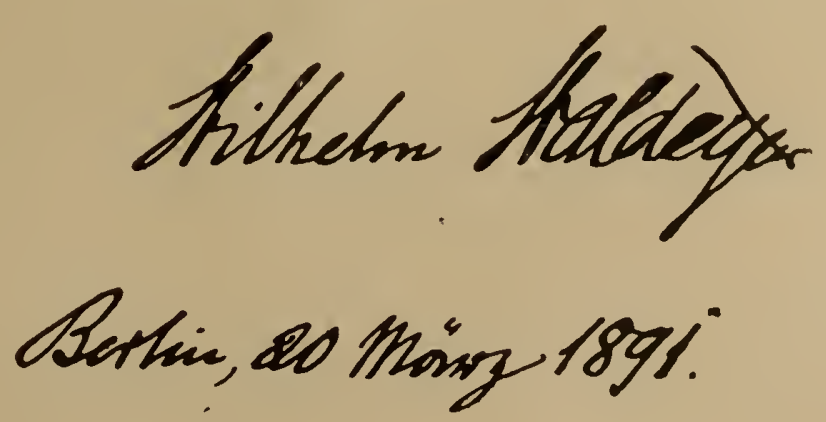



\section{Tafel I.}

Waldeyer: Das Gibbon-Hirn. 


\section{Tafel I.}

Fig. I. Hirn von Hylobates leuciscus, Unterfläche, Doppelgrösse.
I. Tractus olfactorius.
II. nervus opticus.
III. n. oculomotorius.
V. mot. motorische Trigemin. - Wurzel.
V. sens. sensible

VII. n. facialis.

VIII. 11. acusticus.

\author{
VI. n. abducens. \\ IX. n. glossopharyngeus. \\ $X$. n. vagus. \\ XI. n. accessorius. \\ XII. n. hypoglossus. \\ cerv. I u. cerv. 2 die Nervi cervicales \\ primus und secundus.
}

Die übrigen Bezeichnungen bedürfen keiner Erklärung.

\section{Fig. 2. Dasselbe, natürliche Grösse.}

Inc. long. Incisura longitudinalis. ¿ Sulcus principalis.

J, I a, I b Sulc. orbitalis.

$\zeta$ Sulcus fronto-orbitalis.

¿a Vorderer Ast der Fossa Sylvii.

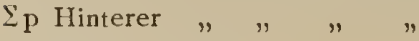

5 a Fissura rhinalis.

$\lambda$ Sulc. temp. I.

8 Fiss. hippocampi.

5 Theilstück des Sulc, temp. III.
4 Theilstück des Sulc. temp. II.

Lob. petr. Lobulus petrosus.

F1. Flocculus.

T. Tonsilla.

H. cerebelli, (lob. inf.) Lobus inferior der Kleinhirnhemisphãre. cerv. 2. Nerv. cervic. II.

Lob. occip. Lobus occipitalis.

m. Medulla oblongata. 


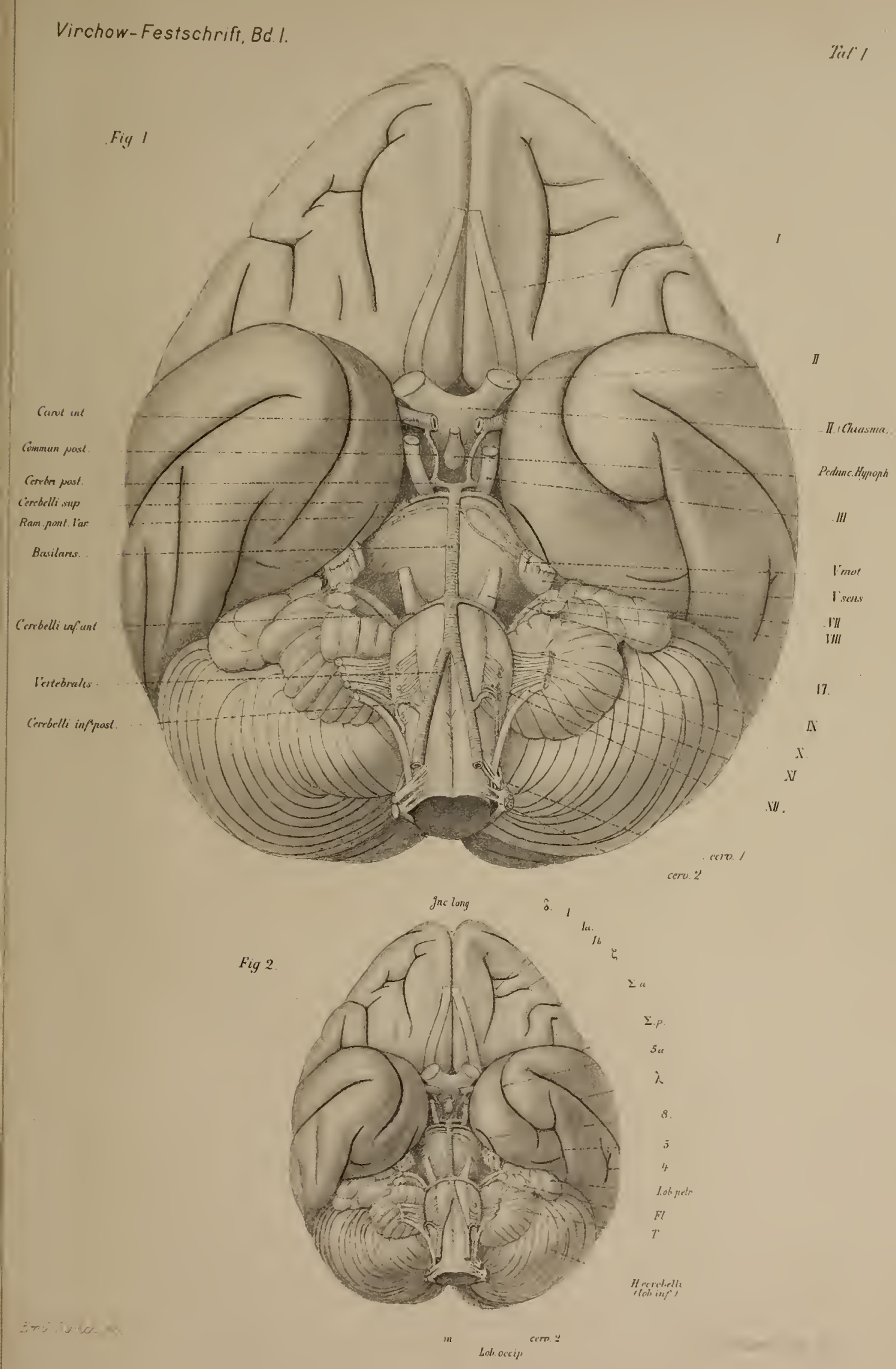

Waldeyer: Gibbon-Hirn. inng: n.August Jirschumald on ... i, 



\section{Tafel II.}

Waldeyer: Das Gibbon-Hirn. 



\section{Tafel II.}

Fig. 3. Gehirn des Hyl. leuciscus von oben.

o Sulcus principalis.

a Sulcus praecentr. infer.

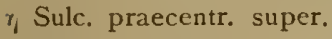

i Sulcus centralis.

i Sulcus postcentralis inf.

k Sulc. postcentralis sup.

¿'p Ram. posterior fossae Sylvii.

$\lambda$ Sulc. temporalis I.

« Nebenfurche (s. im Text).

$\checkmark$ Sulc. intraparietalis.

$\zeta$ Aeusserer Ast des Sulc. calloso.marginalis.:

$\sigma$ Ast der Affenspalte (sulc. parieto-occip. lat.) $\tau$ Nebenfurche (s, den Text).

- Sulc. subparietalis.

$\pi$ Uebergang des Sulcus parieto-occip. lat. zum Sulc. parieto-occip. med.

Ast der Affenspalte (Sulc, par. occ. lat.). $\chi_{1} \chi_{2}$ Sulcus occip. I.

$\downarrow$ Sulcus occip. II.

Vorderer Gabelast der Fiss. calcarina.

(1) Hinterer " " "

$\pi_{1}$ Fiss, parieto-occip. medialis.

Verm. sup. Vermis superior.

Fig. 4. Hirn von Hyl. leuciscus, rechte Seite.

Die griechischen Buchstaben bedeuten dasselbe wie in Fig. 3. Ausserdem

乏. Fossa Sylvii (Anfangstheil).

I. Tractus olfactorius.

I u. I b Sulcus orbitalalis.

7 Seitenfurche des Sulcus tempor. I.

H. cerebelli lob. sup. Oberlappen der Kleinhirnhemisphäre.

H. cerebelli lob. inf. Unterlappen der Kleinhirnhemisphäre.

6 Furchenstück zum Sulcus temp. II. gehörig.

m. Medulla oblongata. cerv $_{2}$. Nerv, cervic. II.

vertebr. Arteria vertebralis.

XI. N. accessorius.

T. Tonsille.

Lob. petr. Lobulus petrosus.

VIII. Nerv. acusticus.

5 Sulcus tempar. III.

4 Zweigfurche des Sulcus temp. I.

3 Gefässfurche.

2 Kleine Nebenfurche der Orbitalfläche.

Fig. 5. Hirn von Hylob. syndactylus, Unterfläche.

I b u. I Sulcus orbitalis.

9 Kleine Nebenfurche des Orbitaltheils.

U. Uncus.

5 a Fissura rhinalis.

8 Fissura hippocampi.

4 u. 6 Stücke des Sulcus tempor. II,

5 a Sulcus temp. III.

5 b " " "

Io Fissura collateralis.

II Nebenfurche des Lobulus fusiformis.

F Lobulus fusiformis.

(1) Fissura calcarina.
C. Cuneus.

P. C. Praecuneus.

L. Lob. lingualis.

c. c. Crus cerebri (Querschnitt).

III. Nerv. oculomotorius."

pd. Pedunculus Hypophyseos.

ch. Chiasma.

tb. Tuberculum olfactorium.

Ia laterale Wurzel d. Tractus olfactorius.

Ib mediale " " "

I. Tractus olfactorius.

Die übrigen griechischen Buchstaben wic vorhin. 
Fig. 6. Hirn von Hylob. syndactylus, Medianschnitt.

for, m. Foramen Monroi.

Spt. Septum lucidum (lamina-dextra).

$p$ Sulcus calloso-margin. $\rho_{1}$ lat. Ende desselben.

Th. Thalamus opticus.

chor. Plexus chorioideus.

- Sulcus subparietalis.

$\pi_{1}$ Sulc. par. occip. medialis.

$\mathrm{m}_{1}$ Mons superior cerebelli.

$\varphi$ Sulcus parieto-occip. lat.

I2 Sulcus cunei.

$\mathrm{ms}_{2}$ mons inf. cerebelli.

spi Splenium corp. callosi.

w) Fissura calcarina.

$\chi_{1}$ Sulcus occipitalis I, Ram. super.

fol. Folium cacuminis.

t. v. Tuber valvulae.

pyr. Pyramis.

uv. Uvula.

can, c. canalis centralis. nod. Nodulus.

li. Lingula.

lc. Lob. centralis.

q, Knötchen des velum med. ant.

q Lamina quadrigemina.

pi. Zirbel.

c. $\mathrm{m}$. Corpus mammillare dextrum.

III. N. oculomotorius.

inf. Infundibulum.

r. o. Recessus opticus.

opt. Nerv. opticus.

z Pedunculus corp. callosi.

y Wulst am Anfang des Gyrus callosomargin.

x Wulst am Anfang der 1. Stirnwindung.

c. a. Commissura anterior.

15 Sulcus rostralis.

rostr. Rostrum corp. call.

I4 Sulcus genualis. 
Virchow-Festschrift, BdI.

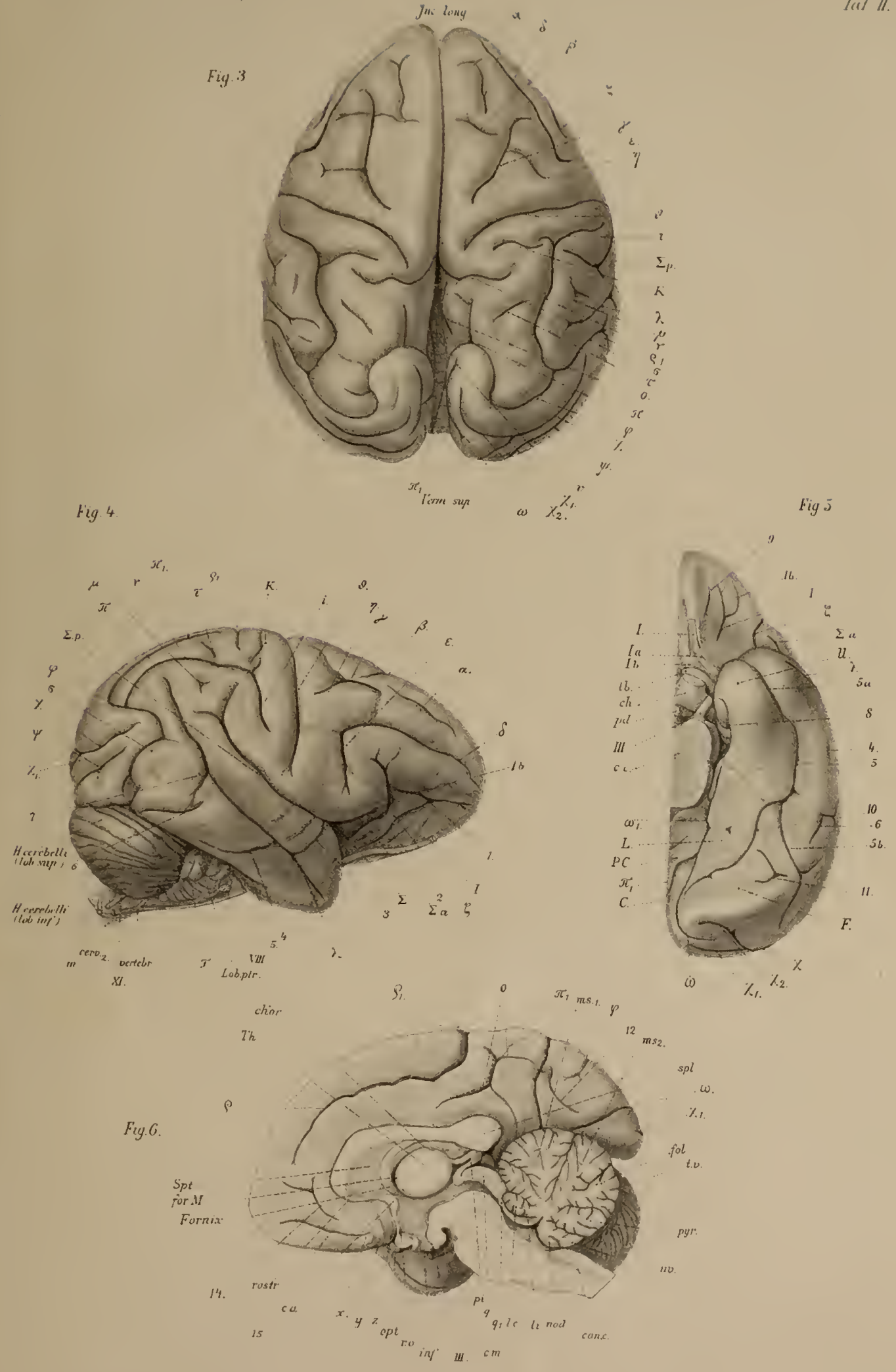

Tist II. 



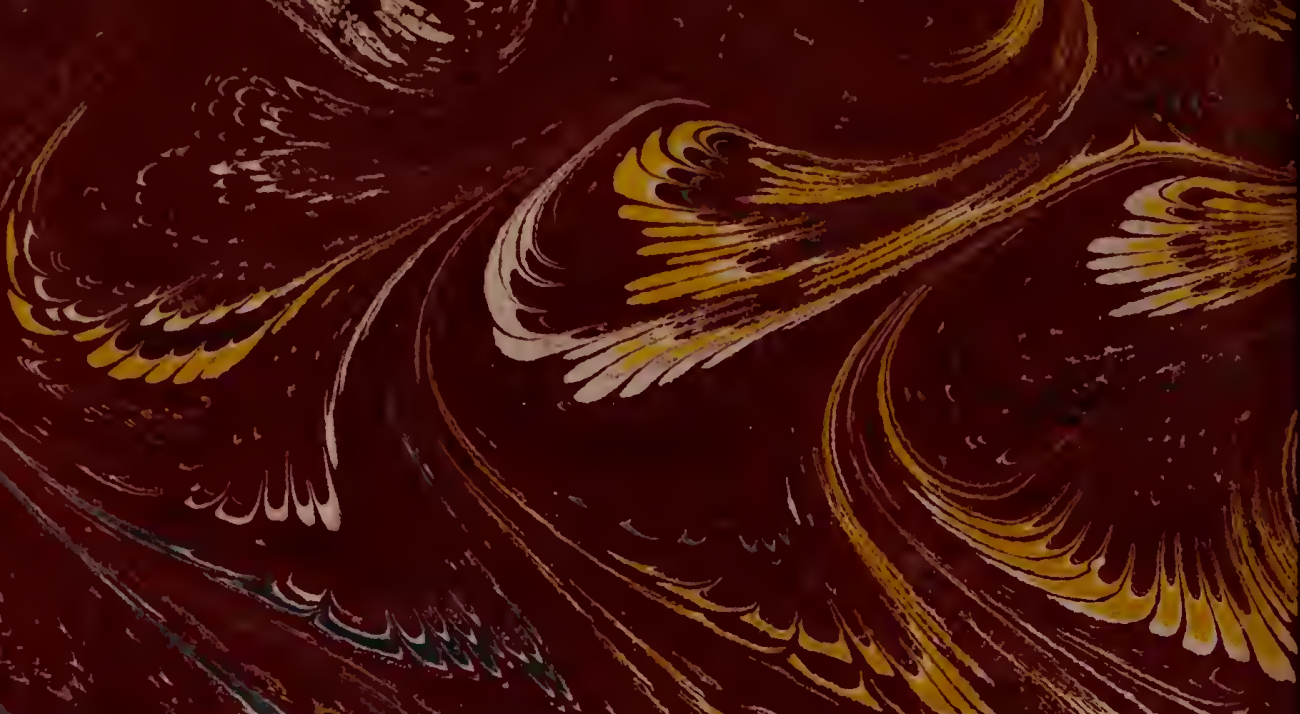

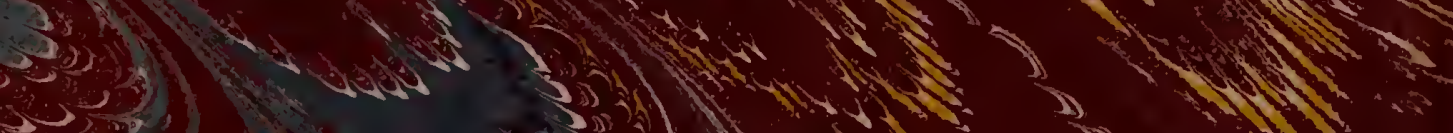

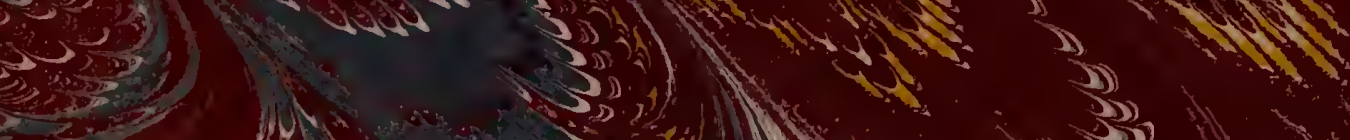
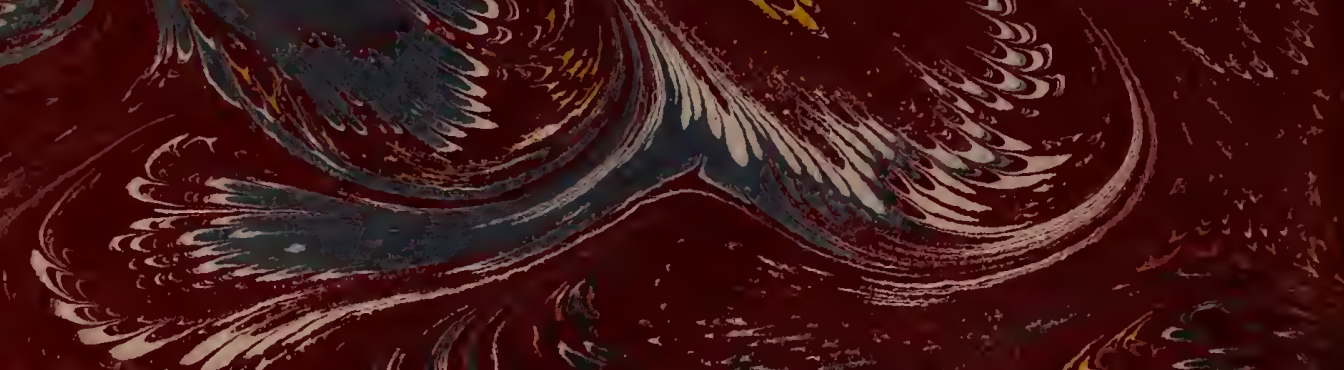

$1(12+3)=$

Howa

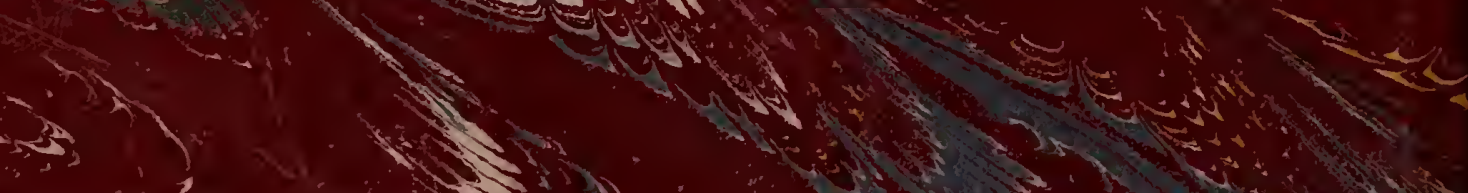

$\left(\left(\frac{c}{c}\right.\right.$ In cecowil (atis

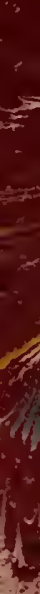

